KAPITEL 5

\title{
Hermann und Dorothea
}

Erzählexperiment zwischen Epos und Idylle

Goethes Auseinandersetzung mit dem Epos, der Antike überhaupt und das Gattungsgespräch mit Schiller finden bekanntlich parallel zur Arbeit an Hermann und Dorothea statt, wodurch das Werk selbst Teil der gattungspoetologischen Erörterung. ${ }^{1}$ Mehr noch wird es zur Vorgabe ${ }^{2}-$ und zwar nicht nur dafür, wie das Epos für die Moderne gerettet werden könnte, wie die folgenden Ausführungen aufzeigen sollen, sondern darüber hinaus auch, wie überhaupt ein produktiver Umgang mit der griechischen Poesie einerseits und den gattungspoetologischen Herausforderungen der Zeit andererseits gefunden werden kann.

Bezeichnenderweise führt der Versuch, Hermann und Dorothea eindeutig einer Gattung zuzuweisen, schon seit jeher zu zwiespältigen gattungstheoretischen Diskussionen, philologischer Unsicherheit und nicht zuletzt zu ideologischer Vereinnahmung. ${ }^{3}$ Goethe selbst hatte seinerseits stets auf dem hybriden Status seiner Dichtung zwischen Idylle und Epos bestanden. Aber gerade die Fragen, worin denn die Vermischung der Gattungen genau aufzuspüren sei und darüber hinaus, was durch die gegenseitige Aneignung von Epos

1 Gerhard Kaiser spricht von einem „Kunststück vor dem Hintergrund einer Kunstdiskussion“, Kaiser, Gerhard: Französische Revolution und Deutsche Hexameter. Goethes Hermann und Dorothea nach 200 Jahren. In: Ders. (Hrsg.): Goethe - Nähe durch Abstand. Vorträge und Studien (= Collegium Europaeum Jenense. Kulturwissenschaftliche Reihe, 1). Weimar: VDG 200o. S. 61-83, hier S. 62.

2 Goethe, Schiller, Wilhelm von Humboldt und die Brüder Schlegel entwickeln alle ihre Auffassungen vom Epos und dem epischen Erzählen explizit mit Bezug auf Hermann und Dorothea.

3 Schlegel befindet Hermann und Dorothea eindeutig als Epos, das den antiken HomerEpen ebenbürtig ist, vgl. Schlegel, August Wilhelm: Goethes Hermann und Dorothea. In: Ders. (Hrsg.): Sämtliche Werke, hrsg. v. Eduard Böcking, Bd. 11. Vermischte und kritische Schriften; 5, Recensionen. Leipzig: Weidmannsche Buchhandlung 1847. S. 183-221. Später nennt Schrimpf Hermann und Dorothea aufgrund des Hauptmotivs der Verlobung ein Idyll, vgl. Schrimpf, Hans Joachim: Gestaltung und Deutung des Wandermotivs bei Goethe. In: Wirkendes Wort 3 (1952). S. 11-23. Im Handbuch der literarischen Gattungen wird Hermann und Dorothea mehrfach herangezogen, um die Idylle um 1800 zu beschreiben, vgl. Mix, YorkGothart: Idylle. In: Lamping, Dieter (Hrsg.): Handbuch der literarischen Gattungen. Stuttgart: Kröner 2009. S. 393-402. Und gleichzeitig stützt sich auch der Artikel zum Epos wesentlich darauf, vgl. von Essen, Gesa: Epos. In: Ebd. S. 204-22O. 
und Idylle geleistet oder erreicht würde, ${ }^{4}$ wurden immer wieder von Neuem gestellt und dennoch nie abschließend geklärt. Auch wenn die Gattungsfrage hier nicht erneut in ihrer Grundsätzlichkeit aufgeworfen wird, sollen einige der wichtigsten Positionen skizziert und an ihren analytischen Zugriffen soll sichtbar gemacht werden, inwiefern die Zuweisungsbemühungen jeweils zentral von zeitspezifischen Erwartungen an und Projektionen auf den Text angetrieben werden.

So beurteilen die Zeitgenossen Goethes Versuch, Gegenwärtiges in antiker Form darzustellen, als fortschrittlich, wenn nicht gar revolutionär: ${ }^{5}$ August Wilhelm Schlegel ordnet das Werk in seiner Rezension als „Epos unsrer Zeit" ein und lobt es als „Individuum seiner Gattung, d.h. als episches Gedicht“, welches auch mit seinem aktuellen Inhalt der Form nach die gleichen Merkmale wie Homers Epen aufweise. ${ }^{6}$ Humboldt findet Goethes Gestalten „so wahr und individuell, als nur die Natur und die lebendige Gegenwart sie zu geben, und zugleich so rein und idealisch, als die Wirklichkeit sie niemals darzustellen vermag. [Hervorhebung M.E.]“. 7 Diese widersprüchliche Verknüpfung von Aktualität und Idealität gelingt gemäß Humboldt nur dem "Genie des Künstlers und auch diesem allein in seinen glücklichsten Stimmungen“. ${ }^{8}$ Schiller bezeichnet Hermann und Dorothea sogar enthusiastisch als „Gipfel seiner und unsrer ganzen neueren Kunst ${ }^{\text {“9 }}$ und verortet das Werk damit entschieden in der modernen Gegenwart. Gerade diese Mischung von Idylle und Epos, Zeitgemäßem und scheinbar Überholtem erscheint dann aber späteren Interpreten als Inbegriff des Reaktionären, Rückgewandten und insofern als Abweichung von der echten Kunst. Mit Blick auf Goethes morphologisches Formdenken im Zeichen des dynamischen Schwankens lässt sich allerdings vermuten, dass diese entgegengesetzten, starren Bewertungsalternativen von Fortschrittlichkeit und Konservativismus dem Text und seiner sublimen Mehrdeutigkeit kaum gerecht werden. Inwiefern diese jedoch nicht nur die eigentliche Signatur des Werks ausmacht, sondern darüber hinaus einem

4 Gerhard Kaiser kommt zum Beispiel zu dem Schluss, dass Goethe das Epos aus der gegenständlichen Welt der Idylle erziele, die Idylle also das Epos in Hermann und Dorothea erst ermögliche, vgl. Kaiser, Gerhard: Wandrer und Idylle: Goethe und die Phänomenologie der Natur in der deutschen Dichtung von Gessner bis Gottfried Keller. Göttingen: Vandenhoeck \& Ruprecht 1977. S. 48-52.

5 Vgl. Oschmann, Dirk: Das Epos in Zeiten des Romans. Goethes Hermann und Dorothea. S. 167-189, hier $171 \mathrm{f}$.

6 Vgl. Schlegel: Goethes Hermann und Dorothea. S. 183-221.

7 Humboldt, Wilhelm von: Ueber Göthes Herrmann und Dorothea (1799). S. 13

8 Ebd.

9 Schiller an Heinrich Meyer, 21.7.1797, HA 4.1. S. 1086, vgl. auch Oschmann: Das Epos in Zeiten des Romans. Goethes Hermann und Dorothea. S. 167-189, hier S. 170 und 183. 
bewussten produktionsästhetischen Programm Goethes entspricht, werden die ersten beiden Abschnitte der folgenden Ausführungen aufzeigen, indem sie die Wirkungs- und Entstehungsgeschichte von Hermann und Dorothea im Zusammenhang mit den modernen Transformationen der Erzählform der Idylle zeigen. Daran wird sichtbar werden, wie die ästhetische Einschätzung der Zeitbezüge in Hermann und Dorothea durchaus zentral, aber stets schwierig und jeweils einer stark ideologisch motivierten Deutung ausgesetzt ist.

Die darauffolgende Lektüre betrachtet Hermann und Dorothea dann im intertextuellen Kontext mit Johann Heinrich Voß' Luise, der wirkungsmächtigen Idyllendichtung der Epochenschwelle. Sie will die komplexen Zeitverhältnisse des Textes, die sich sowohl auf der Ebene der Darstellung wie auch des Dargestellten manifestieren, ergründen und sie als ausschlaggebend für die alternative Erzählform zwischen Innovation und Traditionsanschluss ausweisen, als die das Epische um 1800 fungiert. Wie die immanente Formgebung temporaler Gestaltungsstrukturen den Geltungsverlust äußerlicher, rein normativer Prinzipien zu kompensieren sucht, ${ }^{10}$ wird dabei an Hermann und Dorothea besonders evident. Im Anschluss an die bisherige Perspektivierung von Goethes Epos-Projekt als der Moderne geschuldetem und diese gleichzeitig kritisch reflektierendes Erzählexperiment, soll die hervorragende Bedeutung, die der Zeit als gestaltgebendem Prinzip in diesem Zusammenhang zukommt, am konkreten Einzeltext herausgearbeitet werden. Denn gerade in der exemplarischen Kombination widerständiger Zeitgestaltungen manifestieren sich sowohl der spezifische Werkcharakter der Dichtung als auch die grundlegende Neuausrichtung des modernen epischen Erzählens auf die Sichtbarmachung der eigenen Voraussetzungen und Leistungsvermögen. Welche ästhetischen Lizenzen des Epischen werden in Hermann und Dorothea also erprobt? Und welche gerade nicht? Mit Blick auf die ausgewiesene Nähe zur Idylle wird auch nach den ästhetischen Eigenzeiten des Idyllischen und deren Funktionalisierung gefragt wie auch danach, ob und wie diese zur Erneuerung des Epischen herangezogen werden.

\subsubsection{Vom Geltungsverlust der Idylle in der Moderne und ihrer Erneuerung}

Auf die turbulente Rezeptionsgeschichte ${ }^{11}$ von Hermann und Dorothea und ihre gattungsgeschichtliche Tragweite wurde bereits ganz zu Beginn dieser Untersuchung hingewiesen. ${ }^{12}$ An dieser Stelle soll nun deutlich gemacht

\footnotetext{
10 Vgl. Kap. 3.2: Mediale Beschleunigung und die Verzeitlichung der Form.

11 Vgl. dazu ausführlich Lützeler, Paul Michael: Hermann und Dorothea (1797). In: Ders.; McLeod (Hrsg.): Goethes Erzählwerk. Interpretationen. S. 216-267.

12 Vgl. S. XIII ff. in diesem Buch.
} 
werden, inwiefern die wirkungsmächtige Zäsur der 196oer Jahre gerade auch mit den hier interessierenden Fragen nach Veränderungen im Zeitgefüge, der Erfahrung von Zeit und einem spezifischen zeitlichen Darstellungspotenzial von bestimmten literarischen Formen zusammenhängt. Nach wie vor ist das literaturwissenschaftliche Interesse an einem ausgewiesenen ehemaligen Lieblingstext nicht nur der Deutschen, ${ }^{13}$ sondern auch Goethes ${ }^{14}$ eher gering. Seit den späten 199oer-Jahren bemühen sich allerdings Literaturwissenschaftler wie Dirk Oschmann oder Stefan Willer wieder vermehrt um eine unvoreingenommene Neuentdeckung von Goethes Gedicht. ${ }^{15}$ Und Hermann und Dorothea erscheint in dieser methodischen und poetologischen Neuperspektivierung tatsächlich als höchst komplexe, selbstreflexive Dichtung mit großem Anschlusspotenzial an die Gegenwart. ${ }^{16}$ Aber obwohl heute wieder öfter gelesen, ist das Werk von einer Wiederaufnahme in den Kanon, geschweige denn von der immensen Popularität und Verbreitung während des 19. Jahrhunderts, weit entfernt. Geschuldet ist dieser Umstand vor allem der ideologiekritischen Wende der Germanistik um 1968 und der darin gründenden Ablehnung von Hermann und Dorothea als „höchste[m] und sublimste[m] Kitsch der europäischen Literatur ${ }^{417}$, als süßlicher „Schnulze ${ }^{\text {“18 }}$ - einem Verdikt, das sich bis über die 1970er-Jahre hinaus äußerst hartnäckig hält. Die Vertreter der zwischen 1965 und 1975 ideologiekritisch geprägten Literaturwissenschaft

13 Vgl. Lützeler: Hermann und Dorothea (1797). S. 216-267, hier S. 216.

14 Goethe nennt Hermann und Dorothea ein Lieblingsgedicht im Brief an Staatsrat C. L. F. Schultz, Marienbad, 8.7.1823, vgl. HA 2. S. 737 .

15 Vgl. zum Bsp. Stein, Malte: Stilles Unglück im Winkel. Die Familie in Goethes bürgerlichem Epos Hermann und Dorothea. In: Weimar, Ortsvereinigung Hamburg der GoetheGesellschaft (Hrsg.): Goethe. Literatur und Natur (= Jahresgabe 2015). Wettin-Löbejün: Stekovics 2015. S. 96-122; Oschmann: Das Epos in Zeiten des Romans. Goethes Hermann und Dorothea. S. 167-189; Willer, Stefan: Zur historischen Epistemologie der Zukunft. In: Gess, Nicola; Janssen, Sandra (Hrsg.): Wissens-Ordnungen: Zu einer historischen Epistemologie der Literatur (= Spectrum Literaturwissenschaft, 42). Berlin: de Gruyter 2014. S. 224-26o, insb. die Seiten 243-257; Kost, Jürgen: Die Fortschrittlichkeit des scheinbar Konventionellen. Das Motiv der Liebesheirat in Goethes Hermann und Dorothea. In: Goethe Jahrbuch 113 (1996). S. 281-286.

16 Vgl. S. 3 f. in diesem Buch.

17 Baioni, Giuliano: Märchen - „Wilhelm Meisters Lehrjahre - Hermann und Dorothea. Zur Gesellschaftsidee der deutschen Klassik. In: Goethe Jahrbuch 92 (1975). S. 73-127, hier S. 122 .

18 Geissler, Rolf: Goethes Hermann und Dorothea im Unterricht. In: Wirkendes Wort 13 (1963). S. $5^{2-58}$, hier S. $5^{2}$. 
werfen dem Text eine „Verherrlichung der Spießermoral ${ }^{19}$ vor und attestieren ihm einen „einfache[n], unaufgeklärte[n]“ und „aggressive[n]“ ”Nationalismus $^{\prime 20}$. Dieser weitreichende Forschungskonsens bewertet Goethes Werk als ein „reaktionäres“21 und „konservatives“22 Restaurationsprojekt. ${ }^{23}$ Für Oskar Seidlin scheint 1972 das Vorhaben einer erneuten Besprechung Hermann und Dorotheas eine „unzeitgemäße Betrachtung“ zu sein, denn das „künstliche und hochgesteigerte Amalgam von deutsch bürgerlicher Lebensenge und homerischer Weltenweite, $[\ldots]$ in dem vergangene Generationen gern ihre stolze Besitzesfreude [...], ihre eitle Zufriedenheit [...] verklärt sahen“, sei wohl kaum noch in der Lage zu begeistern. ${ }^{24}$

Die offenbar stark politisch motivierte Abwertung von Goethes Hermann und Dorothea als spießbürgerliche Selbstverherrlichung lässt sich zum einen auf die ideologische Lektürepraxis des 19. Jahrhunderts zurückführen, die Goethes Gedicht als "goldenes Sittenbüchlein“25 des deutschen Bürgertums installiert und den Text auf dem Hintergrund der historischen Schicksalsdaten von $1815,1830,1848$ und 1871 zunehmend national und nationalistisch, antifranzösisch und sogar militaristisch ${ }^{26}$ auflädt. Diese Projektionen halten sich hartnäckig und werden erst in der Folge des politischen Umbruchs der späten 196oer- Jahre überhaupt erstmals in Frage gestellt - nun dafür umso radikaler. Weiter zeigen sich darin auch die Abwehrbemühungen der 1968er-Generation

19 Krauss, Werner: Goethe und die Französische Revolution. In: Goethe Jahrbuch 94 (1977). S. 127-136, hier S. 135 .

20 Morgan, Peter: Aufklärung, Revolution und Nationalgefühl: Der Topos des Jakobiners und die Frage deutscher Identität in Goethes Hermann und Dorothea In: Zeitschrift für Germanistik NF 1 (1991). S. 533-543, hier S. 539.

21 Elsaghe, Yahya A: Säbel und Schere. Goethes Revolutionierung des Epos und die Rezeptionskarriere von Hermann und Dorothea. S. 121-136, hier S. 121.

22 Elsaghe, Yahya A.: Untersuchungen zu Hermann und Dorothea (= Zürcher germanistische Studien, 22). Frankfurt a. M. et al.: Peter Lang 199o. S. 96.

23 Baioni: Märchen - „Wilhelm Meisters Lehrjahre - Hermann und Dorothea. Zur Gesellschaftsidee der deutschen Klassik. S. 122.

24 Seidlin, Oskar: Über Hermann und Dorothea. Ein Vortrag. In: Ders. (Hrsg.): Klassische und moderne Klassiker. Goethe - Brentano - Eichendorff - Gerhart Hauptmann - Thomas Mann (= Kleine Vandenhoeck-Reihe, 3559). Göttingen: Vandenhoeck \& Ruprecht 1972. S. 20-37, hier S. 20.

25 Staiger, Emil: Hermann und Dorothea, zitiert nach Martens, Wolfgang: Halten und Dauern? Gedanken zu Goethes Hermann und Dorothea. In: Wittkowski, Wolfgang (Hrsg.): Verlorene Klassik? Ein Symposium. Tübingen: Niemeyer 1986. S. 79-98, hier S. 79.

26 Vgl. Schneider, Helmut: Ordnung der Kunst und Ordnung der Häuslichkeit. Arkadischer Topik, Idylle und das deutsche bürgerliche Epos des 19. Jahrhunderts. In: Schneider; Drath (Hrsg.): Prekäre Idyllen in der Erzählliteratur des deutschsprachigen Realismus. S. 13-33, hier S. 21. 
gegenüber der geschichtsabstinenten und apolitischen Literaturwissenschaft der Nachkriegszeit. Als solche kann etwa die Kritik Baionis verstanden werden, die Goethes Gedicht vorwirft, ein apolitisches deutsches Bürgertum zu lobpreisen, das in der Geschichte fast total versagt habe und auf dessen zur Schau gestellten Humanismus sich die Weimarer Republik umsonst berufen habe - den Machtantritt des Faschismus habe dieses idealistisch gemäßigte Bürgertum schließlich nicht zu verhindern mögen. ${ }^{27}$ So problematisch diese Auslegung auch sein mag - tatsächlich waren die Vorstellungen eines deutschen Bürgertums und einer deutschen Nation um 1800 politisch hochbrisant und noch nicht nationalistisch vereinnahmt - wird daran dennoch deutlich, wie die Idylle ab einem bestimmten Zeitpunkt mit einer ähnlichen, sich auf den Lauf der Geschichte stützenden Argumentationsweise kategorisch aus der modernen Gegenwart ausgeschlossen wird wie das Epos. Besonders radikal hat das bereits der französische Literaturkritiker Paul de Saint Victor vor dem Hintergrund des deutsch-französischen Krieges von 1871 formuliert, dessen Kritik an Hermann und Dorothea im Kern auf die endgültige, unhintergehbare Zerstörung der Idylle durch die historische Entwicklung abzielt: „Wir werden nie mehr in den Wald der deutschen Idylle gehen, seine Vergissmeinnicht sind mit Blut bespritzt. Wir wissen jetzt, wie Hermann, von den Preußen in ein Regiment gesteckt, sich im besetzten Lande aufführt.“28

Bezeichnenderweise haben sowohl die französische Kritik des 19. Jahrhunderts als auch die spätere Verdrängung der Idylle überhaupt und Hermann und Dorothea im Besonderen aus der deutschen Literaturwissenschaft ihren poetologischen Bezugspunkt am gleichen Ort wie Hegels Argumentation für den kategorischen Ausschluss des Epos aus der modernen Literatur: Durch die problematische Vermischung mit der Idylle, namentlich dem Rückzug aus den „Völkerereignissen in die Beschränktheit privater Zustände“ ${ }^{\text {“29 }}$, verliere das Epos jeglichen Realitäts- und Zeitbezug. Die moderne Idylle, die sich überhaupt „in ihrer süßlichen Sentimentalität und Verwässerung zugrunde gerichtet ${ }^{“ 30}$ habe,

27 Vgl. Baioni: Märchen - Wilhelm Meisters Lehrjahre - Hermann und Dorothea. Zur Gesellschaftsidee der deutschen Klassik. S. 120 f. und 127.

28 Paul de Saint-Victor, zitiert nach Helmerking, Heinz: Hermann und Dorothea. Entstehung, Ruhm und Wesen (= Goethe-Schriften im Artemis-Verlag, 4). Zürich: Artemis 1948. S. 87.

29 Hegel: Vorlesungen über die Ästhetik III. S. 414.

3о Ebd. 
ist aufgrund ihrer Geschichtslosigkeit ${ }^{31}$ spätestens für Hegel langweilig32 und nur von "geringfügigem Interesse“ ${ }^{33}$.

Während die Annäherung zwischen Epischem und Idyllischem für die Vertreter der Epochenschwelle dem Epos durchaus zum Vorteil gereicht, ist sie für Hegel und seine Nachfolger die eigentliche Ursache für das Ende des Epos. ${ }^{34}$ Nach dem Fiasko des Ersten und erst recht nach der Katastrophe des Zweiten Weltkriegs ist die Beschwörung „deutscher Bürgertugend“35, wie es 1893 noch hieß, höchst verdächtig geworden und spätestens nach 1968 jeglicher Grundlage beraubt. Durch diese historischen Schreckensereignisse wird die Idylle ein für alle Mal zugrunde gerichtet, und zwar nicht nur, weil ihre naiv-lieblichen Motive in größtmöglicher Diskrepanz zum erlebten Desaster stehen, sondern auch, weil die ihr eingeschriebene räumliche und zeitliche Abgeschlossenheit ${ }^{36}$ der modernen Einsicht in die historische Verfasstheit der Wirklichkeit entgegengesetzt ist. Das in Konflikt treten mit dem Wissen um Historizität erweist sich also als gemeinsames Strukturproblem von Epos und Idylle. Das Festhalten an geschichtsvergessenen Gattungstraditionen ist im 20. Jahrhundert endgültig zur selbstbetrügerischen, illusorischen Realitätsflucht geworden - die Zeit der Idylle und des Epos, nicht nur als gesellschaftliche oder kulturelle Idealvorstellungen, sondern eben gerade auch als literarische Formen, ist endgültig vorbei.

Inwiefern eine unvoreingenommene Herangehensweise an Hermann und Dorothea den Text allerdings von diesem zum Allgemeinplatz gewordenen Urteil des Unzeitgemäßen zu lösen vermag, hat etwa Wolfgang Martens mit dem Aufsatz zu den textinhärenten Dimensionen des Politischen und des Religiösen gezeigt, in dem er die sublime Mehrdeutigkeit von Goethes

31 Zur geschichtslosen Konzeption der Idylle bei Hegel vgl. etwa Gethmann-Siefert, Annemarie: Die Funktion der Kunst in der Geschichte. Untersuchungen zu Hegels Ästhetik (= Hegel-Studien, Beiheft 25). Bonn: Bouvier 1984. S. 329ff.; dies.: Einleitung: Gestalt und Wirkung von Hegels Ästhetik. In: Hegel, Georg Wilhelm Friedrich: Vorlesungen: Ausgewählte Nachschriften und Manuskripte, Bd. 2. Vorlesungen über die Philosophie der Kunst (Berlin 1823), nachgeschrieben v. Heinrich Gustav Hotho und hrsg. v. A. GethmannSiefert. Hamburg: Felix Meiner Verlag 1998. S. CCIV ff. und dies.: Einführung in Hegels Ästhetik (= UTB für Wissenschaft, Bd. 2646). München: Fink 2005. S. 335.

32 Hegel: Vorlesungen über die Ästhetik III. S. 391.

33 Hegel: Vorlesungen über die Ästhetik I. Frankfurt a. M.: Suhrkamp 197o. S. 25 o.

34 Vgl. Kap. 1.3: Hegel: Bürgerlicher Weltzustand und der Tod des Epos.

35 Hehn, Viktor: Über Goethes Hermann und Dorothea, aus dem Nachlass hrsg. v. Albert Leitzmann und Theodor Schiemann. Stuttgart: Cotta 1893. S. 45.

36 Vgl. Mix: Idylle. S. 393-402, hier S. 394 f. 
Gedicht sichtbar gemacht hat. ${ }^{37}$ Aus heutiger Sicht weist der Text sogar eine geradezu frappierende Aktualität auf: Die thematische Behandlung einer aus Revolutionskriegen herrührenden Flüchtlingsbewegung, die mit all ihrem Elend in die schön geordnete, heile Welt der deutschen bzw. europäischen Gesellschaft eindringt und damit für Unruhe sorgt, beschreibt gegenwärtige Problemlagen auf den Punkt genau. Die konkrete Konfrontation mit Vertriebenen, deren Schicksalen, aber auch den teilweise krassen kulturellen und ideologischen Unterschieden wird zur Charakterprüfung für die privilegierten Einheimischen, die sich angesichts der Schutzbedürftigen nicht zuletzt auch Fragen über die Sicherung des eigenen Wohlstands stellen. Darüber, dass dieser Text, dem man beständig den Vorwurf der Rückständigkeit, des Reaktionären und Ewiggestrigen gemacht hat, plötzlich gar nicht mehr „Lichtjahre“ von uns entfernt ist, sondern eine unverhoffte und beunruhigende Nähe zur eigenen Gegenwart aufweist, hat sich Gerhard Kaiser bereits im Jahr 2000 bzw. 1997 erschrocken. ${ }^{38}$ Gut zwanzig Jahre später müssen uns die kontrastiven Bilder vom „wohlbehaglich“ „unter dem Tore des Hauses“ (1, V. 20 f.) sitzenden Wirt auf der einen Seite und den "Alten und Kranken“ auf der anderen, die „hoch auf dem schweren / Überpackten Wagen auf Betten sassen und schwankten“ $(1, \mathrm{~V} .135$ f.) noch viel eindringlicher an die aktuelle Notlage gemahnen.

Auch wenn diese Neuperspektivierung stark von außertextlichen Parametern geprägt ist, weist sie Hermann und Dorothea zumal auf inhaltlicher Ebene als durchaus anschlussfähig an aktuelle Konfliktsituationen aus und entkräftet damit die tradierte Kritik des Veralteten und Realitätsfremden. Gleichzeitig zeigt sich hier auch, inwiefern sich die Lesart von Hermann und Dorothea als realitätsfremde Ideologie auf einen sehr eng gefassten Begriff des Idyllischen als unpolitischen Schutzraum stützt, in dem die bürgerliche Familie die arkadische Bukolik eins zu eins ersetzt. ${ }^{39}$ Tatsächlich war diese

Vgl. Martens: Halten und Dauern? Gedanken zu Goethes Hermann und Dorothea. S. 79-98, hier S. 81.

38 Kaiser: Französische Revolution und Deutsche Hexameter. Goethes Hermann und Dorothea nach 200 Jahren. S. 61-83, hier S. 61.

39 Vgl. ders.: Wandrer und Idylle: Goethe und die Phänomenologie der Natur in der deutschen Dichtung von Gessner bis Gottfried Keller. S. 25 f. Die Erneuerung des idyllischen Figurenpersonals fordert vor allem Gottsched in seinem Versuch einer Critischen Dichtkunst (1730): „Der heutige Schäferstand, also die Landbevölkerung des frühen 18. Jahrhunderts, scheint ihm wenig geeignet für die idyllische Darstellung, seien sie doch mehrheitlich armselige, gedrückte, geplagte Leute, unter denen zudem schon so viel Laster herrsche, dass man sie nicht mehr als Muster der Tugend aufführen könne“, Gottsched, Johann Christoph: Versuch einer critischen Dichtkunst (Nachdruck der 4., verm. Aufl., Leipzig, 1751). Darmstadt: Wissenschaftliche Buchgesellschaft 1962. S. 582. Aus dieser Perspektive drängt sich das ländliche Bürgertum als neuer Träger sittlich-moralischer Idealvorstellungen 
rigide Auffassung der Idylle, wie sie etwa in Voß' Luise noch realisiert wird, aber bereits um 1800 verdächtig bzw. zur Folie für einen avancierten Idyllenbegriff geworden. ${ }^{40}$ So zielt etwa schon Herders Kritik an Gessners Idyllen im Wesentlichen auf die überhöhte, idealisierte Darstellung der Figuren, die dadurch jegliche Individualität und in der Konsequenz auch jegliche Menschlichkeit verlören. ${ }^{41}$ Und für Schiller, der sich in seiner theoretischen Abhandlung Über naive und sentimentalische Dichtung prominent mit der Idylle auseinandersetzt, ${ }^{42}$ steht die Vorstellung eines glücklichen - sprich idyllischen - Naturzustands dem bewusst reflektierenden, sentimentalischen Kulturzustand, als den er seine Gegenwart begreift, ${ }^{43}$ unvereinbar gegenüber. Mehr noch siedelt

auf, vgl. Buschmeier, Matthias: Die Idylle bei Salomon Gessner, Friedrich (Maler) Müller und Johann Heinrich. Kritik und Transformation einer Gattung. In: Ders.; Kauffmann, Kai (Hrsg.): Sturm und Drang. Epoche - Autoren - Werke. Darmstadt: Wissenschaftliche Buchgesellschaft 2013. S. 220-237, hier S. 222. Zur bürgerlichen Rekonzeptualisierung der Idylle gehören auch andere Schauplätze wie Gärten, Lauben und stille Teiche, häusliche Feste wie Geburtstage, freundliche Besuche, Tätigkeiten wie Kaffeetrinken, Pfeiferauchen und genüssliche Mahlzeiten, die Grundthemen bilden Behaglichkeit, Frieden, Liebe, vgl. Häntzschel, Günter: Homer im Wohnzimmer. Das bürgerlich-idyllische Epos im 19. Jahrhundert. In: Baillot, Anne; Fantino, Enrica et al. (Hrsg.): Voß' Übersetzungssprache. Voraussetzungen, Kontexte, Folgen (= Transformationen der Antike, Bd. 32). Berlin: de Gruyter 2015. S. 125-140, hier S. 131.

40 Die Idylle entwickelt sich um 1800 von einer antiken, regelhaften Gattung zu einem Denkbild, vgl. Mix, York-Gothart: Idyllik, Anti-Idyllik, Aufklärung und Selbstaufklärung. Zur ästhetischen und philosophischen Kritik des Arkadien-Topos. In: Birkner, Nina; Mix, York-Gothart et al. (Hrsg.): Idyllik im Kontext von Antike und Moderne. Tradition und Transformation eines europäischen Topos (= Untersuchungen zur deutschen Literaturgeschichte 148). Berlin, Boston: de Gruyter 2015. S. 206-222, hier S. 207. Böschenstein spricht sogar von einem Wunschbild, vgl. Böschenstein, Renate: Idyllisch / Idylle. In: Barck; Fontius et al. (Hrsg.): Ästhetische Grundbegriffe. Historisches Wörterbuch in sieben Bänden, Bd. 3. S. 119-138, hier S. 119. Und auch Häntzschel bewertet Voß' Luise „dem Charakter der Idylle gemäss“ als „Wunschbild“. Häntzschel: Homer im Wohnzimmer. Das bürgerlich-idyllische Epos im 19. Jahrhundert. S. 125-140, hier S. 129. Die Idylle soll nun aber mehr an die Realität angeschlossen werden - Landleben, Bauern und ein ländliches Bürgertum werden geschildert. Zudem wird ein dunkler Hintergrund der Gefahr, eine problematische Wirklichkeit geliefert, damit die Idylle nicht schwerelos im Nirgendwo schwebt - darauf hebt sich die Idylle umso strahlender ab. Dass die Idylle nicht als mimetische Gattung modernisiert werden kann, reflektiert bereits Gottsched in seiner Critischen Dichtkunst, vgl. Buschmeier: Die Idylle bei Salomon Gessner, Friedrich (Maler) Müller und Johann Heinrich Voß. Kritik und Transformation einer Gattung. S. 220-237, hier S. 222.

41 Vgl. HW 1. S. 341.

42 Vgl. Schiller: Über naive und sentimentalische Dichtung. S. 744.

43 In Schillers Vorstellung der progressiven Kulturgeschichte entwickelt sich das Verhältnis von Mensch und Kunst analog zum Evolutionsmodel von einer ursprünglichen, naiven Einheit in der Antike über eine notwendige Trennung und Entfremdung durch rationale 
Schiller das „goldene Alter ${ }^{44}$ einer bruchlosen Übereinstimmung von Ideal und Realität vor dem „Anfang der Kultur ${ }^{445}$ und damit überhaupt außerhalb der Geschichte an.

Gleichwohl identifiziert Schiller die Rückkehr zu einer vollkommenen Einheit, ${ }^{46}$ einem Höchststand der Kultur als das "letzte Ziel“ der menschlichen Kulturgeschichte, das allerdings nur durch die Erfahrung und Überwindung des Partialen überhaupt erst erreicht werden kann. Die naiv-arkadische Idylle der Vorzeit gerät dadurch in einen "notwendigen Streit“ mit der von Schiller als lineare Fortschrittsentwicklung begriffenen Kultur, weil sie den Menschen „theoretisch rückwärts“ führt und damit „das Ziel, dem sie uns doch entgegenführen sollte [hinter uns]" stellt.. ${ }^{47}$ Der Mensch kann aber „nun einmal nicht mehr nach Arkadien zurück“48, die Idylle des Naturzustands hat er mit dem Eintritt ins Aufklärungszeitalter nicht nur endgültig hinter sich gelassen, sondern sie genügt auch nicht mehr als Sehnsuchtsort. Spätestens mit der Gewalterfahrungen der Revolution, die selbst die Errungenschaften der Aufklärung als von tiefen Wert- und Sinnkrisen begleitet aufdeckt, ${ }^{49}$ tritt die Idylle - zumindest in ihrer traditionellen Form - endgültig in ein problematisches Verhältnis mit der veränderten Erfahrungswelt. Entsprechend reflektiert Schiller das Ideal der arkadischen Idylle, in dem sich Natur und Kunst selbstverständlich und konfliktfrei begegneten, als einer Zeit zugehörig vor aller geschichtlichen Reflexion sowie einer Gesellschaft vor allem

Reflexion in der Neuzeit hin zur erstrebten Aufhebung der Differenzen zwischen Sinnlichkeit und Vernunft in einer utopischen Zukunft. Zum Verhältnis von Geschichte und Kunst bei Schiller vgl. z.B. Prüfer, Thomas: Ästhetische Geschichtsphilosophie und die Historisierung der Poetik am Ende des 18. Jahrhunderts. In: Fulda, Daniel; Tschopp, Silvia Serena (Hrsg.): Literatur und Geschichte. Ein Kompendium zu ihrem Verhältnis von der Aufklärung bis zur Gegenwart. Berlin: de Gruyter 2002. S. 277-297und Boettcher, Magdalena: Eine andere Ordnung der Dinge: Zur Ästhetik des Schönen und ihrer poetologischen Rezeption um 1800 (= Epistemata. Reihe Literaturwissenschaft, Bd. 236). Würzburg: Königshausen \& Neumann 1998. 132-144.

44 Vgl. Schiller: Über naive und sentimentalische Dichtung. S. 747.

45 Ebd. S. 745. Schiller bezieht sich hier auf die traditionelle Idylle mit ihrer Darstellung einer vergangenen, arkadischen Hirtenwelt, wie sie zum Beispiel Gessner verfasst hat. Diese Form der bukolischen Idylle wird um 1800 grundsätzlich einer von Kant ausgelösten, kritischen Betrachtung unterzogen, vgl. Mix: Idyllik, Anti-Idyllik, Aufklärung und Selbstaufklärung. Zur ästhetischen und philosophischen Kritik des Arkadien-Topos. S. 206-222.

46 Vgl. Schiller: Über naive und sentimentalische Dichtung. S. 718.

47 Ebd. S. 747.

48 Ebd. S. 75 .

49 Vgl. Boettcher: Eine andere Ordnung der Dinge: Zur Ästhetik des Schönen und ihrer poetologischen Rezeption um 180o. S. $134 \mathrm{f}$. 
„Gedränge des bürgerlichen Lebens“50 - als uneinholbar verloren und naiv. Die damit aufgeworfene Frage nach dem möglichen Bezug naiver Dichtung zur Geschichte überhaupt und der historisch reflektierenden Gegenwart im Besonderen bestimmt also von Anfang an den modernen Gattungsdiskurs über das Idyllische. ${ }^{51}$ Mit dieser Synchronisierung von Anthropologie und Kultur in der Geschichte findet erstmals ein historisches Bewusstsein Eingang in die Gattungsphilosophie. Schiller denkt hier nämlich Gattung und Geschichte bereits vor Hegel als sich gegenseitig bedingend zusammen und bringt damit die einzelnen kulturellen Formen in ein historisch bestimmtes Abfolgeverhältnis. Die unhistorische, apolitische Idylle ist im modernen Entwicklungsmodell der schillerschen Kultur- und Geschichtsphilosophie unproduktiv und auch für das Programm der ästhetischen Erziehung erweist sie sich als nutzlos. Auf die gleiche Problematik kommt auch Karl Philipp Moritz zu sprechen, wenn er kritisch festhält, dass wohl nichts von der Geschichte bekannt wäre, wenn der Mensch tatsächlich in einem idyllischen Zustand glücklicher Unschuld verharrt wäre:

\begin{abstract}
Aber freilich ist das Weiden der Schafe das Allerunschuldigste Geschäft eines Sterblichen: So dass auch die Dichtkunst hier ihren Stoff hernehmen musste, da sie vollkommen glückliche, zufriedene und unschuldige Menschen schildern wollte. Aber freilich, wenn alle Menschen Schafe gehütet hatten, so wären sie zwar an sich wohl ganz glücklich gewesen. Aber was wäre denn aus unsrer Geschichte geworden?52
\end{abstract}

Bemerkenswerterweise hält Moritz dieser Vorstellung einer ahistorischen Idylle gerade das Epos als literarische Form entgegen, die sich vornehmlich

50 Schiller: Über naive und sentimentalische Dichtung. S. 718 .

$5^{1} \quad$ Der Idylle wird um 1800 immer noch unterstellt, dass sie in der Antike in einem rein mimetischen Verhältnis zur Gegenwart gestanden habe. Im Goldenen Zeitalter wären eben Mensch und Natur, Sinnlichkeit und Verstand, Lebenswelt und Kunst in einer totalen Einheit aufgehoben gewesen und in den Idyllen wäre dieser Zustand zur Darstellung gekommen. Ähnlich wie in Bezug auf das Epos und dessen Deutung aufgezeigt wurde, handelt es sich auch bei dieser Auffassung von der Idylle um eine Fehldeutung der antiken Gattung durch gewisse Autoren des 18. Jahrhunderts bzw. wird darin die problematische Grundkonstante klassizistischer Kunstbetrachtung sichtbar. Bei Schiller und Jean Paul wird diese Interpretation aber gerade als Missverständnis ausgewiesen und eine andere, historisch kritischere Idyllen-Konzeption angeboten, vgl. Buschmeier: Die Idylle bei Salomon Gessner, Friedrich (Maler) Müller und Johann Heinrich Voß. Kritik und Transformation einer Gattung. S. 220-237, hier S. 221 f. Zur Idylle bei Jean Paul vgl. Wiethölter, Waltraud: Witzige Illumination. Studien zur Aesthetik Jean Pauls (= Studien zur deutschen Literatur, Bd. 58). Tübingen: Niemeyer 1979. S. 204.

$5^{2}$ Moritz, Karl Philipp: Fragmente aus dem Tagebuche eines Geistersehers. Berlin: Himburg 1787. S. 301. 
historischer Stoffe bedient und insofern auf die Vermittlung historischer Begebenheiten ausgerichtet ist:

Wo hätten wir von Schlachten zu Land' und zur See, von eroberten Städten, von Feldherrntugenden, von Heldenmuth [sic] und Tapferkeit, von Bündnissen und Staatsverfassungen zu hören und zu lesen bekommen? Dieser Welt von Ereignissen, die nun auf dem Schauplatz und in der Geschichte eine so angenehme Wirkung auf unsre Einbildungskraft thut [sic], wären wir dann verlustig gegangen. Wo hätte dann der Stoff zu einer Iliade, zu einer Aeneide herkommen sollen?53

Mit seiner sentimentalischen Bestimmung versucht Schiller nun die Idylle geschichtsphilosophisch zu retten, indem er sie als utopischen Vorstellungsort eines zukünftigen Idealzustands konzipiert. Die Unvereinbarkeit von Wirklichkeit und Ideal kann oder soll die moderne Idylle nicht aufheben, aber sie kann sie der Reflexion zuführen, indem sie die ihr zugeschriebene Harmonie als etwas aus einer anderen Zeit herbeizitiertes markiert. ${ }^{54}$ In dieser selbstbespiegelnden Neuausrichtung soll sie "bis nach Elysium“55, also zu einer selbstbestimmten Mündigkeit führen und den modernen, vernünftigen Menschen in einem vollkommenen Kulturzustand zeigen, der dem natürlichen sogar „unendlich vorzuziehen ist“56. Mit diesem Postulat der elysischen Idylle als Ziel der kulturellen Entwicklung rekurriert Schiller auf Kants Absage an eine mögliche Rückkehr zu archetypischer Harmonie und versucht eine Wendung zur realen Zukunft, ${ }^{57}$ unterläuft mit der Vorstellung eines darin enthaltenen reflektierenden Kulturmenschen aber gerade sein Ideal des differenzlosen ästhetischen Zustands. ${ }^{58}$ Das dialektische Verhältnis von ästhetischem Zustand und konkreter Wirklichkeit, von Utopie und deren Verlust vermag Schiller nämlich nicht aufzulösen: „Weil aber das Ideal ein Unendliches ist, das er niemals erreicht, so kann der kultivierte Mensch in seiner Art niemals

53 Ebd.

54 Das schmerzliche Verlustgefühl wird durch zeitliche Distanz gemildert und steht in Verbindung mit innerer Distanz zu sich selbst und Reflexionstätigkeit, vgl. Schrumpf, AnitaMathilde: Sprechzeiten. Rhythmus und Takt in Hölderlins Elegien. Göttingen: Wallstein 2011. S. $54 \mathrm{f}$.

55 Schiller: Über naive und sentimentalische Dichtung. S. 75 o.

56 Ebd. S. 718.

57 Vgl. Mix: Idyllik, Anti-Idyllik, Aufklärung und Selbstaufklärung. Zur ästhetischen und philosophischen Kritik des Arkadien-Topos. S. 206-222, hier S. 210 und ders.: Idylle. S. 393-402, hier S. 397 .

$5^{8}$ Vgl. Kaiser: Wandrer und Idylle: Goethe und die Phänomenologie der Natur in der deutschen Dichtung von Gessner bis Gottfried Keller. S. 9 . 
vollkommen werden, wie doch der natürliche Mensch es in der seinigen zu werden vermag."59

Insofern war die Idylle also schon am Übergang vom 18. zum 19. Jahrhundert nicht mehr das unhinterfragte Instrument bürgerlicher Neubegründung und Selbstvergewisserung, sondern bereits zur Form der Utopie, zum Vorstellungort einer unrealistischen Wunscherfüllung und damit aber auch zu einer reflexiven Form geworden. ${ }^{60}$ Der unaufhaltsame Einzug des realistischen Zeitgeistes ins Literatursystem und die Dekonstruktion tradierter Gattungsnormen führen dazu, dass sich das Idyllische im Laufe der Moderne immer weiter vom traditionellen Gattungsbild entfernt, vervielfältigt und schließlich vor allem in kontrastierenden, utopischen Effekten realisiert wird. ${ }^{61}$ Ihren Ursprung hat diese Entwicklung im goethezeitlichen Gattungsdiskurs und dem darin artikulierten und reflektierten Zeit-Wissen. Wie im Folgenden dargelegt werden soll, führen die zu diesem Zeitpunkt einsetzenden Bemühungen, der Idylle einen größeren Gehalt an Realität zu geben bzw. sie als sentimentalische Dichtung zu realisieren, zu entscheidenden Modifikationen ihrer strukturellen Merkmale, die dann nicht zuletzt auch der Restitution des Epischen zugutekommen werden. Dabei erscheint die Widerständigkeit der beiden Gattungen gegen Historismus und Realismus nicht länger reaktionär, sondern stellt gerade die eigentliche Voraussetzung dafür dar, das gleichzeitige Nebeneinander von verschiedenen Zeitvorstellungen und -erfahrungen, wie es eben bereits für die frühe Moderne kennzeichnend ist, überhaupt wahrnehmbar zu machen.

\subsubsection{Zwischen idyllischer Beschränkung und epischer Entgrenzung.}

Ein Blick auf die Entstehungsgeschichte von Hermann und Dorothea

Während der erste Abschnitt ausgeführt hat, dass die doppelte Zugehörigkeit von Hermann und Dorothea zum Epischen wie auch zum Idyllischen in der Rezeptionsgeschichte insofern problematisch wird, als das Werk einseitig auf eine ideologisch vereinnahmte Idyllentradition festgeschrieben wird, soll im Folgenden ein komplementärer Blick auf die Entstehungsgeschichte der Dichtung geworfen werden und ihre doppelte Gattungszugehörigkeit als bewusste Aktualisierung von Goethes morphologischem Formdenken ausgewiesen werden.

59 Schiller: Über naive und sentimentalische Dichtung. S. $75^{\circ}$.

6o Vgl. Willer: Zur historischen Epistemologie der Zukunft. S. 224-26o, hier S. 244.

61 Vgl. Böschenstein: Idyllisch / Idylle. S. 119-138, hier S. 131. 
Als das fundamentale Strukturmerkmal der Idylle hat die einschlägige Forschung eine in erster Linie räumliche Bestimmung des „Kleinen“62 hervorgehoben, die Vorstellung eines „eingegrenzten Raums, der vor Aggressionen von außen weitgehend geschützt ist" ${ }^{63}$ Damit ist sie dem Epos, dessen Raumstruktur auch im Gattungsdiskurs der Epochenschwelle vornehmlich durch die Kriterien der Größe und der sinnlichen Breite ${ }^{64}$ bestimmt ist, entschieden entgegengesetzt. Tatsächlich nimmt sich Hermann und Dorothea produktionschronologisch am Anfang aber nicht nur als explizite Idylle, sondern zumindest von der Idee her auch als „kleine $[s]$ Gedicht“"65 aus. Über sein Vorhaben schreibt Goethe an Schiller: „Ich werde, insofern man in solchen Dingen Herr über sich selbst ist, mich künftig nur an kleinere Arbeiten halten, nur den reinsten Stoff wählen, um in der Form wenigstens alles tun zu können, was meine Kräfte vermögen."66 Dieses selbstauferlegte Reduktionsgebot ist durchaus als kritische Reaktion auf die Auflösungs- und Vervielfältigungstendenzen der Erscheinungswelt sowie des Gattungssystems zu verstehen, mit denen sich die zeitgenössische Literaturproduktion konfrontiert sieht. ${ }^{67}$ Wie die Ausführungen im zweiten Teil dieser Untersuchung deutlich gemacht haben, ${ }^{68}$ scheint die untrennbar mit dem Epos verschränkte Idee eines großen Ganzen nicht mehr einlösbar und ist das Poetische überhaupt nur noch durch gegenständliche und produktionsästhetische Restriktionen zu realisieren. Insofern ist zu diesem Zeitpunkt die kleinformatige Idylle im Unterschied zum Epos nicht nur aufgrund ihres modifizierten bürgerlichen Personals eine zeitgemäße Gattung der Literatur, sondern gerade auch, weil sie mit ihrer programmatischen Beschränkung der bereits von Herder geforderten Charakteristik des Spezifischen ${ }^{69}$ entspricht.

Doch schon bald ist aus der geplant kleinen Dichtung eine "grosse Idylle"70 geworden, die sich im Verlauf der Arbeit immer noch weiter ausdehnt ${ }^{71}$ und

62 Vgl. dazu grundlegend Böschenstein-Schäfer, Renate: Idylle. Stuttgart: Metzler 1967. S. 3. Und Böschenstein: Idyllisch / Idylle. S. 119-138, hier S. 120.

63 Ebd. S. 121 .

64 Vgl. Über epische und dramatische Dichtung, BW. S. 539.

65 Goethe an Heinrich Meyer, 5.12.1796, HA 2. S. 734.

66 Goethe an Schiller, Anfang Juli 1796. In: Ebd.

67 Vgl. Kap. 3: Erschütterung der Wissenssysteme und methodische Neuansätze u. Kap. 4: Die Epos-Debatte um 1800 und ihre gattungstheoretischen Problemstellungen.

68 Vgl. Kap. 4: Die Epos-Debatte um 180o und ihre gattungstheoretischen Problemstellungen.

69 Vgl. S. 15 f. in diesem Buch.

$70 \quad$ Goethe an Christiane, 9.9.1796, HA 2. S. 734.

71 Goethe an Christiane, 13.9.1796: „Diese Woche will ich noch hier bleiben. Mit meiner Idylle geht es sehr gut. Sie wird aber viel größer, als ich gedacht habe." HA 2. S. 734. In den 
schließlich sogar zu einem „epischen Gedicht"72 entfaltet. Wie er durch die Arbeit an der Idylle ${ }^{73}$ "in das verwandte epische Fach geführt worden" sei, beschreibt Goethe gegenüber Meyer als dynamischen Prozess, „indem sich ein Gegenstand, der zu einem [...] kleinen Gedichte bestimmt war, zu einem größeren ausgedehnt hat, das sich völlig in der epischen Form darstellt" ${ }^{74}$ Diese Aussage über die eigentümliche Ausdehnung von Hermann und Dorothea wird von Elsaghe als Hinweis darauf gedeutet, dass ein ursprüngliches, älteres Idyllen-Projekt von einem chronologisch späteren, bzw. jüngeren EposProjekt überlagert werde ${ }^{75}$ und die epische Qualität des Gedichts demnach als das Resultat einer vornehmlich nachträglichen Bearbeitung - sprich einer bewussten Episierung der ursprünglichen Idylle - zu verstehen ist. ${ }^{76}$

Nun lassen sich in Goethes Bemerkung aber auch aufschlussreiche Hinweise auf ein verändertes, morphologisch bestimmtes Gattungsdenken aufspüren, wie es im Kapitel zur Verzeitlichung der Form ${ }^{77}$ vorgestellt wurde. Zunächst weist Goethe das Epische nämlich als etwas aus dem Vollzug der Darstellung im Laufe des Gedichts erst Werdendes aus, anstatt als etwas von vornherein Bestimmtes. ${ }^{78}$ Des Weiteren scheint gerade die vorsätzliche Ausrichtung auf Kürze, Beschränktheit und Partikularität wiederum das Bewusstsein für das Große, die Ausdehnung und die Auflösung von Grenzen zu schärfen, und zwar sowohl in Bezug auf den Stoff wie auch dessen Darstellung. Die epische Größe des Gedichts wird allein im Kontrast zur idyllischen Beschränktheit überhaupt erst als solche fassbar - eine exakte Bestimmung der epischen Ausmaße scheint damit am konkreten Werk ebenso wenig evident zu werden, wie in der theoretischen Reflexion. Die Lizenz des Epischen zu räumlicher Grenzenlosigkeit und Unabgeschlossenheit erscheint insofern nicht einfach als gattungstheoretische Konstruktion, sondern vielmehr als eine produktionsästhetische Entdeckung bzw. Problematik. Dass die Hybridisierung mit der Idyllenform ein reorganisierendes, zentripetales Gegengewicht zur potenziellen Unendlichkeit des Epischen schaffen soll, lässt sich hier bereits erahnen. Goethe versucht die Forderung nach antik-epischer Breite und den gleichzeitigen Druck

Tagbucheinträgen vom September 1796 schreibt Goethe am 9.: „von neuem Antrieb zur großen Idylle." Und am 11.: „Anfang die Idylle zu versifizieren." WA III, 2. S. 47.

72 Tagbucheintrag vom 28.9.1796: „Das epische Gedicht wieder aufgenommen." In: Ebd.

73 Gemein ist das Gedicht Alexis und Dora, das im Mai 1796 entstanden war.

74 Goethe an Meyer, 5.12.1796, HA, 2. S. 734.

75 Vgl. Elsaghe: Untersuchungen zu Hermann und Dorothea. S. 9.

76 Vgl. ebd. S. 18-39 und 44.

77 Vgl. Kap. 3.2: Mediale Beschleunigung und die Verzeitlichung der Form.

78 Vgl. Geulen, Hans: Goethes Hermann und Dorothea. Zur Problematik und inneren Genese des epischen Gedichts. In: Jahrbuch des freien deutschen Hochstifts (1983). S. 1-20, hier S. 2. 
zu zeitgemäßer, idyllischer Beschränkung nämlich nicht gegeneinander auszuspielen, sondern vielmehr füreinander produktiv zu machen.

Die Engführung mit der Idylle scheint auch Schiller von großem Vorteil für das Epische zu sein: „Es konnte gar nicht fehlen, dass Ihr Gedicht idyllisch endigte, sobald man dieses Wort in seinem höchsten Gehalte nimmt", schreibt er an Goethe, „[d]ie ganze Handlung war so unmittelbar an die einfache ländliche Natur angebaut, und die enge Beschränkung konnte, wie ich mir's denke, nur durch die Idylle ganz poetisch werden. Das was man die Peripetie darin nennen muss, wird schon von weitem so vorbereitet, dass es die ruhige Einheit des Tons am Ende durch keine starke Passion mehr stören kann“. ${ }^{79}$ Es ist bekanntlich Schillers Überzeugung, dass gerade diejenigen Werke, die sowohl naive als auch sentimentalische Formen enthalten, die größte Wirkung entfalten. In diesen individuellen, d.h. historisch-relativen Synthesen von naiver und sentimentalischer Dichtung sieht er eine mögliche, zeitgebundene Realisierung des Ideals einer absoluten Versöhnung. ${ }^{80}$ Genau aus diesem Grund wird die exemplarische Vermischung der Formen in Hermann und Dorothea von Schiller auch nicht getadelt, sondern vielmehr gelobt, muss sie ihm sie doch geradezu als conditio sine qua non sowohl für das Fortschreiben des Epischen als auch des Idyllischen in der Moderne erscheinen. Goethe erreicht mit Hermann und Dorothea ein höchstes Maß an Individualität, und das nicht durch die in den Propyläen geforderte Reinhaltung der Formen, sondern gerade durch die Verbindung von antiken und modernen, epischen und idyllischen Elementen. Für Schiller ist hier nicht nur der Anschluss des Epischen an die naturnahe Lokalität und die räumliche Enge der Idylle gelungen, sondern vielmehr eine neue, sinnstiftende Form der Poesie geschaffen worden, in der sich das Ideal des ästhetischen Zustands ${ }^{81}$ zu realisieren scheint. Von der gelungenen Rettung des grossen antiken Epos in der kleinen modernen Idylle ist dann auch Jean Paul überzeugt, wie seine berühmte Definition in der Vorschule der Ästhetik bezeugt: „Wenigstens eine kleine epische Gattung haben wir, nämlich die Idylle. Diese ist nämlich die epische Darstellung des Vollglücks in der Beschränkung.“82

Goethes Reflexion des Entstehungsprozesses von Hermann und Dorothea hat darüber hinaus die gattungspoetologische Formgestaltung grundsätzlich als einen schwierigen, eigendynamischen Prozess beleuchtet - noch

79 Schiller an Goethe, 4.3.1797, BW. S. 363.

8o Vgl. von Wiese, Benno: Das Problem der ästhetischen Versöhnung. In: Ders. (Hrsg.): Von Lessing bis Grabbe. Studien zur deutschen Klassik und Romantik. S. 140.

81 Vgl. S. 152 f. in diesem Buch.

82 Paul, Jean: Vorschule der Ästhetik. In: Ders.: Sämtliche Werke, hrsg. v. Norbert Miller, Abt. I, Bd. 5. Darmstadt: Wissenschaftliche Buchgesellschaft 1962. S. 258. 
während der abschließenden Bearbeitung des Gedichts wundert er sich, „wie [es] gegen sein Ende sich ganz zu seinem Idyllischen Ursprung hinneigt". ${ }^{\prime} 3$ Indem Goethe Hermann und Dorothea stets als ein „episches" ${ }^{44}$ bzw. ein explizit „idyllisch-episches Gedicht" ${ }^{\text {“5 }}$ bezeichnet und insofern eine klare Zuweisung entweder zur Idylle oder zum Epos verweigert, beharrt er nicht nur auf der formalen Uneindeutigkeit der Dichtung, sondern gibt auch Hinweis darauf, dass die darin enthaltene Widersprüchlichkeit Programm ist. In diese Richtung kann wohl auch die Aussage gegenüber Heinrich Meyer gedeutet werden, an den Goethe am 5. August 1797 schreibt, er habe die „Arbeit“ an Hermann und Dorothea "mit viel Sorgfalt und völligem Bewusstsein [...] fertig gemacht“ ${ }^{46}$ Der Wunsch, „in der Form wenigstens alles tun zu können“87, wird damit als bewusstes Bekenntnis zu jener Lust am Spiel, am Experimentieren mit ästhetischen Prinzipien jenseits der Gattungsgrenzen lesbar, die Goethes Epos-Projekt bereits von Anfang an ausgezeichnet hat.

Die merkwürdige Eigendynamik des Textes, zwischen dem Idyllischen und dem Epischen hin und her zu pendeln, erhebt Goethe zur übergeordneten produktionsästhetischen Lizenz des Epischen, zwischen den Gattungstraditionen hin und her zu schwanken. In diesem Sinne tut Goethe mit Hermann und Dorothea tatsächlich alles, „was in der Form überhaupt noch getan werden

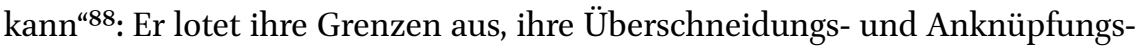
punkte und macht sie damit selbst zum Reflexions- und Erkennungsort poetischer Formen. Obwohl er den modernen Entregelungsprozessen gegenüber skeptisch ist, erkennt Goethe im Geltungsverlust normativer Prämissen auch eine Entlastung und Befreiung von bisher rigiden, äußeren Organisationsstrukturen, die besonders dem Epos und seiner Erneuerung, aber nicht zuletzt auch der Idylle zugute zu kommen scheint - dadurch kann in der Form eben (wieder) etwas (Neues) gemacht werden. Die Anschlussfähigkeit der antiken Form des Epos an die Bedingungen der Moderne liegt für Goethe demnach in deren neuentdeckten Flexibilität und Wandelbarkeit. Die alte Form hat immer noch Gültigkeit für Goethe, er nutzt sie aber nicht primär, um sie im traditionellen Sinn fortzuschreiben, sondern gerade, um in ihr die Spannung von klassisch-antiker Figuration und neuzeitlicher Ausdrucksdimension auszustellen. Dabei geht es nicht darum, die griechische Antike zu konservieren,

\footnotetext{
83 Goethe an Schiller, 4.3.1797, BW. S. 363.

84 Goethe an Schiller, 19.4.1797, BW. S. 375 .

85 Goethe an Körner, 20.7.1797, WA IV, 12. S. 198.

86 MA 4.1. S. 1078.

87 Goethe an Schiller, Anfang Juli 1796, HA. S. 734.

88 Ebd.
} 
vielmehr soll die sichtbar gemachte Aufhebung des Vergangenen auf eine mögliche Darstellung der Gegenwart führen.

Exemplarisch lässt sich das etwa an den doppelten Gesangsüberschriften aufzeigen, deren Verhältnis zueinander und die mit ihnen überschriebenen Textsegmente die Forschung bisher nicht eindeutig zu interpretieren vermag. Antike, in der epischen Tradition verankerte Musennamen ${ }^{89}$ stehen hier über modernen Titel, wie sie eben auch die zeitgenössischen Idyllen kennzeichnen. ${ }^{90}$ Während zwischen einigen Musen- und Untertiteln zumindest ein symbolischer Bezug hergestellt werden kann, wie er sich zum Beispiel am neunten Gesang aus der allegorischen Deutung Uranias als Muse der Sternkunde, der Astronomie und dem Aussichts-Begriffs ergibt - die Zukunft ist offen - bleiben andere Kombinationen zutiefst rätselhaft. So wird die Muse Kalliope, die Schönstimmige, mit der epischen Dichtung assoziiert. ${ }^{91}$ Dass ihr Name den ersten Gesang überschreibt und damit eine klare Gattungszugehörigkeit vorgegeben wird, scheint an sich sinnfällig. Der Versuch, zum Untertitel „Schicksal und Anteil“ einen ähnlich sinnvollen Bezug herzustellen, gerät jedoch zur Spekulation. ${ }^{92}$ So stehen die doppelten Inschriften und mit ihnen auch die literarischen Formen und Traditionen, denen sie zugerechnet werden, in mehr oder weniger offenkundiger Konkurrenz zueinander und setzen antike und moderne Ästhetik in ein spielerisches, aber auch prekäres Gleichzeitigkeitsverhältnis.

Die in Bezug Setzung von sich vermeintlich gegenseitig ausschließenden Positionen und Phänomenen hat sich bereits für die Überlegungen zur Morphologie der Natur sowie den auf Kontinuität ausgerichteten Kulturbegriff als übergreifende erkenntnisfördernde Denkfigur Goethes erwiesen. ${ }^{93}$ An Hermann und Dorothea wird das nicht allein an der Textoberfläche fruchtbar

89 Die Neun-Zahl der Musen und ihre Zuteilung zu Werkabschnitten wurde lange Zeit als antike Gepflogenheit angesehen und auf den Herodot-Korpus aus dem 5. Jh. v. Chr. zurückgeführt, tatsächlich hat dessen Teilung in neun nach den Musen benannte Bücher aber erst rund 300 Jahre später stattgefunden, vgl. Elsaghe: Untersuchungen zu Hermann und Dorothea. S. 37. Nichtsdestotrotz stellen die Musentitel eine eindeutige Referenz auf das antike Epos dar.

90 Auch hier wird die Parallele zu Voß' Luise besonders deutlich, deren erste Idylle neben der Zählung die Überschrift Das Fest im Walde trägt.

91 Vgl. Anmerkungen von Josef Schmidt in Goethe, Johann Wolfgang: Hermann und Dorothea. Stuttgart: Reclam 2010. S. 79.

92 Paul Michael Lützeler bietet eine durchaus einleuchtende Interpretation zur Funktion der Musennamen in Bezug auf den jeweiligen Gesangsinhalt, vgl. Lützeler: Hermann und Dorothea (1797). S. 216-267.

93 Vgl. Kap. 3.1: Die Unruhe in der Kultur und 3.2: Mediale Beschleunigung und die Verzeitlichung der Form. 
gemacht, vielmehr kann das Gedicht die eigene Epizität überhaupt nur fassbar machen, indem es auf allen Ebenen immer wieder Kontraste erzeugt, Vergleiche anstößt und diese reflektiert. Dass dieses regelbefreite Spiel mit den Gattungsmerkmalen zu unauflösbaren Widersprüchen und Ambivalenzen führt, hat Goethe stets klar vor Augen. Das vermögen nicht zuletzt seine Bemerkungen über die mäandernde Entstehung von Hermann und Dorothea zu belegen, mehr noch lenkt er immer wieder ganz bewusst die Aufmerksamkeit auf die Reibungspunkte zwischen Epischem und Idyllischem, Altem und Neuem. Die Bewegung des Schwankens wird sich insofern im Weiteren als poetologisches Verfahren erweisen, das den ganzen Text bestimmt und diesen damit entschieden gegen klassizistisch-orthodoxe Zugriffe in Stellung bringt.

\subsection{Episches Sprechen als Sprachreflexion}

Zum Entstehungszusammenhang von Hermann und Dorothea gehört neben dem direkten gattungstheoretischen Austausch mit Schiller und dem zeitgenössischen Diskurs über das Epische auch Goethes Auseinandersetzung mit dem Altphilologen Johann Heinrich Voß. Dessen Luise-Dichtung gilt nicht nur als die gelungene Gattungsbegründung des idyllischen Epos, sondern kann auch als die entscheidende Hauptinspiration für Hermann und Dorothea ${ }^{94}$ angesehen werden, wie Goethe selbst bezeugt: „Ich werde nicht verschweigen, wie viel ich bey [sic] dieser Arbeit [Hermann und Dorothea] unserm Wolf und Ihnen schuldig bin“, schreibt er im Dezember 1796 an Voß, „[s]ie haben mir den Weg gezeigt und er hat mir Muth [sic] gemacht ihn zu gehen“. ${ }^{95}$ Auch in der gleichnamigen Elegie, die ursprünglich als Einleitung zu Hermann und Dorothea gedacht war, dann aber separat veröffentlich wurde, ${ }^{96}$ huldigt Goethe Voß als künstlerisches Vorbild:

Deutschen selber führ' ich euch zu, in die stillere Wohnung, Wo sich, nah der Natur, menschlich der Mensch noch erzieht. Uns begleite des Dichters Geist, der seine Luise Rasch dem würdigen Freund, uns zu entzücken, verband. (V. 43-46) ${ }^{97}$

94 Vgl. HA 4.1. S. 1076.

95 Goethe an, 6.12.1796, WA IV, 12. S. 276 f.

96 Vgl. FA I, 8. S. 1198.

97 Goethe schreibt die Elegie im Dezember 1796, vgl. HA 4.1. S. 859 . 
Voß’ zunächst einzeln erschienene, ${ }^{98}$ dann 1795 zu einem epischen Ganzen erweiterten Pfarrhaus-Idyllen, ${ }^{99}$ die von Verlobung und Hochzeit in einem bildungsbürgerlichen Haushalt erzählen, lieferten mit der Einführung klassischer Hexameter-Verse ins Deutsche einen vielbeachteten Versuch, antike Form modern nachzubilden und damit das entscheidende sprachlichästhetische Muster für Hermann und Dorothea sowie die daran anschließenden idyllischen Epen des 19. Jahrhunderts. ${ }^{100}$ Darauf, wie Voß mit der Luise auch die maßgebliche Vorlage gibt für die Ritualisierung und Ontologisierung des deutschen bürgerlichen Welt- und Selbstbildes in der Idylle, wird weiter unten noch zurückzukommen sein. Zunächst soll nun aber die besondere Bedeutung aufgezeigt werden, die Voß’ Tätigkeit als Übersetzer und Metriker nicht nur im spezifischen Bezug auf Goethes Hexameter-Verse in Hermann und Dorothea, sondern überhaupt für die deutsche Poetik zukommt. Es wird zum einen darauf hingewiesen, wie das deutsche Sprachmaterial durch die Auseinandersetzung mit der griechischen Poesie und der darin neuentdeckten Beweglichkeit der Sprache eine entscheidende Versinnlichung erfährt. Und zum anderen sollen Goethes Hexameter im direkten Vergleich mit Voß' philologischer Programmatik als eigenständige, auf den veränderten Sprachgebrauch der Moderne reagierende Behandlung der poetischen Rede ausgewiesen werden.

\subsubsection{Von griechischen Versmaßen und der Poetisierung des Deutschen}

Wie die oben bereits zitierte Briefstelle gezeigt hat, stellen Voß' Idyllen unbestritten eine wichtige, aber nicht die einzige Inspiration für Hermann und Dorothea dar. Neben Voß gesteht Goethe auch Wolf großen Einfluss $\mathrm{zu}^{101}$ und diese doppelte Verdankung bei Voß und Wolf wiederholt sich im Widmungsgedicht:

$98 \quad$ FA I, 8. S. 1198.

99 Zumindest das letzte, separat veröffentlichte Luisen-Idyll hatte Goethe bereits zur Kenntnis genommen und auf die später zur epischen Dichtung umgearbeitet Veröffentlichung der drei Idyllen reagierte er äußerst positiv: „Für das, was Sie an Luisen aufs neue gethan haben, danke ich Ihnen, als wenn Sie eine meiner ältesten Freundinnen ausgestattet und versorgt hätten. Ich habe besonders die dritte Idylle, seitdem sie im Merkur stand, so oft vorgelesen und recitirt, dass ich mir sie ganz zu eigen gemacht habe und, so wie das Werk jetzt zusammen steht, ist es eben so national als eigen reizend. Das deutsche Wesen nimmt sich darin zu seinem größten Vortheil aus." Goethe an Voss, 1.7.1795, WA IV, 11. S. 272 f. Auch Schillers Brief an Körner vom 28.10.1796 betont die Luise als zentrale Anregung für Hermann und Dorothea, ebenso wie der Brief Goethes an Wolf vom 26.12.1796, vgl. MA 4.1. S. $1084 \mathrm{f}$.

1 oo Vgl. Schneider: Ordnung der Kunst und Ordnung der Häuslichkeit. Arkadischer Topik, Idylle und das deutsche bürgerliche Epos des 19. Jahrhunderts. S. 13-33, hier S. 22.

101 Vgl. Goethe an Voß, 6.12.1796, WA IV, 12. S. 276 f. 
Erst die Gesundheit des Mannes, der, endlich vom Namen Homeros Kühn uns befreiend, uns auch ruft in die vollere Bahn.

Denn wer wagt mit Göttern den Kampf? Und wer mit dem Einen? Doch Homeride zu sein, auch nur als letzter, ist schön. (V. 37-40 $)^{102}$

Damit zollt Goethe seinen Zeitgenossen Respekt und positioniert sich gleichwohl bewusst zwischen den beiden Extremen der zeitgenössischen HomerRezeption. Im Gegensatz zu Wolfs skeptisch-kritischer Auseinandersetzung mit dem antiken Dichter, beharrt Voß nämlich stets auf einer affirmativen Behandlung Homers und dem ihm zugeschriebenen Werk. Von Wolf fordert er deshalb vehement: „Eine[n] Homer! Eine[...] Illias! Eine[...] Odyssee!“103 Dieser Verehrungsgestus gegenüber der Antike und vor allem gegenüber Homer zeichnet auch Voß' originalgetreuen Übersetzungen der Ilias und der Odyssee besonders aus. Damit gelingt ihm weit mehr als ein bloßes Übersetzen der griechischen Epen: Durch die Nachbildung der epischen Sprache im Deutschen, namentlich des Hexameters, schreibt Voß Homers Werk, an dessen Totalität er unbeirrt festhält, und das damit verbundene Ideal überzeitlicher Kunst wirkungsmächtig in die deutsche Kulturgeschichte ein. Bis ins 20. Jahrhundert wird seine Odyssee nicht nur die deutsche Übersetzungs- und Literatursprache prägen, ${ }^{104}$ darüber hinaus stellt auch sein erneuertes Verfahren eine epochale Zäsur in der Übersetzungspraxis dar, die gemeinhin erst den Romantikern bzw. August Wilhelm Schlegel zugestanden wird. ${ }^{105}$ In der Nachahmung antiker sprachlicher Form - sprich einer deutschen Dichtung im griechischen Versmaß des Hexameters - ist dann wohl auch Voß' größtes Verdienst um die deutsche Poetik und die ausschlaggebende Anregung für Goethes Epen-produktion zu verorten. ${ }^{106}$

\footnotetext{
102 MA 4.1. S. 859 .

103 Voß an Wolf, 3.11.1796. In: Voß, Johann Heinrich: Briefe. Nebst erläuternden Beilagen hrsg. v. Abraham Voß, Bd. 2. Halberstadt: Bei Carl Brüggemann 1829-1833. S. 239.

104 Vgl. dazu grundlegend Häntzschel, Günter: Johann Heinrich Voß. Seine HomerÜbersetzung als sprachschöpferische Leistung (= Zemata. Monographien zur klassischen Altertumswissenschaft, Heft 68). München: Beck 1977. S. 249-261.

105 Vgl. ebd. S. 224.

106 Freilich erschöpft sich der Zusammenhang zwischen Voß’ Übersetzungstätigkeit, der Luise und Goethes Hermann und Dorothea nicht allein in der äußeren Form der Hexameter, darüber hinaus sind zahlreiche intertextuelle Bezüge aufzuspüren, auf die an gegebener Stelle insofern noch hingewiesen werden soll, als sie für die fokussierte Fragestellung aufschlussreich sind.
} 
Das antike Versmaß107 war in Deutschland bereits durch Klopstocks Messias erstmals bekannt geworden, der damit paradoxerweise einen sprachphilosophischen sowie poetologischen Wendepunkt hin zur Moderne markiert: ${ }^{108}$ die Dynamisierung der neudeutschen Sprache und Dichtkunst durch antikes Formeninventar sowie die Verzeitlichung der deutschen Prosodie im Zeichen des Griechischen. Der griechische Hexameter "hat den großen, und der Harmonie wesentlichen Vorzug der Mannigfaltigkeit“, ist Klopstock überzeugt“" „da er aus sechs verschiedenen Stücken, oder Füßen, besteht, so kann er sich immer durch vier, bisweilen auch durch fünf Veränderungen, von dem vorhergehenden oder nachfolgenden Vers unterscheiden. Und da diese Füße bald zwo, bald drei Silben haben, so entsteht daher eine neue Abwechslung “. ${ }^{109}$ Mit dieser positiven Ausrichtung auf die Beweglichkeit der Sprache deutet Klopstock gewissermaßen bereits die von Friedrich Schlegel und Novalis später postulierte progressive Universalpoesie voraus. ${ }^{110}$

Die am Hexameter von Klopstock bis Goethe so hochgeschätzte Eigenart der metrischen Gestaltungsvielfalt gründet allerdings nicht allein auf der Lizenz zur variablen Versifikation, sondern wesentlich auf den spezifischen prosodischen und syntaktischen Eigenarten des Griechischen: Dessen Intonation ist einer festen, quantitativen Norm von langen und kurzen Silben und damit einer zeitlichen Verfasstheit unterworfen, der im Deutschen ein Wortakzent - betonte und unbetonte Silben - gegenübersteht. Im griechischen Versbau kann der Akzent deshalb zugunsten der metrischen Ordnung vernachlässigt werden, wodurch die Wortwahl relativ frei wird. Die deutschen Versmaße sind hingegen an den sinnstiftenden Wortakzent gebunden,

107 Der griechische Hexameter besteht aus sechs Daktylen (eine lange, dann zwei kurze Silben), deren erste vier jeweils durch Spondeen (zwei lange Silben nacheinander) ersetzt werden können, deren letzter um eine Silbe verkürzt ist (katalektisch), vgl. Wagenknecht, Christian: Deutsche Metrik. Eine historische Einführung (5. Aufl.). München: Beck 2007. Zum Hexameter vgl. insb. S. 102-116. Die Diskussion um Quantität und Akzent des 18. Jahrhunderts bespricht zum Beispiel Schrumpf: Sprechzeiten. Rhythmus und Takt in Hölderlins Elegien. S. 62-69.

108 Über die Entwicklungsrichtungen im Versbau um und nach 1750 vgl. Heusler, Andreas: Deutsche Versgeschichte. Band 3: Der frühneudeutsche Vers. Der neudeutsche Vers (= Grundriss der germanischen Philologie, Bd. 8). Berlin: de Gruyter 1968.

109 Klopstock, Friedrich Gottlieb: Von der Nachahmung des griechischen Sylbenmaßes im Deutschen (Messias). In: Ders.: Sämtliche Werke, hrsg. v. Georg Joachim Göschen, Bd. 10. Leipzig: Göschen 1856-1857. S. 3-11.

110 Vgl. Oschmann, Dirk: Bewegliche Dichtung. Sprachtheorie und Poetik bei Lessing, Schiller und Kleist. München: Fink 2007. S. 73. Zum Konzept der progressiven Universalpoesie vgl. Bär, Jochen: Sprachreflexionen der deutschen Frühromantik: Konzepte zwischen Universalpoesie und Grammatischem Kosmopolitismus; mit lexikographischem Anhang (= Studia linguistica germanica, 50). Berlin: de Gruyter 1999. S. 224-318. 
Hebungen und Senkungen erzeugen im Wechselspiel eine fixe phonologische Grundstruktur. In der akzentuierten deutschen Sprache stehen deshalb höchst selten zwei lange bzw. betonte Silben nebeneinander, wie es etwa der Spondeus verlangt. ${ }^{111}$ Aber gerade die Verwendung des Spondeus scheint das Langsame und Erhabene des Hexameters auszumachen bzw. hängt daran die Möglichkeit, verschiedene Zeitmaße zu gestalten. ${ }^{112}$ Damit die neudeutschen Hexameter durch die Lautfülle der deutschen Silben nun weder monoton klingen noch die angestrebte "homerische Mannigfaltigkeit" ${ }^{113}$ einbüßen, sieht sich Klopstock genötigt, entscheidende Zugeständnisse zugunsten der Prosodie der deutschen Sprache zu machen. ${ }^{114}$ Er plädiert deshalb für die Bevorzugung des Daktylus gegenüber dem Trochäus - eine lange, dann eine kurze Silbe - und dieser beiden Maße wiederum gegenüber dem Spondeus. ${ }^{115}$ Durch die Verwendung des schnelleren Trochäus auf Kosten des langsamen Spondeus würde „unser epischer Vers“ sogar "noch manichfaltiger [sic] als der homerische". ${ }^{116}$ Diese Veränderung bedeutet eine Beschleunigung des antiken Versbaus und nähert den Messias eher den freien Rhythmen an, was Voß seinem ehemaligen Vorbild später indirekt vorwerfen wird. ${ }^{117}$

111 Hehn meint sogar unmöglich: „Wirkliche Spondeen sind in der deutschen, wie in jeder akzentuierenden Rhythmik, unmöglich, ja selbst der Schein solcher, wie beim Daktylus, Iambus usw. lässt sich nicht erregen. Der Grund liegt sehr nahe. Bei den Alten, wo die Länge etwas für sich Bestehendes, durch die Zeit gemessenes und von dem metrischen Iktus Gesondertes war, konnte auch diejenige Silbe lang sein, die in das sogenannte schlechte Taktteil fiel; im Deutschen, wo die Länge durch Erhebung des Tones ersetzt wird, können zwei Silben, von denen in der Bewegung des Verses nur eine den vollen Ton hat, keinen im Gleichgewicht beider Hälften schwebenden Versfuß bilden." Hehn, Viktor: Gedanken über Goethe (1887). Berlin: Bornträger 1925. S. 246.

112 Vgl. Sulzer, Johann Georg: Allgemeine Theorie der schönen Künste, Bd. 2. Leipzig: bey M. G. Weidmanns Erben und Reich 1777. S. 623.

113 Klopstock an Bürger, 20.4.1773. In: Bürger, Gottfried August; Strodtmann, Adolf (Hrsg.): Briefe von und an Gottfried August Bürger. Ein Beitrag zur Literaturgeschichte seiner Zeit (aus dem Nachlasse Bürgers und andern, meist handschriftlichen Quellen, Bd. 1). Berlin: Verlag von Gebrüder Paetel 1874. S. 103.

114 Vgl. Hehn: Gedanken über Goethe (1887). S. 243.

115 Vgl. Klopstock, Friedrich Gottlieb: Vom deutschen Hexameter, aus einer Abhandlung vom Sylbenmaß. In: Ders.: Messias, Bd. 3. Halle: Hemmerde 1769. S. 2-16, hier S. 2.

116 Ebd.

117 Vgl. Liggieri: Warum gelingt uns das Epische so selten? Ein Blick hinter Goethes Achilleis. S. 140. Voß Ablehnung der klopstockschen Hexameter wird von Goethe und Herder festgehalten. Voß selber schreibt, dass Klopstocks regelhafte Abweichung vom antiken Hexameter „den meisten als Regellosigkeit schien; dass nun ein jeder glaubt, der sechs zählen konnte, auch einen Hexameter abfingern zu können."Voß, Johann Heinrich: Zeitmessung der deutschen Sprache (Beilage zu den Oden und Elegien). Königsberg: Nicolovius 
Für Voß steht die Paarung von griechischem Hexameter und deutscher Sprache nämlich eindeutig im Dienst einer dringend nötigen ästhetischen Aufwertung des neuen Deutschen, dem man noch bis Lessing kaum eine hohe Poetizität zugestanden, sondern es vielmehr mit grober Prosa in Verbindung gebracht hatte. ${ }^{118}$ Voß' Ziel ist die Erneuerung der deutschen Poesie und der Schlüssel dazu liegt auch für ihn in der Beweglichkeit und Lebendigkeit des Zeitmaßes der Sprache.119 Für Voß liegt - im Gegensatz zu Klopstock - die unbestreitbare Qualität der homerischen Epen und damit eben auch das ausschlaggebende Merkmal des Epischen überhaupt, allein in der äußeren, sprachlichen Form und deren Regelhaftigkeit begründet. Sein Anspruch richtet sich deshalb ganz darauf, die deutsche Poesie im Zeichen der griechischen Sprache und im Geiste Homers zu reformieren. Vergleicht man die erste Odyssee-Übersetzung von 1781 mit der Überarbeitung von 1793, zeigen sich diese Radikalisierung von Voß' Arbeitsmethode und ihre Konsequenzen deutlich: So wird etwa aus „Und sie stürzten auf ihn lautschreiend“ „Und mit lautem Geschrei herstürzten sie“ (V. 30). Die noch einigermaßen natürliche, dem aktuellen Sprachgefühl entsprechende erste Ausgabe bildet er nach noch strengeren Prosodie- und Versifikationsregeln zu einer bedeutend artifizielleren Fassung um. ${ }^{120}$ Jede Abweichung vom Original, jede sichtbare eigene Produktivität des Übersetzers „[zerstört] den Bau der Periode zugleich und des Verses". ${ }^{121}$ Anstatt um die Freisetzung deutscher Dichtkunst, geht es Voß vielmehr um deren Rettung durch den an der antiken epischen Form so hochgeschätzten Eindruck von Klarheit und Einfachheit, den er in den spezifischen prosodischen und syntaktischen Eigenarten des Griechischen bzw. deren rigider Regelhaftigkeit verortet.

\footnotetext{
1802. S. XVIII. Zu Klopstocks Hexametern und Voß' Beurteilung vgl. Häntzschel: Johann Heinrich Voß. Seine Homer-Übersetzung als sprachschöpferische Leistung. S. 53-63.

118 Vgl. Oschmann: Bewegliche Dichtung. Sprachtheorie und Poetik bei Lessing, Schiller und Kleist. S. 118 f. Im Deutschen bleibe sogar der Hexameter Prosa, während er bei Homer Dichtung sei, meint etwa Herder, vgl. HW 1. S. 201.

119 Voß, Johann Heinrich: Publii Virgilii Maronis Georgicon Libri Quatuor = Des Publius Virgilius Maro Landbau. Vier Gesänge. Eutin, Hamburg: C. E. Bohn 1789. S. 259.

120 Voß übernimmt in der zweiten Fassung sogar die antiken Zäsurregeln, wodurch die deutsche Wortfolge stark verändert wird und artifiziell wirkt, vgl. Häntzschel: Johann Heinrich Voß. Seine Homer-Übersetzung als sprachschöpferische Leistung. S. 63 u. 8o.

121 Voß: Zeitmessung der deutschen Sprache (Beilage zu den Oden und Elegien). S. 256. Damit ist eins von zwei um 1800 virulenten Übersetzungskonzepten auf den Punkt gebracht: die möglichst getreue Rekonstruktion von Prosodie, Lexik und Syntax der Ausgangssprache. Vertreter des anderen versuchten den Text von Grund auf neu zu bauen, indem sie versuchten, die Gedanken und Figuren des Originalautors so zu simulieren, wie wenn dieser der aktuellen Realität der Zielsprache angehört hätte, vgl. dazu etwa Herder in der Rechenschaft des Übersetzers, HW 27. S. 276.
} 
In der Luise bringt Voß diese Maxime deutlich zum Ausdruck und tadelt im gleichen Atemzug jede alternative, weniger strenge Versifikationspraxis:

Klappt nicht immer sein Glas wie ein spaltiger Topf, und des neuern Dichterschwarms ungeschlifner Hexameter, welcher daherplummt Ohne Takt und Musik, zum Ärgernis? Kann er nicht anders, Oder gefällt es ihm nicht? Ein jegliches Ding hat doch Regeln! Kein Vernünftiger fasst an den oberen Kelch, wenn er anklingt;

Nein an den Fuß! Dann klingts, wie Harmonikaklang in den Glückwunsch! $(1, \text { V. } 519-524)^{122}$

Die Stelle beleuchtet zudem einen weiteren zentralen Aspekt von Voß' MetrikProjekt: Er erfasst die Versfüße des Hexameters grundsätzlich als Takte, ${ }^{123}$ seine Bemühungen um eine Nachbildung im Deutschen stehen damit auch ganz im Zeichen der Musikalität. ${ }^{124}$ Verse sind für Voß, wie für viele seiner Zeitgenossen, in erster Linie akustische Phänomene, sie sollen laut vorgelesen werden und entfalten dadurch erst ihre eigentliche Wirkung. Wie Frauke Berndt in ihrer Habilitationsschrift aufgezeigt hat, bedeutet das eine entschiedene Versinnlichung der deutschen Sprache, vor allem auch der deutschen Poesie im Zeichen der Oralität und gleichzeitig eine Abwehrhaltung gegenüber schriftlich fixierter prosaischer Narration. ${ }^{125}$ Insofern können die intensive Beschäftigung mit dem griechischen Hexameter und der Versuch, diesen für die deutsche Poesie fruchtbar zu machen, als kritische Reaktion auf die medialen Veränderungen der Epochenschwelle und den damit einhergehenden

122 Voß: Luise. Ein ländliches Gedicht in drei Idyllen (Nachdruck des Originals von 1799). Paderborn: Salzwasser 2017. Sämtliche Zitate aus Voß' Luise folgen im Weiteren dieser Ausgabe und werden mit der Verszahl in Klammern direkt im Text angegeben.

123 Vgl. Couturier-Heinrich, Clémence: Autorität und Konkurrenz. Zur Reaktion von Goethe und Schiller auf Vossens Hexameterlehre und -praxis. In: Baillot; Fantino et al. (Hrsg.): Voß' Übersetzungssprache. Voraussetzungen, Kontexte, Folgen. S. 71-91, hier S. 73 .

124 Gegen Ende des 18. Jahrhunderts schlagen sich die Bemühungen um eine metrisierte, musikalische Poesie allgemein in Theorie nieder, angefangen bei Gottscheds Versuch einer critischen Dichtkunst, vgl. Korten, Lars: Metrik als Tonkunst. Zur Zeitmessung der deutschen Sprache von Johann Heinrich Voß. In: Baillot; Fantino et al. (Hrsg.): Voß' Übersetzungssprache. Voraussetzungen, Kontexte, Folgen. S. 33-49, hier S. 38, vgl. dazu auch Schrumpf: Sprechzeiten. Rhythmus und Takt in Hölderlins Elegien. S. 69-89.

125 Vgl. Berndt, Frauke: Poema/Gedicht. Die epistemische Konfiguration der Literatur um 1750 (= Hallesche Beiträge zur Europäischen Aufklärung, hrsg. v. Daniel Fuldaet al., Bd. 43). Berlin, Boston de Gruyter 2011 [Habilitationsschrift], insb. S. 128-178 und S. 233-278, Vgl. auch dies.: Mit der Stimme lesen - F.G. Klopstocks Tonkunst. In: Messerli, Alfred; Pott, Hans-Georg et al. (Hrsg.): Stimme und Schrift. Geschichte und Systematik sekundärer Oralität. München: Fink 2008. S. 149-171. 
Bedeutungsgewinn von Zeitung und Roman ${ }^{126}$ gelesen werden. Stärker noch als Goethe und Schiller betont Voß in Bezug auf das Epos dessen Ursprung nicht nur in der mündlichen Tradition, sondern spezifisch im Gesang. In seiner Zeitmessung der Sprache geht es vor allem darum, das Geheimnis des Wohlklangs, also die sinnlich-ästhetischen bzw. eben musikalischen Seiten des Sprachklangs zu ergründen. Sein Hauptinteresse richtet sich demnach auf Rhythmik und Melodie, womit Zeitmaß und Bewegung auch in Bezug auf die Metrik zu den ausschlaggebenden Leitkategorien erhoben werden. Wie Neumann sinnfällig aufzeigt, können deutsche Hexameter aufgrund der prosodischen Ausgangslage stets nur in einem Ähnlichkeitsverhältnis zu antiken Hexametern stehen, diesen aber nie wirklich gleich sein. Diese Ähnlichkeit soll primär auf akustischer Ebene erzeugt werden und hier ein zeitlich verfasstes, hörbares Hexameter-Erlebnis ermöglichen. ${ }^{127}$ Das deckt sich mit Goethes Restitution eines sinnlichen Erkenntnismodus ${ }^{128}$ sowie der sich durch die ganze theoretische Debatte durchziehenden Emphase des Epischen als ein zugleich sinnlich erzeugtes und auf die Sinne wirkendes Erzählen. ${ }^{129}$

Dass Voß das Zeitmaß zum entscheidenden Kriterium seiner Metrik macht und sowohl Goethe als auch Schelling in ihren Hexameter-Beurteilungen an diesen Konnex von (gedehnter) Zeit und sinnlicher Wirkung anschließen, zeigt, wie grundlegend sich die Frage nach der zeitlichen Verfasstheit um 1800 in den Vordergrund schiebt, wann immer kulturelle Kategorien wie eben auch die Sprache zur Debatte stehen. Langsamkeit und Gleichmaß sind auch für Voß die Zeitgestaltungen, die für die Gegenwart aus dem griechischen Hexameter zu gewinnen sind: „Die Versfüsse des Hexameters bewegen sich alle in gleichmässiger Dauer", sodass die Hebungen in "gleichen Abständen“ gehört werden. ${ }^{130}$ Voß’ Aufmerksamkeit gilt spätestens ab 1793 der künstlichen Hervorbringung eines echten deutschen Spondeus - zum Beispiel durch eine stark betonte Silbe in der Senkungsposition, die zur vorausgehenden Hebung ein gleichwertiges Gegengewicht erzeugen soll131 - wobei er auf allerlei Listen und Zwangsmittel zurückgreifen muss. ${ }^{132}$ So heißt es in der Luise etwa

126 Vgl. S. $88 \mathrm{ff}$. in diesem Buch.

127 Vgl. Neumann, Friedrich: Grundsätzliches zum epischen Hexameter Goethes. Geprüft am 1. Gesang von Hermann und Dorothea. In: Deutsche Vierteljahrsschrift für Literaturwissenschaft und Geistesgeschichte 40, Heft 3 (1966). S. 328-359, hier S. 347.

128 Vgl. S. $106 \mathrm{ff}$. in diesem Buch.

129 Vgl. S. $167 \mathrm{ff}$. in diesem Buch.

130 Voß: Zeitmessung der deutschen Sprache (Beilage zu den Oden und Elegien). S. 171.

131 Vgl. Neumann: Grundsätzliches zum epischen Hexameter Goethes. Geprüft am 1. Gesang von Hermann und Dorothea. S. 344.

132 So brauchte Voß z.B. Diminutiva, um eine Silbe mehr oder vielleicht gar einen Spondeus zu gewinnen: „Söhnlein“, wo die Sache den „Sohn“ verlangte; er setzte den Komparativ 
exemplarisch: „Draußen in dunkeler Kühle der zwo breitlaubigen Linden“ $(1$, V. 1) - dass niemand "dunkeler" sagt, kümmert Voß wenig und er versifiziert hier sogar den sechsten Versfuß, der selbst in der Antike trochäisch sein konnte, als Spondeus. ${ }^{133}$ Daraus ergibt sich eine starre, durchregulierte, höchst künstliche Versform, eine semantisch und syntaktisch schwer verständliche, konstruierte Kunstsprache und vor allem auch ein eintönig-langsamer Silbenrhythmus. ${ }^{134}$

Zweifelsfrei stellt die an der antiken griechischen Metrik orientierte ReRhythmisierung und Versinnlichung des Deutschen für Voß auch die Lösung der seit der Spätaufklärung konstatierten Sprachkrise dar. ${ }^{135}$ Denn die besondere ästhetische Leistung, die er dem Hexameter zuschreibt, ist, dass er zu den "gemeinen Gegenständen“ nicht herabsinkt, sondern im Gegenteil diese „zu einer Würde“ erhebt. ${ }^{136}$ Dieses konservative Grundprinzip seiner Bemühungen und die darin enthaltene kulturpädagogische Absicht werden

für den Positiv, wo es sich nicht um eine Vergleichung handelte: „der grünere Hain“, statt „der grüne“, behielt das durch den Sprachgebrauch schon ausgestoßene „e“ der Verbalflexion bei, wie „wallete besänftiget“, beides wegen des Daktylus, und brach die Worte, um Spondeen zu gewinnen, wie „drauf antwortetest“, „du ehrwürdiger“ in „Drauf antwortetest du, ehrwürdiger Pfarrer zu Grünau“ (Luise 1, V. 38) - durch welches letztere Verfahren das Grundgesetz von der Geltung des Akzents umgestoßen wird, da niemand sagt „antworten“, „ehrwürdig“. Auch prosodisch eignet sich Voß ein fast brachiales Vorgehen an, das auf dem Kunstgriff gründet, die deutschen Silben gleich den griechischen als lang und kurz zu konstituieren. Voß half sich hier auf doppelte Weise, um dennoch Spondeen zu erzwingen, indem er beide Mal nach seiner Art gewalttätig und mechanisch verfuhr. Er fasste nämlich entweder zwei wirklich betonte Silben zusammen und sagte „Der Herrscher im Donnergewölk Zeus“ und „Fasste, dieweil Karl drängte, den Arm des bescheidenen Jünglings“ wo aber die zweite Silbe „Zeus“, „Karl“ in widersinniger Weise gesprochen werden muss oder beide Silben gleich stark betont werden, folglich aufhören, sich zu der Einheit eines Fußes zu verbinden, und statt des Hexameters eigentlich ein Heptameter entsteht, das heißt ein Vers mit sieben Hebungen. Oder er bildete sogenannte geschleifte Spondeen, indem er die stark betonte Silbe in die Thesis, die schwach betonte in die Arsis brachte und zum Beispiel sagte: „es erfolgt Schwachheit absterbenden Alters“ oder: „wer getrost fortgehet, der kommt an“, womit abermals der deutschen Wortbetonung Hohn gesprochen ist. Niemand sagt "fortgehet“, es müsste denn sein, dass der Gegensatz zum Fortreiten, Fortlaufen, Fortfliegen den Ton auf das „Gehen“ verlegte, und „kommt an“ könnte in einem jambischen Gedicht ohne Anstop als Jambus gebraucht werden, wie "Schwachheit" als Trochäus oder als die beiden Anfangssilben eines Daktylus. Hehn: Über Goethes Hermann und Dorothea. S. 133 f.

133 Wagenknecht: Deutsche Metrik. Eine historische Einführung. S. 105.

134 Neumann spricht von Schleppton, vgl. Neumann: Grundsätzliches zum epischen Hexameter Goethes. Geprüft am 1. Gesang von Hermann und Dorothea. S. 345 .

135 In den 179oer Jahren verlaufen sprachtheoretischer Diskurs und ästhetische Debatte über die Antikenbehandlung eng ineinander verschlungen.

136 Voß: Zeitmessung der deutschen Sprache (Beilage zu den Oden und Elegien). S. 189. 
in der Luise am deutlichsten. Allein durch die dem Griechischen entlehnte, äußere Form der Sprache und ihrer Konnotation mit der vornehmsten Gattung ${ }^{137}$ wird hier schon eine exemplarische Nobilitierung des deutschen Bürgertums erzeugt. Realistische, im Sinne von zeitgemäßen Figuren bedienen sich der gleichen, hohen und vornehmen Sprache wie die Helden und Götter der Antike, deren Attribute übertragen sich so auf die moderne Welt des Bürgertums. ${ }^{138}$ Inwiefern durch die philologische Methode von Voß allerdings tatsächlich eine Erweiterung und Erhebung des Deutschen gelingt oder dessen sprachlichen Strukturen vielmehr zerstört werden, bleibt selbst für die Zeitgenossen höchst fragwürdig. 139

Einen Gleichgesinnten findet Voß mit seiner doch sehr einseitigen und parteiischen Ausrichtung auf die Antike allerdings im Altphilologen Humboldt. Dieser ist beindruckt von Voß' „tiefem Studium der Verskunst und dem unerhörten Fleiß ${ }^{\prime \prime} 140$, den er auf seine metrischen Ausführungen verwendet. Humboldt teilt nicht nur Voß’ Überzeugung von einer überragenden, gleichwohl unerreichbaren Antike als Maßstab für die Moderne, sondern auch dessen idealisiertes Homerbild. „Was vortrefflich ist, ist auch Homerisch, und was nicht das letztere ist, ist auch nicht das Erstere ${ }^{\text {"141 }}$, hält er einmütig fest. Durch die „Einführung des klassischen Altertums in die deutsche Sprache“ habe Voß „der deutschen Nation und Sprache einen unglaublichen Rückhalt und gemeinsame Stärke gegeben“, ist Humboldt überzeugt und attestiert dem Homer-Übersetzer darüber hinaus eine "mächtige und wohltätige Einwirkung auf die Nationalbildung ${ }^{142}$ In dieser Aussage zeigt sich zunächst,

137 Vgl. Häntzschel:Johann Heinrich Voß. Seine Homer-Übersetzung als sprachschöpferische Leistung. S. 251.

138 Vgl. ders.: Homer im Wohnzimmer. Das bürgerlich-idyllische Epos im 19. Jahrhundert. S. 125-140, hier S. 128.

139 Das Urteil über Voß blieb stets zwiespältig. Während er für die erste Odyssee-Übersetzung von Wieland und Schelling gelobt wird, heimst er für die Überarbeitung wiederum von Wieland aber auch seinem Übersetzerfreund Stolberg Kritik ein - er gehe zu weit, würde die Grenzen seiner Muttersprache (Metrik u. Wortfolge) nicht respektieren. Humboldt bleibt ihm aber treu und ist von Luise begeistert - Hölderlin lehnt ihn dagegen als abschreckendes Beispiel ab, vgl. Liggieri: Warum gelingt uns das Epische so selten? Ein Blick hinter Goethes Achilleis. S. 153 ff. und Häntzschel: Johann Heinrich Voß. Seine Homer-Übersetzung als sprachschöpferische Leistung. S. VI (Vorwort). Auch in der späteren Forschung bleibt die Meinung über Voß' Leistung geteilt.

140 Humboldt, Wilhelm von: Tagebücher. Gesammelte Schriften, hrsg. v. Albert Leitzmann, 3. Abt., Bd. 14. Berlin: de Gruyter 1968. S. 312.

141 Ebd.

142 In der Einleitung von Humboldts Agamemnon-Übertragung der Ausgabe von 1816. In: Humboldt, Wilhelm von: Gesammelte Schriften, hrsg. v. Albert Leitzmann, 1. Abt., Bd. 8. Berlin: Behr 1909. S. 131. 
wie um 1800 grundsätzlich Fragen nach der Sprache, ihrem ästhetischen Vermögen und ihren Wirkungsmöglichkeiten ins Zentrum nationalistischer Argumentationen rücken. Der Mangel einer zentralen politischen Reichsgewalt erhöht in Deutschland zusätzlich den Druck auf die eigene Sprache als neues Ordnungssystem der kollektiven Identität. Gemäß Voß und Humboldt soll hier die Übernahme fremder, antiker Formen das Deutsche zu einer leistungsfähigen Literatursprache ausbauen und der aktuellen deutschen Literatur neues, poetisches Leben einhauchen. ${ }^{143}$ Von einer derart im Zeichen des Griechischen restituierten Dichtung versprechen sich die beiden Philologen nicht nur eine Festigung der deutschen Identität, sondern überhaupt die Stiftung einer deutschen Kulturnation. Diese Perspektive auf die Wechselwirkungen zwischen Sprache, Dichtung und nationaler Identität unterscheidet sich doch erheblich von Herders Auffassung. ${ }^{144}$ Dieser hatte die Poesie noch als notwendigerweise aus dem Volk entstehend begriffen und deshalb für die Anpassung der Dichtung an den zeitgenössischen Sprachgebrauch plädiert.

Voß' und Humboldts Denkrichtung folgt auch die philologische Bewertung der zeitgenössischen Hexameterdichtung der Brüder Schlegel. So stellt Voß’ Homer-Übertragung für Friedrich Schlegel nämlich gerade „ein[en] glänzende[n] Beweis“ dafür dar, „wie treu und glücklich die Sprache der Griechischen Dichter im Deutschen nachgebildet werden kann". ${ }^{145}$ Dass überhaupt ein deutschsprachiges Epos im griechischen Stil geschaffen wurde, wird hier ganz zugunsten der deutschen Sprache ausgelegt: An der Gestalt der Sprache werden sowohl die erreichte Kulturstufe wie auch der spezifische Charakter einer Nation evident - das Epos als Kulturmerkmal schlechthin gereicht hier sowohl zum Beleg für die besondere Poetizität der deutschen Sprache wie auch für die Tugendhaftigkeit des deutschen Volkes. Diese positive Perspektive wird von August Wilhelm Schlegel noch verstärkt, wenn er schreibt: „[D] ass ein so bescheidner, schmuckloser und doch an Farbe und Gestalt durchhin epischer Ausdruck, wie er in Hermann und Dorothea herrscht, in unserer Sprache möglich war, beweist die hohe Bildung, welche sie schon erreicht hat. Denn nur durch diese wird sie der Mäßigung, Entäußerung und Rückkehr zur ursprünglichen Einfalt fähig!"146 Für Voß und Humboldt konstituiert sich der Zusammenhang zwischen Sprache, Kultur und Gesellschaft dagegen gerade in entgegengesetzter Richtung und verlangt nach einem rückwärtsgerichteten, kulturpädagogischen Aufwertungsprogramm.

\footnotetext{
143 Vgl. Seidlin: Über Hermann und Dorothea. Ein Vortrag. S. 20-37, hier S. 22.

144 Vgl. S. 15 f. in diesem Buch.

145 KFSA I, 1. S. 342 f.

146 Schlegel, August Wilhelm: Kritische Schriften, erster Theil. Berlin: Reimer 1828. S. 68.
} 
An dieser Stelle wird nun allerdings die grundlegende Aporie dieser strengklassizistischen Programmatik einsehbar. Das Festhalten an normativen Prämissen erhält durch die Einsicht in eine sprachlich und politisch veränderte Gegenwart überhaupt erst seine Legitimation. Oder anders gesagt: Um die Antike als überzeitliches Ideal und politisch-kulturelles Gegenbild zur Gegenwart zu installieren, braucht es das Bewusstsein für die Probleme der Moderne. Erst aus der Retrospektive kann die Metrik der Antike überhaupt als eine zeitbedingte, entschieden langsame Verskunst erscheinen. ${ }^{147}$

\subsubsection{Goethes Hexameter: Freie Rhythmen und sinnliche Versbewegung}

Voß hatte Goethes Hexameter stets kritisiert oder sogar offen abgelehnt - in einem Brief an Gleim spottet er: „[D]ie Dorothea gefalle wem sie wolle. Eine Luise ist sie nicht." ${ }^{118}$ Umgekehrt brachte Goethe dem strengen Metriker jedoch lange Zeit Hochachtung entgegen ${ }^{149}$ für dessen Arbeit an den griechischen Epen und ihren Versmaßen, wie etwa aus einem Brief an Schiller hervorgeht: „In diesen Tagen da ich mich seiner [Voß'] Homerischen Übersetzung wieder viel bedient, habe ich den großen Werth [sic] derselben aufs neue bewundern und verehren müssen. ${ }^{150}$ Goethe erkennt den Zeitgenossen aber auch als orthodoxen Dogmatiker, der „mit Macht und Gewalt [auftritt]“, wenn sein Ideal angezweifelt wird:

Dann steht der friedliche Mann auf, greift zum Gewehr und schreitet gewaltig gegen die ihn so fürchtlich bedrohenden Irrsale, gegen Schnellglauben und Aberglauben, [...] gegen Verketzerer, Baalspriester, Hierarchen, Pfaffengezücht und gegen ihren Urahn, den leibhaftigen Teufel. ${ }^{151}$

Erst in späteren Jahren wird Goethe Voß offen für die starre Regelkonformität seiner Dichtungssprache kritisieren: „für lauter Prosodie ist ihm die Poesie ganz entschwunden“, heißt es dann 1808 über das frühere Vorbild. ${ }^{152}$ Das Jahr zuvor hatte er bereits A.W. Schlegel der "modernen Rhythmik ohne Poesie“ bezichtigt, sie eine „Krankheit“ genannt und prophezeit, dass „der Dünkel,

147 Vgl. Neumann: Grundsätzliches zum epischen Hexameter Goethes. Geprüft am 1. Gesang von Hermann und Dorothea. S. 347.

148 Voß an Gleim am 24.9.1797, zitiert nach Hehn: Über Goethes Hermann und Dorothea. S. 140 .

$149 \mathrm{Zu}$ der persönlichen Beziehung zwischen Goethe und Voß vgl. z.B. Baudach, Frank: Klassizist und Klassiker. Zum Verhältnis von Voß und Goethe. In: Baillot; Fantino et al. (Hrsg.): Voß' Übersetzungssprache. Voraussetzungen, Kontexte, Folgen. S. 51-69.

15 o Goethe an Schiller, am 6.5.1797, BW. S. 394.

151 MA 6.2. S. $572 \mathrm{f}$.

$15^{2}$ Goethe an C.F. Zelter, 22.6.1808, WA IV, 2o. S. 85 . 
womit die Rhythmiker von der strengen Observanz sich jetzt vernehmen lassen, höchst lächerlich sein" werde in der Zukunft. ${ }^{153}$ Zunächst scheint das Epische aber auch für Goethe eng mit der sprachlichen Hexameterform verbunden zu sein, denn obwohl im Gattungsgespräch mit Schiller kaum auf dessen Besonderheit und Bedeutung eingegangen wird, entscheidet er sich bei seinen epischen Produktionen nach der Italienreise doch konsequent für das griechische Versmaß.

Goethes Hexameter zeichnet sich signifikanterweise durch Langsamkeit aus, wie Pierre Bertauxs Vergleich mit Hölderlins Archipelagus offenbart. Während Goethes Versen ein gedrosseltes Rezitationstempo besonders zugutekomme, eine erhöhte Geschwindigkeit dagegen den Eindruck von Holprigkeit erwecke, sei es bei Hölderlin gerade andersherum. ${ }^{154}$ Der Schlüssel für einen sinnlichen Rezeptionsmodus, wie er in der theoretischen Eposdebatte vorgestellt wird, liegt demnach nicht allein in der Annäherung an die Medialität der gesprochenen Sprache, sondern ganz spezifisch in der zur Langsamkeit verpflichtenden Gestaltung des Versmaßes. ${ }^{155}$ Ein genauerer Blick auf die Hexameterbildung in Hermann und Dorothea macht aber schnell klar, dass der Fokus hier nicht allein auf die Langsamkeit, sondern eindeutig auch auf die eigentümliche Beweglichkeit und Variabilität des Metrums gelegt wird, die im Deutschen eben durch die Verwendung des Trochäus ausgeschöpft wird. Eher als an Voß schließt Goethes metrische Gestaltung also an Klopstock und dessen freieren Hexameter an, er geht gewissermaßen sogar darüber hinaus. Seine Übertragung der antiken Metrik auf die deutsche Sprache nimmt sich als eine gegenseitige Integration von prosodischer Besonderheit zweier Einzelsprachen aus, die mehr darauf ausgerichtet ist, Neues und Antikes miteinander zu vermitteln, anstatt jegliche modernen Eigenarten aus der poetischen Sprache zu tilgen. ${ }^{156}$

Anders als Voß modifiziert Goethe den Hexameter auch eindeutig zugunsten des Deutschen bzw. erzeugt er bewusst eine hybride Sprachform, in der die Diskrepanzen eben gerade nicht ausnivelliert werden. Das ermöglicht ihm, die traditionelle epische Sprache als ungewohnt und fremd - sprich einer anderen, vergangenen Zeit angehörig - auszustellen und gleichzeitig

\footnotetext{
153 Goethe an C.W. Knebel, 14.3.1807, WA IV, 20. S. 282.

154 Vgl. Bertaux, Pierre: Friedrich Hölderlin. Frankfurt a. M.: Suhrkamp 1978. S. 284, zitiert nach Oschmann: Das Epos in Zeiten des Romans. Goethes Hermann und Dorothea. S. 167189, hier S. $174 \mathrm{f}$.

155 Vgl. Oschmann: Das Epos in Zeiten des Romans. Goethes Hermann und Dorothea. S. 167189, hier 175 .

156 Vgl. Kaiser: Wandrer und Idylle: Goethe und die Phänomenologie der Natur in der deutschen Dichtung von Gessner bis Gottfried Keller. S. 51 .
} 
das ihr innewohnende Potenzial zur sprachästhetischen Erneuerung bzw. Sinnstiftung sichtbar zu machen. Mit anderen Worten: Goethe erzeugt eine anspruchsvolle, ambivalente Sprachform, die gleichzeitig einen unverstelltnaiven und einen reflexiv-sentimentalischen Zugang zum Text eröffnet. Wie Voß geht es auch Goethe darum, die deutsche Poesie durch syntaktische, rhythmische und stilistische Elemente der griechischen Dichtung zu erweitern und daraus eine signifikante kulturelle Bereicherung zu schöpfen. ${ }^{157}$ Den Anschluss an die Gegenwart und ihre Sprachrealität gilt es dabei allerdings gleichwohl zu bewahren und mit der griechischen Poetik zu vermitteln, nur so kann die modifizierte epische Sprache für die Aufrechterhaltung des kulturhistorischen Kontinuums ${ }^{158}$ genutzt werden.

Darin wird eine alternative Antikenbehandlung erkennbar, die mehr die reflektierende und zuweilen auch ironisierende Kraft einer kritischen Philologie produktiv macht und der streng klassizistisch ausgerichteten Maxime eines Voß entgegensteht. Während sich dieser darum bemüht, sein Antikenideal als bereits erloschenes Leuchtfeuer in einer defizitären Gegenwart aufzuzeigen, will Goethe die Antike an die Gegenwart heranholen und für die moderne Kunst fruchtbar machen. In der starren Form der vossischen Hexameter erkennt Goethe wohl aus diesem Grund eine tatsächliche Entfremdung des Homer, anstatt eine Annäherung; das Epos wird der Gegenwart, dem Volk und damit dem Publikum, für das es ursprünglich geschrieben wurde, entrückt: „Wie weit unser sonst verdienstlicher Vossischer Homer noch von der allgemeinen Fasslichkeit absteht", schreibt Goethe an Knebel, „hab ich vor kurzem gesehen, als ich mir von einer jungen Actrice, die gar nicht ungescheidt ist, einige Gesänge der Odyssee vorlesen liess. Diesen Kindermund wollten gar manche Stellen gar nicht kleiden und doch waren diese Dinge zuerst für Kinder und für das Volk calculiert [sic]“. ${ }^{159}$ Einer rigorosen Freisetzung der Kunst steht Goethe zwar nach wie vor skeptisch gegenüber, diagnostiziert er doch eine damit einhergehende stilistische Nivellierung und Armut in Bezug auf höhere literarische oder eben poetische Ansprüche. Der einseitige, streng mimetische Zugriff auf das Epische ist aber ebenso wenig dazu in der Lage, eine neue sprachliche Stilhöhe zu schaffen, aus der eine erneuerte, leistungsstarke Dichtung zu gewinnen wäre. In Hermann und Dorothea sprechen die Figuren deshalb sehr wohl in gesetzten, antikisierenden Hexametern, die Verse überschreiten

157 Neumann unternimmt eine eingehende metrische Analyse, vgl. Neumann: Grundsätzliches zum epischen Hexameter Goethes. Geprüft am 1. Gesang von Hermann und Dorothea. S. ${ }^{28-359}$.

$15^{8} \mathrm{Zu}$ Goethes Kulturbegriff vgl. Kap. 3.1: Die Unruhe in der Kultur.

159 Goethe an Knebel, 10.3.1813, WA IV, 23. S. 295. 
allerdings immer wieder die strengen metrischen Regeln. Das zeigt sich etwa daran, dass Goethe den Spondeus verhältnismäßig selten setzt, dafür den von Voß verpönten Trochäus gebraucht. Dadurch wird die sprachliche Form von Hermann und Dorothea bereits entschieden von der homerischen entfernt. Darüber hinaus zielt Goethe eher auf eine „prosaische Akzentuation“ ${ }^{160}$, die Versschlüsse tendieren zu leichten Silben, was geschmeidige, schwebende Übergänge erzeugt ${ }^{161}$ und den Text weiter an den modernen Sprachgebrauch annähert.

Die Absicht hinter diesem unorthodoxen Vorgehen wird dann im zweiten Gesang besonders deutlich: Hier steht der viel zitierte siebenhebige, regelwidrige Vers „Ungerecht bleiben die Männer, und die Zeiten der Liebe vergehen“ (2, V. 186) ${ }^{162}$. Durch den Artikel „die“ vor "Zeiten“ wird der dritte Versfuß viersilbig, das entspricht einer irregulären Taktfüllung, die allerdings der Sinnbewegung zugutekommt. Die dogmatischen Prosodisten, deren Hilfe Goethe bereitwillig sucht, ${ }^{163}$ fordern vehement eine Korrektur dieser "Bestie ${ }^{“ 64}$. Humboldt, der das Gedicht ansonsten in den höchsten Tönen lobt, tadelt Goethes Behandlung der Verse, die „einer Kritik [...] zu mancherlei Bemerkungen Stoff [gäbe]“. Es sei nicht zu leugnen, „dass hier eine Menge kleiner Flecken ins Auge fallen, die man in einem übrigens so vollkommenen Ganzen lieber wegwünschte“. 165 Obwohl Goethe manchen Korrekturvorschlag von Humboldt und Voß annimmt, ${ }^{166}$ besteht er beim oben genannten Vers darauf, ihn "als Wahrzeichen“167 stehen zu lassen. Keineswegs ist diese Äusserung dahingehend zu deuten, dass der Dichter entweder nicht fähig war, richtige Hexameter zu dichten oder er keinen Wert darauf gelegt hätte. Mit den römischen Elegien hatte Goethe bereits eingehend bewiesen, dass er die antiken Versmaße sehr wohl beherrschte und eine regelkonforme Ausführung

16o Neumann: Grundsätzliches zum epischen Hexameter Goethes. Geprüft am 1. Gesang von Hermann und Dorothea. S. 357 .

161 Vgl. ebd. S. 348.

162 Sämtliche Zitate aus Goethes Hermann und Dorothea folgen im Weiteren der ReclamAusgabe und werden mit der Verszahl in Klammern direkt im Text angegeben.

163 Zur Mitwirkung Humboldts, A.W. Schlegels und Voß' vgl. Couturier-Heinrich: Autorität und Konkurrenz. Zur Reaktion von Goethe und Schiller auf Vossens Hexameterlehre und -praxis. S. 71-91, hier S. $81 \mathrm{f}$.

164 Zitiert nach FA I, 8. S. 1205.

165 Humboldt: Ueber Göthes Herrmann und Dorothea (1799). S. 177.

166 Vgl. dazu Couturier-Heinrich: Autorität und Konkurrenz. Zur Reaktion von Goethe und Schiller auf Vossens Hexameterlehre und -praxis. S. 71-91, hier S. 81 f.

167 FA I, 8. S. 1205 . 
schätzte. ${ }^{168}$ Wenn Goethe nun seinen falschen Hexameter explizit als Wahrzeichen stehen lässt, anstatt ihn zu korrigieren, dann handelt es sich dabei wohl um eine geplante und exponierte Dissonanz. ${ }^{169}$ Hier wird das Fremde und Widerständige absichtlich erzeugt und ausgestellt. Im Gegensatz zum monotonen Gleichmaß der Luise stellt Goethe keine pseudo-natürliche Synthese von deutscher Sprache und griechischem Metrum vor, sondern bewusst unregelmäßige Hexameter mit einer freieren, sinnlichen Klangbewegung. Auch in Bezug auf die sprachliche Form sucht Goethe demnach einen Mittelweg, eine Verbindung zwischen Voß klassizistischer Position und den romantischen Programmen, die eine neue, variable, syntaktisch unkomplizierte, leichte, geschmeidige und vor allem prosaische Erzählsprache fordern. ${ }^{170}$ Anstelle eines durchgehend einheitlichen Zeitmaßes gestaltet Goethe verschiedene Tempi, die er einander gegenüberstellt, ohne sie in eine gleichmäßige Stetigkeit zu überführen, wie die syntaktische Verschachtelung im folgenden Beispiel zeigt: „Oh, verzeih, mein trefflicher Freund, dass ich, selbst an dem Arm dich / Haltend, bebe! So scheint dem endlich gelandeten Schiffer / Auch der sicherste Grund des festesten Bodens zu schwanken“ (9, V. 294 ff.). Das resultiert auf prosodischer Ebene in einem einzigartigen, unregelmäßigen Rhythmus, der gleichzeitig als formende Kraft auftritt und die erzeugte Form gerade wieder auflöst. Das ist das Schwanken zwischen Form und Unform, das in der Darstellung der Skelette der Nagetiere als morphologisches Grundprinzip beschrieben wird ${ }^{171}$ und dessen gleichsam fruchtbare wie gefährliche Dynamik sich in Hermann und Dorothea sowohl auf der sprachlichen wie auch auf der Ebene des Dargestellten manifestiert, wie die Szene von Dorotheas Sturz und Hermanns Auffangen im achten Gesang exemplarisch zeigt:

Aber sie, unkundig des Steigs und der roheren Stufe, Fehlte tretend, es knackte der Fuss, sie drohte zu fallen. Eilig streckte gewandt der sinnige Jüngling den Arm aus, Hielt empor die Geliebte; sie sank ihm leis auf die Schulter, Brust war gesenkt an Brust und Wang' an Wange. (8, V. 89-93)

168 Vgl. Liggieri: Warum gelingt uns das Epische so selten? Ein Blick hinter Goethes Achilleis. S. 139-141.

169 Vgl. Seidlin: Über Hermann und Dorothea. Ein Vortrag. S. 20-37, hier S. 26.

170 Das Aufbrechen der poetischen Regelhaftigkeit bedeutet eine Annäherung an das Prosaische - der Unterschied zwischen gebundener und ungebundener Sprache liegt in regelhafter Versifikation, vgl. Neumann: Grundsätzliches zum epischen Hexameter Goethes. Geprüft am 1. Gesang von Hermann und Dorothea. S. 351.

171 Vgl. S. 122 f. in diesem Buch. 


\subsection{Poetologische Verdichtungen}

\subsubsection{Goethes Relativierung der idyllischen Bürgertumsutopie}

Wie die bisherigen Ausführungen bereits angedeutet haben, ist der Ausrichtung der Idylle auf eine „heile Welt im Kleinen“172 insofern eine entscheidende soziale Implikation eingeschrieben, als der Isolationsbegriff der Beschränkung im Laufe des 18. Jahrhunderts auf die Vorstellung einer idealen, utopischen Gesellschaft übertragen ${ }^{173}$ und die Idylle damit funktional um die Formulierung und Vermittlung von politischen Wunschvorstellungen ${ }^{174}$ erweitert wird. In seiner Luise stellt Voß das Bürgerleben prototypisch als Insel des privaten Glücks inmitten eines politischen Chaos dar, wie es durchaus dem naiven Wunschdenken bestimmter bürgerlicher Schichten im Deutschland der Revolutionsjahre entspricht. Die traditionelle Forschung hat in dieser Erhebung des bürgerlichen Selbstgefühls nicht nur das eigentliche Verdienst von Voß' Dichtung gesehen, sondern auch die ausschlaggebende Programmatik der neuen Idylle, an die Goethe mit Hermann und Dorothea anschließen wollte. ${ }^{175}$ Es ist gerade diese Identifizierung von Idylle und bürgerlichem Leben, die die Gattung dann im 19. Jahrhundert zum Artikulationsort eines idealisierten, bildungsbürgerlichen Selbstverständnisses werden lässt und als deren Urbilder die bürgerlichen oder idyllischen Epen der Epochenschwelle - namentlich Voß' Luise und Goethes Hermann und Dorothea - gelten. ${ }^{176}$ In der unreflektierten Vorstellung einer Gesellschaft, die unberührt ist von den zivilisatorischen Krankheiten der Moderne, liegt dann allerdings bereits für Hegel die eigentliche Problematik der Idylle begründet. In der Darstellung eines „so genannten Goldenen Zeitalters oder auch eines idyllischen Zustands ${ }^{\star 177}$ erscheine der Mensch „auf jene idyllische

172 Schneider: Ordnung der Kunst und Ordnung der Häuslichkeit. Arkadischer Topik, Idylle und das deutsche bürgerliche Epos des 19. Jahrhunderts. S. 13-33, hier S. 17.

173 Vgl. S. 16 in diesem Buch.

174 Vgl. Böschenstein: Idyllisch / Idylle. S. 119-138, hier S. 119 und Wellbery, David E.: Die Grenzen des Idyllischen bei Goethe. In: Barner; Lämmert (Hrsg.): Unser Commercium: Goethes und Schillers Literaturpolitik. Vorträge des Symposiums vom 6. bis 9. September 1982 aus Anlass des Goethe-Jahres. S. 221-240, hier S. 226 und Willer: Zur historischen Epistemologie der Zukunft. S. 224-26o, hier. S. 244.

175 Vgl. FA I, 8. S. $1126 \mathrm{f}$.

176 Exemplarisch verwiesen sei hier auf den besonders einschlägigen Aufsatz von Helmut J. Schneider: Gesellschaftliche Modernität und ästhetischer Anachronismus. Zur geschichts-philosophischen und gattungsgeschichtlichen Grundlage des idyllischen Epos. In: Seeber, Hans Ulrich; Klussmann, Paul Gerhard (Hrsg.): Idylle und Modernisierung in der europäischen Literatur des 19. Jahrhunderts. Bonn: Bouvier 1986. S. 13-24.

177 Hegel: Vorlesungen über die Ästhetik I. S. 335. 
Armut geistiger Interessen beschränkt ${ }^{1178}$, zurückgeworfen auf eine unmittelbare Lebensbewältigung, fern jeglicher sittlicher oder kultureller Tätigkeit und Entwicklung. ${ }^{179}$ Die idyllische Gesellschaft, die sich jeglicher Reflexion oder Entwicklung und damit auch jeglicher Anbindung an die reale, gegenwärtige Welt enthält, erscheint insofern nicht als Ideal, sondern einem naiven Geisteszustand der Unmündigkeit verhaftet. ${ }^{180}$

In einer seiner frühesten Bemerkungen über Hermann und Dorothea hatte Goethe mit der Begründung, doch auch "so etwas" gemacht haben zu müssen, tatsächlich explizit eine "bürgerliche Idylle“ angekündigt. ${ }^{181}$ Ein oberflächlicher Blick auf den Text scheint das auch zu bestätigen, wird hier doch ein äußerst reduzierter Personenkreis porträtiert, dessen Mitglieder allesamt einem sittlich-moralisch ausgerichteten Bürgertum entstammen - Apotheker, Geistlicher, Wirt und Kaufmann stellen die repräsentierte Gesellschaft dar. Auffallend abwesend sind hingegen gleichfalls Vertreter der unteren wie der oberen Gesellschaftsschichten: Von Hirten und Schnittern ist zwar die Rede (4, V. 57 f.), in Erscheinung treten sie jedoch nicht, genauso wenig wie Fabrikarbeiter, Handwerker oder Bauern. Adlige, Fürsten oder Patrizier finden gleichfalls keine Erwähnung, wodurch der politische Status des Städtchens betont unklar bleibt und jegliche soziale Spannung von vornherein verhindert wird. ${ }^{182}$ Diese auffällige Aussparung der politischen Dimension, zumindest in Bezug auf die am Personeninventar dargestellten Gesellschaftsverhältnisse der

178 Ebd. S. 299 .

179 Hegel: Vorlesungen über die Ästhetik III. S. 39 o f., vgl. auch Berr, Karsten: Hegels Bestimmung des Naturschönen. Zur Betrachtung und Darstellung schöner Natur und Landschaft. Saarbrücken: Südwestdeutscher Verlag für Hochschulschriften 2013. S. 210 f. und Costazza, Alessandro: „Aber freilich, wenn alle Menschen Schafe gehütet hätten, so wären sie zwar an sich wohl ganz glücklich gewesen. Aber was wäre denn aus unserer Geschichte geworden?" Idylle, Theodizee und Geschichtsphilosophie bei Karl Philipp Moritz. In: Birkner; Mix et al. (Hrsg.): Idyllik im Kontext von Antike und Moderne. Tradition und Transformation eines europäischen Topos. S. 169-187, hier S. 183.

180 Hegel ist nicht der erste, der die Diskrepanz zwischen historischem Zeitbewusstsein und idyllischer Zeitlosigkeit bemerkt und nach dem ästhetischen Stellenwert der Idylle gefragt hat, auch Jean Paul ist diese Problematik keineswegs entgangen, er findet aber bekanntlich einen positiver besetzten Idyllen-Begriff, vgl. dazu Hagel, Ulrike: Elliptische Zeiträume des Erzählens. Jean Paul und die Aporien der Idylle (= Epistemata. Reihe Literaturwissenschaft, Bd. 463). Würzburg: Königshausen \& Neumann 2003. S. 24-28 und Frei Gerlach, Franziska: Jeremias Gotthelf auf der Spur der Jean-Paulschen Doppelschreibweise: „Erdbeeri“-Idylle gegen „Zeitgeist“-Satire. In: Schneider; Drath (Hrsg.): Prekäre Idyllen in der Erzählliteratur des deutschsprachigen Realismus. S. 98-117.

181 Goethe an Schiller, Anfang Juli 1796, HA 2. S. 734.

182 Vgl. dazu auch Martens: Halten und Dauern? Gedanken zu Goethes Hermann und Dorothea. S. 79-98, hier insb. S. 81 f. 
kleinen Stadt, sowie der Verzicht auf Orts- und Personennamen - außer beim werktitelgebenden Liebespaar - entspricht also durchaus einer idyllischen Beschränkung auf das rein Menschliche. ${ }^{183}$

Bei genauem Hinschauen geht es dann aber in Goethes Gedicht vielmehr um die skeptische Durchleuchtung bürgerlicher Verhältnisse - und zwar einmal in Bezug auf ihre vermeintliche Homogenität und einmal bezüglich ihrer Tugendhaftigkeit - als um deren Verklärung. Dies ist umso bemerkenswerter, wenn man bedenkt, dass die Vorstellung einer bürgerlichen Identität zu diesem Zeitpunkt überhaupt erst im Entstehen begriffen und von höchster politischer Virulenz ist. In Hermann und Dorothea stellt sich die porträtierte Gesellschaft nicht als ideale, harmonische und in sich geschlossene Einheit dar, sondern als heterogene Gemeinschaft differenzierter Individuen mit unterschiedlichen Auffassungen und Wahrnehmungen: Dem Apotheker ist die Enge seines kleinbürgerlichen Lebens schmerzlich bewusst (2, V. 83-9o und 3, V. 72 f.: „Nur zu sehr ist der Bürger beschränkt; das Gute vermag er / Nicht zu erlangen, wenn er es kennt."), für Hermanns Vater, den menschlichen Hauswirt, liegt dagegen gerade darin der Garant fortwährender Prosperität (2, V. 162-166: „Aber besser ist besser. Nicht einen jeden betrifft es, / Anzufangen von vorn sein ganzes Leben und Wesen [...] Oh, wie glücklich ist der, dem Vater und Mutter das Haus schon / Wohlbestellt übergeben") und sein wohlgebildeter Sohn Hermann ist schließlich derjenige, der die Grenzen des idyllischen, beschränkten Lebensraums bewusst überschreitet. ${ }^{184}$

Ganz entgegengesetzt fallen auch die Urteile des trefflichen Pfarrers und des gesprächigen Apothekers über die Neugier der Stadtbewohner aus. Während der Geistliche einen natürlichen Trieb des Menschen darin erkennt, sich das Neue, das Nützliche und das Gute zu erschließen, verurteilt der Apotheker die Sensationslust und den „unverzeihlichen Leichtsinn“ der Menschen aufs Schärfste (1, V. 70-77 und V. 87-95). Diese mit allen Zeichen der Ernsthaftigkeit eingenommene Position unterläuft er allerdings gerade wieder, wenn er die Neugier der Wirtin bereitwillig befriedigt, indem er ihr ausführlich vom Elend der Flüchtlinge berichtet (1, V. 102-150) und damit letzten Endes selbst dem Laster der Neugier anheimfällt. Überhaupt entspricht in Hermann und Dorothea kaum eine Figur den bürgerlichen Idealvorstellungen, angefangen bei den Titelhelden. Damit geht Goethe entschieden anders auf Herders

183 Vgl. Elsaghe: Untersuchungen zu Hermann und Dorothea. S. 106. Für E. widerspricht aber diese Anonymie dem antiken Epos und dessen Bestreben, das was einmal war, treu und unverstellt festzuhalten. Die Namenlosigkeit würde aber eine eindeutige Identifikation und Unverwechselbarkeit der hist. verbürgert geltenden Vergangenheit verhindern.

184 Vgl. Lypp, Maria: Ästhetische Reflexion und ihre Gestaltung in Goethes Hermann und Dorothea. Stuttgart: Vogt 1969. S. 62. 
Forderung nach einer realistischeren Figurenkonzeption ein ${ }^{185}$ als Voß, und das trotz der scheinbaren Idealisierung, die durch die Namenlosigkeit der meisten Figuren und typisch epischen Epitheta stilistisch angezeigt wird.

Im weiteren Gegensatz zu Voß' akademisch gebildetem Walter ist Goethes Hermann ein schlechter Schüler, einfältig und kulturell unwissend (Hermann kennt die Zauberflöte nicht, 2, V. 22O-230; der Wirt kritisiert seinen Sohn für dessen mangelhafte schulische Leistung und fehlenden Ehrgeiz, 2, V. 251-255). Die selbstbewusste, tatkräftige Dorothea widerspricht auch ohne direkten Vergleich offensichtlich dem bürgerlichen Weiblichkeitsbild, gegenüber der anmutig-kindlichen Luise erscheint ihre irritierende Virilität aber schon fast erschreckend, zumindest für Goethes Zeitgenossen. ${ }^{186}$ Zwischen ihr und Hermann herrscht zudem eine ambivalente Asymmetrie - ihr kommen Bewegung und Weltläufigkeit zu, Hermann dagegen ist passiv, stoisch und in der häuslichen Sphäre verortet - während Luise und Walter ganz konventionell zusammenpassen, weil sie sich entsprechen. Und auch bei der älteren Generation scheinen die bürgerlichen Identitätsentwürfe in Hermann und Dorothea eher gescheitert als erfüllt. Hermanns Mutter, die „kluge verständige Hausfrau" (1, V. 22), erinnert zwar eindeutig an den Darstellungsgestus ihres Pendants in der Luise, wenn sie Spenden für die Flüchtlinge zusammenträgt„nicht gerne verschenk ich die abgetragene Leinwand, [...] Doch heute gab ich so gerne / Manches bessere Stück an Überzügen und Hemden, / Denn ich hörte von Kindern und Alten, die nackend dahergehn" (1, V.23-27). Im Gegensatz zur Pfarrersfrau, von der sie ganz offensichtlich inspiriert ist, nimmt Hermanns Mutter aber viel mehr Raum für sich selbst ein und bezieht auch ihrem Gatten gegenüber stärker eine eigene Position, etwa wenn sie Hermann gegen dessen Attacken verteidigt („Immer bist du doch so ungerecht gegen den Sohn! und / So wird am wenigsten dir den Wunsch des Guten erfüllet. / [...] Ich lass mir meinen Hermann nicht schelten; Denn ich weiß es, er ist der Güter, die er dereinst erbt, / Wert und ein trefflicher Wirt, ein Muster Bürgern und Bauern“, 3, V. 45, 52-54).

Im Gegensatz zu Voß' Pfarrer wird Goethes Wirt dadurch mit Schwäche behaftet und einem feinen erzählerischen Spott ausgesetzt, der den LuiseIdyllen gänzlich abgeht. Wenn der Pfarrer von Grünau mit heiligem Ernst Toleranz predigt, sich neben seinen christlichen Idolen auch auf Homer, Sokrates, Konfuzius und Zarathustra und sogar auf Franklin und Washington

\footnotetext{
185 Vgl. Buschmeier: Die Idylle bei Salomon Gessner, Friedrich (Maler) Müller und Johann Heinrich Voß. Kritik und Transformation einer Gattung. S. 220-237, hier S. 230.

186 Vgl. Elsaghe: Untersuchungen zu Hermann und Dorothea. S. 102.
} 
beruft, dann wird damit das überhöhte Idealbild eines aufgeklärten protestantischen Geistlichen nicht etwa unterlaufen, sondern hochgehalten:187

O Himmelswonne! wir freun uns,

Alle, die Gutes gethan nach Kraft und redlicher Einsicht, Und die zu höherer Kraft vorleuchteten: freun uns mit Petrus, Moses, Konfuz und Homer, dem liebenden, und Zoroaster, Und, der für Wahrheit starb, mit Sokrates, auch mit dem edlen Mendelsohn! (1, V. 334-339).

Wie grundsätzlich verschieden die Patriarchenfiguren in Szene gesetzt werden, manifestiert sich darüber hinaus immer wieder an Gegenständen, die besonders typisch sind für die bürgerliche Idylle, wie etwa am Schlafrock, der in der Luise als höchste Insignie bürgerlichen Wohlstands erscheint: So wird der Pfarrer im ersten Gesang als „im Schlafrocke“ behaglich schmausender pater familias eingeführt (1, V. 4) und ganz am Schluss wird Luises Bräutigam seinerseits mit einem "stattlichen Bräutigamsschlafrock, / Fein von Kattun, kleeröthlich, mit farbigen Blumen gesprenkelt" (3, V. 872-879) ausgestattet. In Hermann und Dorothea hat der Schlafrock des Löwen-Wirtes dagegen bereits allen Glanz und damit auch seinen Repräsentationscharakter eingebüßt: „Und besonders den Schlafrock mit indianischen Blumen, / Von feinstem Kattun, mit feinem Flanelle gefüttert" - im direkten Stellenvergleich wird auch der intertextuelle Bezug besonders deutlich - gab die Wirtin an die bedürftigen Flüchtlinge, denn „er ist dünn und alt und ganz aus der Mode“ (1, V. 29-37). Aber schon in den Augen von Hermanns kindlichen Gespielen war der Schlafrock zum Gegenstand der Lächerlichkeit verkommen, aufgrund dessen sie Hermanns Vater auf seinem sonntäglichen Kirchengang verspotteten (4, V. $165^{-168) \text {. }}$

Weiter wird auch in der Art und Weise, wie die einzelnen Bürger am Schicksal der Flüchtlinge Anteil nehmen, mit zuweilen bissigem Zynismus auf die Defizite idyllischer Beschränktheit aufmerksam gemacht. Diese erstreckt sich nämlich nicht nur auf die räumliche Einrichtung, sondern auch über das Denken und die Mentalität der Kleinstädter: Angesichts des politischen Wandels reflektieren sie über Modeerscheinungen - die Löwen-Wirtin veräußert den Schlafrock, weil er aus der Mode gekommen ist - und angesichts der mittellosen Flüchtlinge über den eigenen Besitz - Hermanns Spendenfahrt ist für den Vater vor allem Anlass, die geräumige neue Kutsche zu loben (1, V. 16 f.). Solidarität und Zusammenhangsbewusstsein lassen sie jedoch

187 Vgl. Häntzschel: Homer im Wohnzimmer. Das bürgerlich-idyllische Epos im 19. Jahrhundert. S. 125-140, hier S. 128. 
missen. ${ }^{188}$ Das ist keine naive oder idealisierende Darstellung kleinbürgerlicher Humanität und Selbstgenügsamkeit, sondern vielmehr deren ironische Relativierung. Einem konfliktlosen Dasein, wie es exemplarisch in Voß' Luise dargestellt wird, wird in Hermann und Dorothea gleichwohl von außen wie auch innerhalb des Bürgerkreises widersprochen - wie die Welt erscheint auch das Städtchen im Wandel begriffen: Die geplante Chausseestraße wird es an die grosse Welt anschließen und aus der Isolation lösen. Deren Bau ist allerdings fraglich, denn während die ältere Generation noch nach einem gemeinsamen Ziel strebte (3, V. 38), „wird die Jugend nicht [so] handeln! / Denn die einen, sie denken auf Lust und vergänglichen Putz nur; / Andere hocken zu Haus und brüten hinter dem Ofen" ( 3 , V. 4O-42).

Traditionell endet die Idylle mit einem positiven Höhepunkt, mit der Erfüllung einer Wunschvorstellung von privatem Glück - bei Voß gipfelt die Handlung in der vorzeitigen Vermählung der Pfarrerstochter, durchgeführt von Luises Vater im eigenen Haus und ohne jegliches kirchliches Zeremoniell. 189 Von einem Hochzeits- und gleichzeitigen Friedensfest träumt auch Hermanns Vater, bei dem sich an dieser Stelle erneut der für die Allgemeinheit gewünschte Friede in ein Privatbegehren verkehrt:

Müde schon sind die Streiter, und alles deutet Frieden.

Möge doch auch, wenn das Fest, das lang erwünschte, gefeiert

Wird, in unserer Kirche, die Glock dann tönt zu der Orgel, Und die Trompete schmettert, das hohe „Te Deum“ begleited Möge mein Hermann doch auch an diesem Tage, Herr Pfarrer, Mit der Braut, entschlossen, vor Euch am Altar sich stellen, Und das glückliche Fest, in allen den Landen begangen, Auch mir künftig erscheinen, der häuslichen Freuden ein Jahrestag! (1, V. 198-205)

Tatsächlich bleibt dann in Hermann und Dorothea aber beides aus oder wird zumindest entschieden marginalisiert. Während der rituelle Bund zwischen den Liebenden und der damit gesicherte Fortbestand bürgerlicher Lebensart in der Luise den krönenden Abschluss bilden, nimmt die eigentliche Vermählung in Goethes Dichtung gerade mal das erste Drittel des Schlusses ein. Das Verlobungsritual dient Goethe nicht der Darstellung eines (nur noch) im Privaten zu erlangenden Glückszustands, sondern es ermöglicht vielmehr das Aus- und Gegenüberstellen zweier aktueller politischer Positionen, die sich in der fatalistischen Rede des toten Revolutionärs einerseits und den beherzten

188 Vgl. Geulen: Goethes Hermann und Dorothea. Zur Problematik und inneren Genese des epischen Gedichts. S. 4.

189 Vgl. Häntzschel: Homer im Wohnzimmer. Das bürgerlich-idyllische Epos im 19. Jahrhundert. S. 125-140. S. 127. 
Worten Hermanns andererseits manifestieren. Seine Schlussverse schickte Goethe an die Herzogin Luise, „in der Hoffnung, dass Sie ihn dem Übrigen nicht ungleich finden werden. Das Ganze schien mir zu fordern, dass die zwei Gesinnungen in die sich jetzt beinahe die ganze Welt teilt, neben einander und zwar auf die Weise, wie es geschehen ist, dargestellt würden“.190 Dass hier die Verlobung mit keinem Wort erwähnt wird, bekräftigt die subordinierte Bedeutung, die Goethe ihr zumisst und weist auf eine deutliche Stellungnahme hin, die im Werk ansonsten eher sublimiert wird. Der Schluss, der weiter unten noch eingehender betrachtet werden soll, aber auch der ganze Text, erfahren damit eine entschiedene Ausrichtung auf das Politische, auf öffentliche Interessen und damit eben auch auf Epizität. Nicht nur ist darin eine grundlegende Diskrepanz zur Luise zu sehen, mehr noch wird diese einer prüfenden Betrachtung unterzogen.

Am Ende von Hermann und Dorothea wird die naive Hoffnung auf Hochzeit, Frieden und damit verbunden auch auf eine Erneuerung der bestehenden familiären und politischen Strukturen zwar ausgesprochen, ${ }^{191}$ deren Erfüllung aber gerade nicht vorgestellt. Die letzten Worte gemahnen zwar an Frieden, aber machen gleichzeitig auch deutlich, dass dieser erst noch erkämpft werden muss bzw. zunächst eine Erschütterung der bisherigen Ordnung bevorsteht. Das beschworene Gesellschaftsideal der Idylle und das damit verbundene Glücksversprechen einer selbstgenügsamen, harmonischen Gemeinschaft im Kleinen werden in Hermann und Dorothea kritisch reflektiert und als bereits mit den Sozialpathologien der Moderne durchsetzt aufgezeigt. Insofern nutzt Goethe hier die Erzählform der Idylle einerseits, um seine Dichtung an die gesellschaftliche Wirklichkeit der Gegenwart anzuschließen und gleichzeitig lenkt er den Blick auf die problematischen Aspekte dieser Wirklichkeit - neben Solidarität und Bescheidenheit machen sich auch Habsucht, Profitdenken und Eigensinn breit in der bürgerlichen Gesellschaft - wodurch die Idylle selbst prekär erscheint.

\subsubsection{Verschränkung der Zeithorizonte}

Angesichts Goethes freien Hexametern sowie seiner höchst kritischen Bezugnahme auf die bürgerliche Welt und ihres Selbstverständnisses darf wohl bezweifelt werden, dass mit Voß' Luise bereits eine stoffliche und formale Erneuerung gelungen oder gar eine verbindliche Neubestimmung des Epischen gegeben war. Böttiger hat diesbezüglich die Aussage Goethes

190 Goethe an die Herzogin Luise, 13.6.1797, HA 2. S. 737.

191 Vgl. Lypp: Ästhetische Reflexion und ihre Gestaltung in Goethes Hermann und Dorothea. S. 63 . 
festgehalten, dass Voß durch die epische Behandlung einer Landpredigerfamilie zwar durchaus einen verständigen Fingerzeig gegeben habe, wo „unser" Epos hingehöre. Seine Luise könne aber nur schon darum „kein eigentliches Heldengedicht" sein, weil ihr "alle Continuität, aller Zusammenhang“ fehle [Hervorhebung M.E.]. ${ }^{192}$ Damit spielt Goethe ganz eindeutig auf die in der Luise fehlende Beziehung zur Gegenwart sowie die daraus resultierende Tendenz der Idylle zu Geschichtsvergessenheit an und gibt insofern selbst Hinweis auf die eminente Bedeutung, die einer kritischen Bezugnahme auf die Gegenwart für die Erneuerung der epischen Erzählform zukommt. Eine eingehendere Betrachtung der vielfältigen Zeitgestaltungen und -reflexionen, die Goethes Dichtung im Vergleich mit Voß' Luise anbietet, soll nun aufzeigen, wie die geschichtsphilosophischen und gattungspoetologischen Spannungen, die in Hermann und Dorothea zum Tragen kommen, gleichwohl auf der Anschauungs- wie auf der Darstellungseben sowohl vertieft als auch wieder durchkreuzt werden und das dadurch entstehende hochkomplexe Zeitgefüge $\mathrm{zu}$ hervorragender Bedeutung für Hermann und Dorothea und überhaupt Goethes Epos-Projekt gelangt.

Tatsächlich wird in Voß' Dichtung nicht ein einziger Anhaltspunkt zur historischen Einordnung der Geschehnisse gegeben, weder Jahreszahlen noch bekannte, verbürgte Ereignisse finden darin Erwähnung. Die einzige Stelle, die die Handlung in der unmittelbaren Gegenwart verortet, erschließt sich nur Kennern von seiner Arbeiten: Wenn der Pfarrer Luise auffordert, „Singe den neuen Gesang, mein Töchterchen, welchen im Frühling / Unser Freund in Eutin hier dichtete“ (1, V. 376 f.), ist der Dichter damit selbst ins Gedicht eingegangen. Luises idealische Verlobungsgeschichte hat aber nicht nur keinen realen Ort - und ist damit im wahrsten Sinn des Wortes eine Utopie - sondern sie hat auch keine wirkliche Zeit. Dieser Versuch, den Menschen aus der Zeit auszuschließen, ist gemäß Renate Böschenstein-Schäfer ein zwar oft vernachlässigter, aber neben topologischen und motivgeschichtlichen Gesichtspunkten gleichwohl einer der auschlaggebenden Aspekte der Gattung, ${ }^{193}$ dem im Horizont der allgemeinen Verzeitlichung um 1800 besondere Bedeutung zukommt. So fordert etwa bereits Jean Paul die Befreiung und Erweiterung der idyllischen Schauplätze - nur die „Menge der Mitspieler und die Gewalt der großen Staatsräder ${ }^{\text {"194 }}$ [Hervorhebung M.E.] würden aus der Idylle als

192 Böttiger, Carl August: Literarische Zustände und Zeitgenossen. In Schilderungen aus Carl August Böttigers handschriftlichem Nachlass, hrsg. v. Karl Wilhelm Böttiger, Bd. 1. Leipzig: Brockhaus 1838. S. 76 .

193 Vgl. Böschenstein-Schäfer: Idylle. S. 9 .

194 Paul: Vorschule der Ästhetik. S. 258. 
Vollglück in der Beschränkung ausgeschlossen - während er an einer engen zeitlichen Beschränkung der Idylle aber gleichwohl festhält. Zum einen legt Jean Paul alle idyllischen Handlungen mehr oder weniger auf einen Tag oder auf ein Tagesgeschehen fest und zum anderen stellt er diesen Tag als positives Einzelereignis heraus:

So kann z.B. die Ferienzeit eines gedruckten Schulmannes - der blaue Montag eines Handwerkers - die Taufe des ersten Kindes - sogar der erste Tag, an welchem eine von Hoffesten mattgehetzte Fürsten-Braut endlich mit ihrem Fürsten ganz allein (das Gefolge kommt sehr spät nach) in eine volle blühende Einsiedelei hinausfährt - kurz alle diese Tage können Idyllen werden und können singen: auch wir waren in Arkadien. [Hervorhebung M.E.] ${ }^{195}$

Damit konstituiert er das Glücksversprechen der modernen Idylle im Kern als zeitlich verfasst: Während sich die Vorstellung vom Glück im Zusammenhang mit dem Reflexivwerden der Zeit immer mehr als eine flüchtige Erfahrung ausprägt, ${ }^{196}$ verspricht die Idylle gerade ein zeitübergreifendes, andauerndes Glück. Um diese Illusion eines in die Ewigkeit überführten, glücklichen Augenblicks zu erzeugen, bedarf es einer konsequenten Entrückung aus dem linearen Zeitgeschehen der Geschichte. Im Gegensatz zu Schillers Verortung der Idylle an einem Anfangs- oder Endpunkt der Zeit außerhalb des historischen Geschehens, konstituiert sich die Zeitlichkeit der paulschen Idylle aber als absolute Gegenwart. Den Hinweis darauf, dass Jean Paul die Idylle damit aber nicht einfach auf totalen Stillstand, sondern vielmehr auf eine innere, bipolare Bewegtheit ausrichtet, verdankt die vorliegende Arbeit dem Vortrag zur Idyllen-Schaukel, den Franziska Frei Gerlach im November 2018 an der Universität Zürich gehalten hat. ${ }^{197}$ Diese poetische Form der Idylle kennt keine geschichtliche Entwicklung, geschweige geschichtliche Konflikte, denn ihre Handlung wird entweder in eine goldene Vorzeit bzw. eine utopische Zukunft

195 Ebd. S. 259. Daran wird auch deutlich, dass die Idylle durch das Bewusstsein für Historizität zum Idyllischen geworden ist, zum Bruchstück.

196 Vgl. dazu Tanzer, Ulrike: Fortuna, Idylle, Augenblick. Aspekte des Glücks in der Literatur. Würzburg: Königshausen \& Neumann 2011. 171-175. „Ein Glück ist erreicht, nun soll es dauern; aber Dauer und Glück schließen sich aus", schreibt Robert Musil dazu am 2. April 1905-19o8 (oder später ca. 1918/1919) in sein Tagebuch. Musil, Robert: Tagebücher, hrsg. v. Adolf Frisé. Reinbek b. Hamburg: Rowohlt 1976. S. 200.

197 Das „Vollglück“ der Idylle: Gattungspoetik und Affect Studies im Gespräch. Workshop des SNF-Projekts "Welt im Winkel. Idylle als Denkraum in der Prosa des Realismus“ im Doktoratsprogramm, vgl. https://www.ds.uzh.ch/de/agenda?show=2610 [abgerufen am 27.11.2O21]. 
verlegt oder spielt in einer ahistorischen Zeit-Ellipse. ${ }^{198}$ Jean Pauls Festlegung der Idyllenhandlung auf ein besonderes, arkadisches Tagesgeschehen folgen die einzelnen Luise-Idyllen, die alle zeitlich in sich geschlossene Einzelereignisse des Privatlebens darstellen, geradezu prototypisch: Das Fest im Walde schildert den Tag von Luises 18. Geburtstagsfeier, auch Der Besuch des Verlobten und der Gräfin Amalia ist ein besonderer Freudentag und schließlich kulminiert Der Brautabend in einem spontanen, einmaligen Hochzeitsfest.

Für Hermann und Dorothea lässt sich diese Diskontinuität zwischen der Zeit des Textes und der historischen Zeit nun aber nicht nachweisen. Im Gegenteil wird hier die Handlung, die zwar nur wenige Stunden umfasst, ganz grundsätzlich mit den zeitgenössischen, realen Ereignissen in Bezug gesetzt: Am kleinen, am Rhein gelegenen Städtchen zieht ein Strom von Flüchtlingen vorbei, die von der französischen Revolutionsarmee von ihren linksrheinischen Gütern verjagt wurden - dieses Ereignis lässt sich ziemlich genau auf den August des Jahres 1796 datieren. ${ }^{199}$ Es sind gerade diese hoch aktuellen, realhistorischen Umstände, die das eigentliche Geschehen überhaupt erst in Gang bringen. Die Möglichkeit einer Begegnung zwischen Hermann und Dorothea ergibt sich nämlich allein dadurch, dass Dorothea durch den Krieg zur Flucht gezwungen wird. Dass just in der sichtbaren Gegenüberstellung und Problematisierung von kleinbürgerlicher Geschichtsvergessenheit und dem wohl geschichtsträchtigsten Ereignis der damaligen Zeit der eigentümliche Werkcharakter von Hermann und Dorothea begründet liegt, hat bereits Hegel herausgestellt: In diesem „vollendete[n] Musterbild“ wäre, obwohl „im ganzen Tone zwar idyllisch“, im Gegensatz zu Voß' Luise keine „Beschlossenheit“, denn „die großen Interessen der Zeit, die Kämpfe der französischen Revolution, die Verteidigung des Vaterlandes“ würden "höchst würdig und wichtig“ hereinspielen. ${ }^{200}$ Die „in den mächtigsten Verhältnissen tiefbewegte Welt ${ }^{“ 201}$ würde hier eben nicht ignoriert, sondern das Familienleben des Kleinstädtchens an die „grösseren Weltbewegungen“202 "durchaus zwanglos “203 angeschlossen, wodurch die ganze „Szene in den erweiternden

198 Vgl. Hagel: Elliptische Zeiträume des Erzählens. Jean Paul und die Aporien der Idylle. S. 9-24 und Costazza: „Aber freilich, wenn alle Menschen Schafe gehütet hätten, so wären sie zwar an sich wohl ganz glücklich gewesen. Aber was wäre denn aus unserer Geschichte geworde?" Idylle, Theodizee und Geschichtsphilosophie bei Karl Philipp Moritz. S. 169-187, hier S. 183.

199 Goethe schreibt am 5.12.1796 an Meyer: „Die Zeit der Handlung ist ungefähr im vergangenen August." HA 2. S. 748.

200 Hegel: Vorlesungen über die Ästhetik I. S. $299 \mathrm{f}$.

201 Hegel: Vorlesungen über die Ästhetik III. S. 415.

202 Hegel: Vorlesungen über die Ästhetik I. S. 299 f.

203 Hegel: Vorlesungen über die Ästhetik III. S. 415. 
Umfang eines gehaltreicheren Lebens hineinversetzt" erscheine. ${ }^{204}$ Gerade im Aufbrechen der temporalen Geschlossenheit, im Herausfinden und Darstellen von „Züge[n], Schilderungen, Zustände[n], Verwicklungen“ „mitten aus der modernen Wirklichkeit" und deren in Beziehung bringen mit dem aktuellen Weltgeschehen, erkennt Hegel eine wahrhaft epische, lebendige Darstellung, die den „unvergänglichsten Reiz in den ursprünglich menschlichen Verhältnissen der Odyssee ${ }^{205}$ erneuert.

Während moderne Studien diesen deutlichen Gegenwartsbezug in Hermann und Dorothea mit Verweis auf die Forderung nach einer „Darstellung des vollkommen Vergangenen“, die Goethe und Schiller im Aufsatz Über epische und dramatische Dichtung formulierten, als Entfernung vom „eigentlich“ Epischen deuten, ${ }^{206}$ erlangt die Dichtung für Hegel dadurch eine spezifisch epische Qualität. Der Vergangenheitscharakter der theoretischen Eposbestimmung bleibt in Hermann und Dorothea tatsächlich unbeantwortet. Vielmehr findet genau das Gegenteil statt: Die Handlung beruht auf der realhistorischen Vertreibung lutheranischer Protestanten aus dem Bistum Salzburg, die zwischen $173^{1}$ und $173^{2}$ stattgefunden hat. Diese Begebenheit verlegt Goethe in die aktuelle Revolutionszeit und holt damit die Vergangenheit näher an die Gegenwart heran. Darin lässt sich nun gerade eine besondere Leistung von Goethes Eposbehandlung verorten: Das zeitlich und räumlich Entfernte wird nämlich ent-fernt bzw. in die Nähe geholt. Wie die vorangehenden Kapitel jedoch für einmal in Übereinstimmung mit Hegel deutlich gemacht haben, wird das Darstellungsdogma absoluter Zeiten im Laufe der Aufsatz-Argumentation unterlaufen und das Spezifische der epischen Eigenzeit kristallisiert sich tatsächlich als Integration von Vergangenheit und Gegenwart heraus. Das Schließen einer Allianz zwischen Nähe und Distanz, Gestern und Heute ist ein poetologisches Verfahren, dessen sich Goethe nicht nur als Darstellungsmittel bedient, sondern das er explizit auch auf der Ebene der Sprache immer wieder zu Bewusstsein führt. ${ }^{207}$ Diesbezüglich hält Elsaghe fest, dass das Werk deshalb keineswegs auf eine Synthese von Epos und Idylle zu reduzieren, sondern vielmehr in

\footnotetext{
204 Hegel: Vorlesungen über die Ästhetik I. S. 299 f.

205 Hegel: Vorlesungen über die Ästhetik III. S. 415.

206 Für Elsaghe ist das ausschlaggebende Merkmal der epischen Zeitgestaltung die eindeutige, historisch verbürgte Zurückversetzung der Handlung in die Vergangenheit. Nur durch eine derartige radikale Entrückung aus der Gegenwart würde eine echte epische Distanz entstehen, die Hermann und Dorothea eben gerade nicht zu leisten vermöge, vgl. Elsaghe: Untersuchungen zu Hermann und Dorothea. S. 106.

207 Vgl. Mayer, Mathias: Mythos und Ironie. Goethes Relativitätspoesie. In: Valk, Thorsten (Hrsg.): Heikle Balancen. Die Weimarer Klassik im Prozess der Moderne. S. 139-159, hier S. 155 .
} 
direkter Konkurrenz mit dem Roman zu betrachten sei. Allerdings führt ihn diese wichtige Feststellung dann nicht zu einer Beobachtung des Gedichts als alternatives episches Erzählexperiment, wie sie hier vertreten wird. Elsaghe interpretiert Goethes „verbissene Insistenz" auf dem Präteritum vielmehr als Versuch, die unepische Nähe zur Gegenwart auf der Handlungsebene sprich die „romaneske Form des Gegenwartsbezugs“ - durch hyperkorrekte Wahrung der äußeren Distanz zu kompensieren. ${ }^{208}$ Das Spannungsverhältnis der Zeithorizonte lässt sich in Hermann und Dorothea aber nicht auf eine starre Gegenüberstellung von inhaltlicher Gegenwärtigkeit und formalem Vergangenheitscharakter, modernem Stoff und antiker Sprachform reduzieren. Mit derThematisierung der Französischen Revolution wählt Goethe zwar einen aktuellen Stoff, schließt damit gleichzeitig aber auch an die antike Tradition an, große und bedeutende Ereignisse der Geschichte episch zu behandeln. Die Verortung der Handlung in der Revolutionszeit gelingt leicht, so sind mit der Bemerkung des Wirts „alles deutet auf Frieden“ ( 1, V. 198) wohl die französischpreußischen Friedensschlüsse von Leobon im April 1797 bzw. Campo Formio im Oktober $1797^{209}$ gemeint; und die Erwähnungen von fliehenden Fürsten, verbannten Königen (5, V. 100), einem verderbten Geschlecht (6, V. 41) und nicht zuletzt der "fürchterliche[n] Bewegung“ (9, V. 305) spielen eindeutig auf verbürgte revolutionäre Ereignisse an.

Aufgrund seiner Geschichtsträchtigkeit und der zeitlichen Nähe des Gegenstands zum Erfahrungshorizont des Lesers ist deshalb zwar eine gewisse Entfernung von der Idylle, aber noch lange keine klare Gattungsindikation zum Dramatischen oder Romanhaften gegeben. Vielmehr wird dadurch an den historiographischen Charakter des homerischen Epos gemahnt, denn Mythos und Geschichte waren in der Archaik noch nicht auseinandergetreten. Und schließlich hat auch die Analyse des Gattungsgesprächs zwischen Schiller und Goethe deutlich gemacht, dass die Differenz zwischen Epos und Roman nicht allein in der Historizität des Dargestellten, sondern vielmehr in der Zeitorganisation der Darstellung begründet liegt. Ausschlaggebend für die Wiedergabe des Revolutionsgeschehens ist in Hermann und Dorothea auch, dass sie nicht von dramatischer Unmittelbarkeit, sondern von einer epischen Distanzierung geprägt ist. Obwohl vor allem der zeitgenössische Leser die Handlung problemlos im historischen Jahr 1796 verorten kann, verzichtet der Text doch auffällig konsequent auf eine exakte Zeitangabe. Diese eigentümliche zeitliche Unbestimmtheit relativiert die Nähe zur Gegenwart, vor allem zur Historizität des Textes und entrückt ihn ein Stück weit der Zeit. Ohne

208 Elsaghe: Untersuchungen zu Hermann und Dorothea. S. 105-107.

209 Vgl. HA 2. S. 753. 
konkretes geschichtliches Datum erscheinen die dargestellten Ereignisse weniger als einzigartige Begebenheit der Geschichte, sondern eher als grundlegende, menschliche Erfahrungen mit Allgemeingültigkeit. Die einzige wirklich eindeutige Zeitangabe bezieht sich dann auf den Jahrgang des Weins, den die Bürger sich genehmigen - nach der Konfrontation mit der Geschichte in Gestalt des Flüchtlingszuges suchen die Stadtbewohner Zuflucht im Innersten des Wirtshauses, um dort im kühlen und dunklen Sälchen, geschützt durch starke Mauern, unbehelligt von der Außenwelt ein Gläschen „Dreiundachtziger" zu trinken (1 V. 156-164). Der klare, herrliche Wein soll die „traurigen Bilder" vergessen machen, die "Grillen" vertreiben und bald schon klingen heiter die Gläser von Wirt und Pfarrer. Nur der Apotheker hält denkend einen Moment inne, bevor ihn der Wirt mit seinen „männlichen, klugen Gedanken“ von der gottgeschenkten Immunität des Städtchens gegenüber dem Weltgeschehen überzeugt (1 V. 172-184, 189).

Dass die einzige verbürgte Jahreszahl ausgerechnet im Kontext selbstauferlegter Isolation gegeben wird, sich dann aber nicht auf ein Ereignis der Geschichte bezieht, sondern auf ein Symbol bürgerlichen Wohlstands aus dem vossischen Idyllen-Inventar - es handelt sich bei der Wein-Szene um eine Variation der Kaffee-Szene in derersten Luise-Idylle ${ }^{210}$ - ist keinZufall.Vielmehr wird dadurch erneut ausgestellt, wie sich die durch die Gesangsüberschrift in Aussicht gestellte Anteilnahme stets in Eigenbezug verkehrt. Diese szenische Verdichtung von räumlicher Beschränkung und zeitlicher Konkretisierung eröffnet gleichzeitig einen kritischen Blick auf die Figuren und die Form der Idylle. Durch den bewussten Rückzug in einen ausdrücklichen Schutzraum angesichts der anrollenden Geschichte werden nämlich das Weltfremde und Künstliche der Idylle sowie das Fragwürdige bürgerlicher Abschottungsbemühung gegenüber allem Politischem explizit deutlich gemacht. Tatsächlich kann aber in Goethes Hermann und Dorothea der in Bewegung geratenen Geschichte im Gegensatz zu Voß' Luise nicht entflohen werden, unerbittlich holt sie die kleine Stadt damit ein, dass sie ihre Opfer hier anspült. Anstatt über die Auflösungstendenzen der Gegenwart hinwegzutäuschen, geht es hier dezidiert darum, die historische Erfahrung eines Bruchs im Zeit- und Sozialgefüge fassbar zu machen und die damit einhergehende politische Herausforderung anzunehmen. Während man sich in der Luise mit Erdbeerpflücken beschäftigt, ${ }^{211}$ regt Goethes Dichtung zur reflexiven Auseinandersetzung

\footnotetext{
210 Vgl. FA I, 8. S. 1163.

211 Vgl. Theisohn, Philipp: Erdbeeren. Ökonomie und Mediologie der Idylle in Voß' Luise (1795) und Storms Immensee (1849). In: Schneider; Drath (Hrsg.): Prekäre Idyllen in der Erzählliteratur des deutschsprachigen Realismus. S. 152-181, hier S. $170 \mathrm{ff}$.
} 
an, und zwar sowohl mit dem historischen Zeitgeschehen als auch mit der Art und Weise, wie dieses in den literarischen Darstellungsformen repräsentiert wird.

Paradoxerweise gelingt dem Epos diese Reflexionsleistung ausgerechnet durch die Aneignung idyllischer Ordnungsstrukturen. So wird das Revolutionsgeschehen nie direkt in seiner ganzen Unübersichtlichkeit und Überstürzung geschildert, sondern erscheint stets nur indirekt: vermittelt durch die Erzählungen der Figuren oder symbolisch vertreten im Flüchtlingszug, der allerdings ebenfalls in einiger Entfernung am Städtchen vorbeizieht. Während die Anbindung an zeitgenössische Ereignisse die enge Zeitkonzeption der Idylle episch öffnet, reduziert ein idyllischer Beschränkungsgestus das potenziell endlose, hektische und zerstückelte Weltgeschehen auf einen bestimmten Augenblick der Geschichte. Die Fixierung geschieht nicht durch ein absolutes Außerkraftsetzen der Zeit, wohl aber durch eine entscheidende Reduktion der diagnostizierten Vervielfältigung der Zeit im Sinne der Prägnanz, wie sie hier weiter oben als bedeutende Zeitkonzeption in Goethes Denken aufgezeigt worden war. ${ }^{212}$ Mit der Konzentration auf einen temporal und räumlich begrenzten Ausschnitt der Welt - nur wenige Stunden umgreift das Vorbeiziehen der Flüchtenden am Städtchen - wird zwar nicht eine antike, den ganzen Kosmos umfassende Totalität wiederhergestellt, wohl aber ein symbolisches Äquivalent dazu. ${ }^{213}$ Der dargestellte Zeitraum enthält einen die Weltgeschichte repräsentierenden Sinn: Die Goethe als welt- und lebensbestimmend erscheinenden, widerstrebenden Kräfte von Ordnung und Auflösung, Mannigfaltigkeit und Beweglichkeit werden hier hineinprojiziert und ausgestellt. In der ästhetischen Konzentration und Abstraktion kann deren anarchischer Energie entgegengewirkt werden, indem das, was sich als unstrukturiert, bewegt und formlos präsentiert, eben eine prägnante Form erhält bzw. nun fassbar wird. ${ }^{214}$

Damit tritt die Möglichkeit einer epischen Einheit als partielle Totalität zurück ins moderne Bewusstsein, das die Vorstellung einer totalen Welt bereits aufgegeben hat oder für das zumindest eine sinnfällige Totalität nicht mehr einfach gegeben ist. ${ }^{215}$ Allerdings anders, als das in den theoretischen

\footnotetext{
212 Vgl. S. 95 in diesem Buch.

213 Vgl. Lypp: Ästhetische Reflexion und ihre Gestaltung in Goethes Hermann und Dorothea. S. 70 .

214 Vgl. Schneider, Sabine: „ein strenger Umriß“ - Prägnanz als Leitidee von Goethes Formdenken im Kontext der Weimarer Kunsttheorie. In: Goethe Jahrbuch 128 (2011). S. 98-106.

215 Vgl. Pfotenhauer, Helmut: Um 180o. Konfigurationen der Literatur, Kunstliteratur und Ästhetik (= Untersuchungen zur deutschen Literaturgeschichte, Bd. 59). Tübingen: Niemeyer 1991. S. $248 \mathrm{ff}$.
} 
Gattungsgesprächen erörtert wurde. Der Rückgriff auf die Idylle lässt sich hier als Versuch Goethes begreifen, die Glücksqualität und Totalität des antiken Epos für die neuzeitliche Literatur symbolisch zu erneuern, indem der potenziell unendlich fortschreitenden Zeit eine klare Kontur zeitlicher Begrenzung gegeben wird. Wie Lukács konstatiert, gibt es in der Moderne keine „spontane Seinstotalität“ mehr, die Kunst bzw. die Formen der Kunst müssen das, was zuvor als hingenommene Gegebenheit galt, nun aus sich selbst hervorbringen. Die Form muss also entweder „das zu Gestaltende soweit verengen und verflüchtigen, dass es von ihr getragen werden kann" oder aber es „entsteht für sie der Zwang, die Unrealisierbarkeit ihres notwendigen Gegenstandes und die innere Nichtigkeit des einzig Möglichen polemisch darzutun und so die Brüchigkeit des Weltaufbaus dennoch in die Formenwelt hineinzutragen“.216 Die modernen Möglichkeiten, Totalität darzustellen, beschränken sich demnach für Lukács ganz im Sinne Hegels einerseits auf die radikale, hermetische Beschränkung der Idylle auf einen realitätsfremden Mikrokosmos und andererseits aber auch auf die kritische Reflexion der abstrakt und unüberschaubar gewordenen, ausdifferenzierten Welt des Romans. Das bedeutet nicht nur die gattungspoetologische Fortschreibung und Zuspitzung der schillerschen Differenzierung zwischen naiver und sentimentalischer Dichtung in der Moderne, sondern auch die Erweiterung des idyllischen Leistungspotenzial um die Verhandlung prekärer Aspekte in der Etablierung übergeordneter Wissensstrukturen.

In Hermann und Dorothea zeigt Goethe nun aber eine alternative dritte Möglichkeit auf, die sich zum einen sowohl idyllisch-reduktionistischer als auch reflektierend-romanhafter Strategien bedient und zum anderen gleichzeitig die alte Vorstellung einer empirischen Totalität durch die Anwendung des antiken Stils immer wieder ins Bewusstsein ruft. Die grosse Weltbewegung selbst tritt zwar nicht in Erscheinung, aber anstatt die Erfahrung unausweichlicher historischer Progressivität kategorisch auszublenden oder sich ihr resignativ auszuliefern, wie es eine dramatische oder romanhafte Darstellung kennzeichnen würde, wird sie in Hermann und Dorothea zwar durchaus kritisch betrachtet, aber trotzdem auch als anschlussfähig ausgestellt. Hermanns Emanzipation gründet nämlich darauf, dass er im Gegensatz zu seinen Mitbürgern tatsächlich Anteil nimmt am Schicksal der Flüchtenden und dadurch eine Verwandlung, eine Selbstfindung einsetzt. Die Revolution wird als Ereignis der Gegenwart in ihrer Komplexität und Unmittelbarkeit zwar auf eine Begebenheit reduziert. Als bedeutendes, alles veränderndes Geschehen der Weltgeschichte stellt sie dann aber die an der Luise vermissten

216 Lukács, Georg: Die Theorie des Romans (1920). Bielefeld: Aisthesis 2009. S. 29. 
Eigenschaften der "Continuität“ und des „Zusammenhang[s]“ her, ${ }^{217}$ die Hermann und Dorothea so deutlich von der Idylle abheben und dem Epischen zuführen. Das historische Weltgeschehen dient hier nicht bloß als Folie, auf der sich die der Geschichte entrückte Kleinstadt umso idealischer abhebt, was sich in der Idylle des 19. Jahrhunderts dann zum Topos verfestigt. Aber genauso wenig wird die bürgerliche Gemeinschaft durch die Konfrontation mit der Zeitgeschichte ihrer Zerstörung zugeführt, wie es Lukács' Romanbestimmung insinuiert. Dass die Revolution zwar sicht- und spürbar wird, jedoch im Hintergrund bleibt oder vielmehr gehalten wird, entspricht gerade dem Maß, in dem sich das Gedicht mit ihr auseinandersetzen will. Die Geschichte fordert in Gestalt der Revolution als Weltbewegung die statische, bürgerliche Intimität just in einer Intensität heraus, in der eine produktive Begegnung der Gegensätze stattfinden kann. Durch die Kombination von idyllischer Beschränkung und epischer Distanzierung wird die Komplexität der tatsächlichen Erscheinungswelt auf ein verständliches, mittelbares Ausmaß reduziert und dem damit zusammenhängenden Überforderungserleben entgegengewirkt dieses Erfahrbarmachen der Gegenwart ist ein Hauptanliegen von Goethes Formbegriff und wird in Hermann und Dorothea von der Hybridisierung der Gattungen geleistet.

Das Aufeinandertreffen von Weltgeschichte und kleinbürgerlichen Verhältnissen nimmt sich allerdings entgegen Hegels Aussage nicht zwanglos aus, ${ }^{218}$ sondern bleibt durchweg schwierig. So führen Dorotheas Erscheinen im Städtchen und Hermanns immer stärker werdender Wunsch, sie zu ehelichen, im fünften Gesang schließlich zur Eskalation des von Anfang an schwelenden Konflikts zwischen Vater und Sohn: „Wie ist, o Sohn, dir die Zunge gelöst, die schon dir im Munde / Lange Jahre gestockt und nur sich dürftig bewegte!", empört sich Hermanns Vater: „Muss ich doch heut erfahren, was jedem Vater gedroht: / Dass den Willen des Sohns, den heftigen, gern die Mutter / Allzu gelind begünstigt und jeder Nachbar Partei nimmt, / Wenn es über den Vater nun hergeht oder den Ehmann" (5, V.109-114). Und auch am Schicksal des nahegelegenen Dorfes, das im Gegensatz zum Städtchen nicht durch einen Schutzwall geschützt wird und deshalb auch nicht von den historischen Ereignissen verschont bleibt, zeigt sich deutlich, wie der Einfall der Weltgeschichte zu Gedränge, Chaos und Aggressivität führt. Zwischen der geordneten Sphäre des Städtchens und der chaotischen, heimgesuchten Sphäre des Flüchtlingszuges

\footnotetext{
217 Böttiger: Literarische Zustände und Zeitgenossen. In Schilderungen aus Carl August Böttigers handschriftlichem Nachlass. S. 76 .

218 Vgl. Hegel: Vorlesungen über die Ästhetik I. S. 746.
} 
entstehen Krisenmomente, die der Text weder nivelliert noch sublimiert, sondern vielmehr exponiert. Das Verhältnis von idyllischer Kleinwelt und katastrophischer Außenwelt zeigt sich bei Goethe bereits vom ersten Gesang an als schwierige Dialektik von Geschichtsverweigerung und Historismus, die an keiner Stelle des Gedichts aufgehoben wird. Der Zwiespalt zwischen der Diagnose des Ausgeliefertseins an die Zeit und ihre Beschleunigung zum einen und der Einsicht in die Relevanz zeitlicher Kontinuität für die Verankerung der Kunst in der Kultur zum anderen wird in Hermann und Dorothea in seiner ganzen Ambivalenz betrachtet. Dabei zieht sich die Problematisierung der Moderne nicht allein als literarisches Thema durch, sondern wird in der versuchten Hybridisierung von Idyllischem und Epischem, statischer Zeitenthobenheit und dynamischem Zeitbezug zugleich gattungstheoretisch abgebildet und aufgehoben. Insofern gelingt Goethe genau das, was Schiller mit seinem theoretischen Konzept der elysischen Idylle vergeblich versucht hat, nämlich die -nur vorgestellte und nicht realisierte - Verknüpfung von Idealität und Wirklichkeit, indem er die Gegensätze in einem unaufhebbaren, schwankenden Spannungsverhältnis hält. Die eigentliche ästhetische Aufgabe stellt sich damit als eine unabgeschlossene Vermittlung von Moderne und Antike, Naivem und Sentimentalischem dar.

\subsubsection{Das Glücksversprechen beschränkter Zeiterfahrung}

Die innere Eigenzeit des Städtchens scheint auf den ersten Blick einer naturhaften Gleichförmigkeit zu folgen, in der das Leben in einem immer gleichen Wechsel der Tageszeiten, Wochentage und Jahreszeiten verläuft. Dieser Eindruck wird durch zahlreiche Parallelen zwischen der gegenwärtigen Handlung und herbeizitierten Ereignissen der Vergangenheit erzeugt. In der Verlobung von Hermann und Dorothea und ihren Umständen wiederholt sich die Verbindung des Wirtepaares, auch dieses schloss seinen Bund über Trümmern und zwar ebenfalls an einem heißsen Sommersonntag, vor genau 20 Jahren (2, V. 107-114). Im nun drohenden Gewitter kehrt auch der damalige Brand als katastrophisches Naturereignis wieder, in dem seinerseits das biblische Erleuchtungsfeuer widerhallt und selbst der aktuelle Flüchtlingszug wird mit dem alttestamentarischen Auszug aus Ägypten in Verbindung gebracht (5, V. 225-227). „Wahrlich, unsere Zeit vergleicht sich den seltensten Zeiten, die die Geschichte bemerkt“, konstatiert der Richter, „wir dürfen uns wohl mit jenen vergleichen, / Denen in ernster Stund' erschien im feurigen Busche / Gott der Herr; auch uns erschien er in Wolken und Feuer" (5, V. 229-237). So werden die Tage, die sich potenziell aus dem Gleichmaß herausheben, zu Verwaltungseinheiten einer übergeordneten Zyklizität - wie Hermanns künftiger 
Hochzeitstag, der ein „Jahrestag der häuslichen Freuden“ (1, V. 205) werden soll. ${ }^{219}$ Die Ereignisse werden durch ihre Wiederholung in der Zeit zu typischen Grunderfahrungen, die über die Zeit hinweg vergleichbar bleiben - darin liegt ihre epische Bedeutsamkeit - gleichwohl scheint die Zeit selbst dadurch zum Stillstand zu kommen. ${ }^{220}$

Wenn im Zug der Flüchtlinge der Exodus erneuert wird, im Richter Moses reinkarniert scheint und sich für Hermann die elterliche Liebesgeschichte wiederholt, werden damit Grenzen von Zeitspannen markiert und gleichzeitig der Blick auf allgemeine, zeitlose Wissensbestände eröffnet: Das Bild vom fliehenden Volk unter der Führung eines weisen Mannes scheint über alle Zeiten hinweg Gültigkeit zu haben, genau wie dasjenige vom Liebespaar, das alle äußeren Widerstände überwindet. Damit werden die Zeithorizonte von Vergangenheit und Gegenwart nicht aufgelöst, aber doch so weit nivelliert, dass auch die Zukunft als bereits in der Gegenwart beginnend vorgestellt werden kann. Die zeitlichen Grenzen von Einzelerscheinungen werden dadurch relativiert, die Unterschiede zwischen den Generationen verwischen, Geburt und Tod des Individuums werden irrelevant bzw. rücken Anfang und Ende so nah zusammen, dass sie zu einem ewigen Kreislauf verschmelzen. Die Bedeutung des Einzelnen wird damit überhaupt massiv zurückgenommen was der modernen Idee eines autonomen, aber isolierten Individuums entgegengesetzt ist - und dafür die Emphase auf das gelegt, was über den Einzelnen hinausgeht und ihn gleichwohl zum Teil eines großen Ganzen macht. Damit gelingt es Goethe, seine dem Alltag entnommenen Figuren und Ereignisse ins Allgemeine, Symbolische zu erheben ${ }^{221}$ bzw. ihnen epische Bedeutung zu verleihen, ohne dass sie ihre Eigenartigkeit einbüßen.

In der zirkulär organisierten Eigenzeit entspricht die gegenwärtige Mittagsstunde einer gestauten Zeit, die den Gang der Gespräche in sich aufnimmt, ohne selbst fortzuschreiten bzw. nur sehr langsam fortschreitet - der Tag neigt sich erst im achten Gesang dem Ende zu und im neunten wird es endlich Nacht. Zum einen scheint der sommerliche Sonntag dadurch dem bewegten Lauf der Zeit entrückt und zum anderen wird eine geregelte, entschleunigte Zeit als das bürgerliche Lebensmaß festgelegt. ${ }^{222}$ Besonders deutlich wird diese Bestimmung in der Rede des Pfarrers, der den immer tätigen, rastlosen

\footnotetext{
219 Lypp: Ästhetische Reflexion und ihre Gestaltung in Goethes Hermann und Dorothea. S. 71.

220 Vgl. Geulen: Goethes Hermann und Dorothea. Zur Problematik und inneren Genese des epischen Gedichts. S. 12.

221 Vgl. Häntzschel: Homer im Wohnzimmer. Das bürgerlich-idyllische Epos im 19. Jahrhundert. S. 125-140, hier S. 13 o.

222 Vgl. Oschmann: Das Epos in Zeiten des Romans. Goethes Hermann und Dorothea. S. 167189, hier S. 173 u. 189 .
} 
Mann zwar nicht tadeln will, dem allerdings „der ruhige Bürger, / Der sein väterlich Erbe mit stillen Schritten umgehet / Und die Erde besorgt, so wie es die Stunden gebieten“, ebenfalls „wert [ist]“ (5, V. 15-20):

Nicht verändert sich ihm in jedem Jahre der Boden,

Nicht streckt eilig der Baum, der neugepflanzte, die Arme

Gegen den Himmel aus, mit reichlichen Blüten gezieret.

Nein, der Mann bedarf der Geduld; er bedarf auch des reinen, Immer gleichen, ruhigen Sinns und des graden Verstandes. [...] Und Heil dem Bürger des kleinen

Städtchens, der ländlich Gewerb' mit Bürgergewerb gepaaret!

Auf ihm liegt nicht der Druck, der ängstlich den Landmann beschränket;

Ihn verwirrt nicht die Sorge der vielbegehrenden Städter,

[...]

Segnet immer darum des Sohnes ruhig Bemühen (5, V. 22-37)

Das Phänomen der Statik sowie die daran haftenden Werte von Stabilität, Einfachheit und Langsamkeit werden von Hermann verkörpert: Stets hält er die Pferde in Zaum (2, V. 6o; 6, V. 222), steht oft lange in Gedanken und blickt still vor sich hin (2, V. 242; 6, V. 222 f.; 6, V. 315 f.). Ja, „[n]icht beweglich ist er“ ( 5, V. 77 ) heißt es sogar zugespitzt vom Sohn des Löwenwirten. Die stoische Geisteshaltung von "halten und dauern“ (9, V. 300) führt der Text nicht nur als positiv besetzte Charaktereigenschaft Hermanns vor, sondern überhaupt werden Langsamkeit und Geduld im Kontrast zu Eile und Ungeduld als lohnende Zeitverhalten in den Blick genommen - Hermann und Dorothea finden schließlich nur deshalb zusammen, weil beide aufgehalten werden. Dynamik und Vorwärtsdrängen erscheinen dagegen als letztlich tödlich ${ }^{223}$, das führt natürlich das Schicksal des französischen Revolutionärs besonders eindringlich vor. Aber bereits in der Anfangssequenz werden Neugier, Leichtsinn und Eile als Formen einer verwerflichen, maßlosen Übereilung gezeigt, die ins Unglück führen (1, V. 4-99).

Nicht zuletzt gründet im Vertrauen auf eine unveränderliche Zeitordnung auch die Wohlbehaglichkeit, die in Hermann und Dorothea zum ultimativen Ausdruck des bürgerlichen Selbstbildes stilisiert wird: „Alles Behagen am Leben ist auf eine regelmäßige Wiederkehr der äußeren Dinge gegründet ${ }^{\text {“224, }}$ wird Goethe später in Dichtung und Wahrheit konstatieren. Der Entwurf einer durch die ewige Wiederkehr menschlicher Grunderfahrungen

223 Vgl. ebd. S. 172.

224 WA I, 28. S. 209. 
bestimmten Zeitordnung entspricht ganz der Charakteristik der Idylle. ${ }^{25}$ So diskontinuierlich das Verhältnis zwischen den äußeren Zeitbezügen der Idylle und dem zeitlichen Erfahrungshorizont des Lesers auch ist, so kontinuierlich ist die innere Zeit der Idyllenhandlung. Bereits bei Vergil war die Idylle ein „Bild in sich ruhenden Daseins“226, ein „bedürfnislos glücklicher Zustand der Ruhe ${ }^{u 227}$ und noch bei Bachtin ist ihr zyklischer Zeitrhythmus charakteristisch für die Idylle. ${ }^{228}$ In der idealen Idyllenordnung ist die Zeit nicht linear bzw. Medium der Veränderung, sondern Träger des immer gleichen natürlichen Rhythmus wiederkehrender Ereignisse ${ }^{229}$ - in der Idylle geht es morgen genauso zu wie gestern und heute. ${ }^{230}$ Diesen erzählökonomischen Prämissen entspricht Voß' Luise-Dichtung wiederum in geradezu idealtypischer Art und Weise. Sequenzen wie das Erdbeerpflücken oder das Kaffeetrinken verzögern die Handlung stark bzw. tragen überhaupt nichts zu deren Entwicklung bei, nehmen aber mit ausschweifenden, detailversessenen Beschreibungen von der umgebenden Natur und den zum Picknick gereichten Speisen sehr viel Darstellungszeit ein. ${ }^{231}$ Die Darstellung erstarrt durch derartige Beschreibungen des Räumlichen insgesamt zu einem statischen Bild. August Schlegel erklärt bezeichnenderweise gerade mit Verweis auf dieses besondere Raum-ZeitVerhältnis die Abweichung der Luise von der epischen Form, diese sei zwar ein „ländliche[s] Sittengemälde im epischen Vortrage, ein[e] anmutig[e] gemischt[e] Gattung“ aber kein „eigentliches Epos“, denn sie sei „mehr Darstellung des Ruhenden als ruhige Darstellung des Fortschreitenden"232 [Hervorhebung M.E.].

Überhaupt werden die idyllische Zeitvorstellung einer Wiederkehr des immer Gleichen und die darin eingeschriebene Glücksvorstellung bei Voß besonders zugespitzt. So beschreibt der Text selbst die idyllisch-bürgerlicher Lebensart als selbstgenügsame Behaglichkeit: „Also schmauseten jen', in

225 Vgl. Buschmeier: Die Idylle bei Salomon Gessner, Friedrich (Maler) Müller und Johann Heinrich Voß. Kritik und Transformation einer Gattung. S. 220-237, hier S. 221.

226 Kaiser: Wandrer und Idylle: Goethe und die Phänomenologie der Natur in der deutschen Dichtung von Gessner bis Gottfried Keller. S. 15.

227 Lypp: Ästhetische Reflexion und ihre Gestaltung in Goethes Hermann und Dorothea. S. 61.

228 Vgl. Bachtin, Michail M.: Chronotopos, aus dem Russischen von Michael Dewey, mit einem Nachwort von Michael C. Frank und Kristen Mahlke (= suhrkamp taschenbuch wissenschaft 1879). Berlin: Suhrkamp 2008. S. 161.

229 Vgl. Buschmeier: Die Idylle bei Salomon Gessner, Friedrich (Maler) Müller und Johann Heinrich Voß. Kritik und Transformation einer Gattung. S. 220-237, hier S. 221.

230 Vgl. Wellbery: Die Grenzen des Idyllischen bei Goethe. S. 221-240, hier S. 223.

231 Vgl. Theisohn: Erdbeeren. Ökonomie und Mediologie der Idylle in Voß' Luise (1795) und Storms Immensee (1849). S. 152-181.

232 Schlegel: Goethes Hermann und Dorothea. S. 183-221, hier S. 205. 
behaglicher Ruhe vereinigt, / Auf dem blumigen Rasen des weitumschattenden Buchbaums." (1, V. 498 f). Auch die Erneuerung der patriarchalischen Ordnung verläuft unhinterfragt und orientiert sich hier weitaus enger am Muster der älteren Generation, wenn Luise mit Walter wieder einen Pfarrer heiratet. Mit dieser Parallelisierung von Vater und Ehemann sowie den latent erotisch konnotierten Interaktionen zwischen Vater und Tochter wird allerdings der Blick auf eine innere Spannung der Idylle freigegeben, droht sie damit doch schon fast in ihr Feindbild, den Inzest ${ }^{233}$, zu kippen.

Der Natur kommt in der Idylle eine wichtige gattungstypische Funktion $\mathrm{zu}$, sie wird darin als großes Ganzes semantisiert und fungiert als überragendes Ordnungssystem. ${ }^{234}$ Dieses Konzept einer nur in sich bewegten und dadurch gleichfalls unveränderten Zeit teilt sie gemäß Lukács bezeichnenderweise mit dem Epos der Antike. ${ }^{235}$ Auch Goethe stellte sich das Verhältnis des antiken Menschen zur Zeit wohl als feste Verwurzelung des Lebens in der gegenwärtigen Wirklichkeit vor: Die Griechen hätten "mit allem Sinn, aller Neigung, aller Kraft auf die Gegenwart" gewirkt, weshalb es dem gleichgesinnten Dichter nicht schwer fiel, ebenfalls „eine solche Gegenwart zu verewigen“. ${ }^{236}$ Ein derart unveränderlicher, natürlicher Gang der Dinge, auf den die Kleinbürger vertrauen, wird nun in Hermann und Dorothea durch eine Parallelisierung der Zeiten hervorgerufen. Die bürgerliche Lebensart wird damit gleichwohl als die natürliche bzw. richtige vorgestellt - sie steht im

233 Der Luise-Text weist noch viele andere Stellen auf, in denen ein inzestuöses Moment mitschwingt. Fast alle Interaktionen zwischen Vater und Tochter durchzieht eine sublimierte Erotik. Nur auf den ersten Blick mag es seltsam erscheinen, dass Hermann und Dorothea auch diesbezüglich ganz anders ist (die Ausgangslage ist schon verkehrt - hier wird die Familie des Bräutigams präsentiert, dort die der Braut. Zwischen Hermann und seiner Mutter herrscht zwar ein inniges Vertrauensverhältnis, sexualisierte Untertöne findet man aber keine). Tatsächlich bedeutet auch das Verzichten auf latente Erotik - selbst Dorothea wird kaum erotisiert - eine stärkere Ausrichtung auf das Epische anstatt das Idyllische. In der traditionellen Idylle ist Erotik ein festes Element, sie ist untrennbar mit dem Liebesmotiv verbunden - im Epos spielt sie dagegen nur eine untergeordnete Rolle. Die bürgerliche Erneuerung der Idylle musste diese aber auch an die veränderten Sittlichkeitsvorstellungen heranführen und sah sich daher gezwungen, erotische Spannungen so weit wie möglich zu sublimieren. Die moderne bürgerliche Idylle erscheint dann auch als Zurichtungsort der Disziplinierung, Erziehung, Kulturalisierung der vor allem weiblichen Sexualität - und insofern als Elemente des politischen Machtdiskurses. Sie zeigt keine Erotik mehr, sondern in bürgerliche Bahnen gelenkte Sexualität bzw. Sublimierung von illegitimer Sexualität (Inzest).

234 Vgl. Wellbery: Die Grenzen des Idyllischen bei Goethe. S. 221-240, hier S. 224.

235 Vgl. Lukács: Die Theorie des Romans (1920). S. 124.

236 WA I, 46. S. 23, vgl. dazu auch Lypp: Ästhetische Reflexion und ihre Gestaltung in Goethes Hermann und Dorothea. S. $69 \mathrm{f}$. 
Einklang mit der organischen Natur. Dem gerade virulent werdenden telelogischen Geschichtsbild läuft das freilich entgegen. Wie bei Schiller gesehen, ist das Auseinanderfallen von Natur- und Menschenbild in der Moderne der Grund aller geschichtsphilosophischen Überlegungen, und daran hängen nicht zuletzt auch entgegengesetzte Zeitordnungen: Während die Natur in einer zyklischen Erneuerung verharrt, wird die menschliche Entwicklung nun als eine lineare Fortschrittsgeschichte konstituiert. Die auffällige Gleichtaktung von Natur und Geschichte, Individuum und Gesellschaft bedeutet in Hermann und Dorothea also auch die bewusste (Re-)Synchronisierung von unterschiedlichen Erfahrungsbereichen bzw. deren jeweiligen Rhythmen.

Damit ist eine herausragende kommunikative Funktion des Textes beschrieben: Er ermöglicht seinen Lesern eine Erfahrung, die in der modernen Lebenswelt nicht mehr gemacht werden kann, nämlich die Subordination von Pluralität und Vereinzelung unter eine ewige Ordnung der Kontinuität. Das Vorstellen einer umfassenden organischen, zyklischen Zeitordnung lässt sich hier als kritische Reaktion auf die diagnostizierte Vervielfältigung und Desynchronisierung der Erfahrungswelt begreifen. Die sinnstiftende Wiederkehr des Gewesenen durchzieht als Interpretationsmuster den ganzen Text: Der Apotheker stellt bereits im ersten Gesang eine erhellende Verbindung her zwischen Vergangenheit und Gegenwart, wenn er das Verhalten der Flüchtenden mit demjenigen der Städter während der Brandkatastrophe vergleicht (1, V. 121-131). Durch die Parallelisierung von biblischem und aktuellem Flüchtlingszug werden die Ereignisse der Gegenwart mit allerhöchster Bedeutsamkeit belegt, und weiter wird durch den Vergleich mit den Stadtbewohnern die eigene Vergangenheit, die eigene Geschichte als ebenso bedeutungsvoll festgeschrieben. „Wir Eltern gaben das Beispiel“ (2, V. 108), bringt Hermanns Mutter die Sache auf den Punkt. Die zeitliche Distanz zu den Vorgängen der Vorzeit bleibt wohl erhalten, diese erfahren jedoch durch die Funktionalisierung zum Deutungs- und Bewertungsmaßstab eine besondere epistemische Aufwertung. Die Vergangenheit wird zum Exemplum, an dem sich die Gegenwart ablesen lässt und die Zukunft voraussehbar wird. Der Blick in die Geschichte erläutert die Gegenwart - das gilt in Hermann und Dorothea für die Privatgeschichte gleichwohl wie für die politische und die Naturgeschichte. In Hermann und Dorothea repräsentiert die idyllische Zeitvorstellung eines gleichförmigen Zyklus ein organisches Erneuerungsmodell, das nicht unbedingt auf die Wiederherstellung des Vergangenen angelegt ist, in dem aber das Alte als Bezugsgröße erhalten und sichtbar bleibt: „Noch einmal sei der goldenen Reifen Bestimmung, / Fest ein Band zu knüpfen, das völlig gleiche dem alten“ (9, V. 243 f.). Das Wissen um derartig zirkuläre und integrative Wissensordnungen wird um 1800 von der Fortschrittseuphorie und 
einer damit verbundenen Überzeugung von einem gegenseitig exkludistischen Verhältnis von Neuem und Altem verdrängt. Wenn Goethe also entgegen der allgemeinen Tendenzen die historischen und menschlichen Erfahrungen in seinem Gedicht als zirkulär beschreibt, beharrt er damit auf dem zyklischen Repräsentationscharakter des Historischen und stellt eine kontinuierliche Fortschreibung der Kulturgeschichte bzw. eine Möglichkeit des kulturellen Anschlusses der Moderne an die Antike vor.

Auch in der Form der Sprache wird allein schon durch den formelhaften, am antiken Epos orientierten Duktus die alternative Vorstellung einer kreisförmigen Zeitordnung reflektiert. Feste syntaktische Figuren wie die Anfangsposition der Konjunktion „und“, Zitationsformeln oder der Gebrauch von Epitheta erscheinen in hoher Dichte und bestimmen so die Zeichenabfolge als eine repetitive. Wenn Dorotheas Gestalt einmal ausführlich von Hermann beschrieben wird (5, V. 169-176) und dies kurz darauf im fast gleichen Wortlaut vom Apotheker paraphrasiert wird (6, V. 137-147), wird die Aufmerksamkeit des Rezipienten ganz besonders stark auf ihre äußerliche Erscheinung gelenkt. Das entspricht der literarischen Evokation eines unmittelbaren, sinnlichen Erlebnisses und eröffnet dem Betrachter einen eigenen Wahrnehmungsund Denkraum ${ }^{237}$, wie es Goethe und Schiller in ihrem Aufsatz als die spezifische Lizenz des Epischen ausgewiesen hatten. ${ }^{238}$ Die Darstellung der Szene nähert sich damit der bildhaften, räumlichen Ästhetik ${ }^{239}$ der Ekphrasis an und referenziert insofern auf die antike Gattungstradition epischer Bildbeschreibungen. Darüber hinaus wird damit aber auch einsehbar, wie Goethe die Übertragbarkeit bildender Gestaltungprinzipien auf die Poesie als eine spezifisch epische Programmatik erprobt. ${ }^{240}$

Eine ähnliche und gleichwohl viel komplexere Hervorhebung durch Reduktion markiert auch die schicksalshafte Begegnung von Hermann und Dorothea als erzählerisches Kernstück. Zweimal treffen die Liebenden aufeinander, die erste Begegnung wird allerdings nicht direkt geschildert, sondern von Hermann im zweiten Gesang nacherzählt. Die Wiederholung dieser Szene steht dann prominent in der Mitte der Dichtung, Hermann und Dorothea begegnen sich erneut am Brunnen und diesmal wird das Zusammentreffen ausführlich dargestellt. Obwohl Goethes Dichtung bedeutend weniger wörtliche

237 Vgl. Schneider, Sabine: Die Laokoon-Debatte: Kunstreflexion und Medienkonkurrenz im 18. Jahrhundert. In: Benthien, Claudia; Weingart, Brigitte (Hrsg.): Handbuch Literatur und Visuelle Kunst. Berlin, Boston: de Gruyter 2014. S. 68-85, hier S. 70.

238 Vgl. S. 15 o in diesem Buch.

239 Vgl. Graham, Ilse: Goethe: Portrait of the Artist. Berlin: de Gruyter 1977. S. 299.

240 Vgl. Lypp: Ästhetische Reflexion und ihre Gestaltung in Goethes Hermann und Dorothea. S. 83 . 
und szenische Wiederholungen aufweist als die antiken Vorlagen - und auch als die Luise - wird mit dieser rhetorischen Redundanz eine stilistische Verfahrensweise der Verräumlichung etabliert, die sich gegen den linearen Fortschritt der Zeit wendet. Am Ende des Gedichtes wird die Vorstellung einer totalen, in sich geschlossenen Zeit dann auch explizit vom Pfarrer ausgesprochen:

Lächelnd sagte der Pfarrer: „Des Todes rührendes Bild steht

Nicht als Schrecken dem Weisen und nicht als Ende dem Frommen.

Jenen drängt es ins Leben zurück und lehret ihn handeln;

Diesem stärkt es, zu künftigem Heil, im Trübsal die Hoffnung;

Beiden wird zum Leben der Tod. Der Vater mit Unrecht

Hat dem empfindlichen Knaben den Tod im Tod gewiesen.

Zeige man doch dem Jüngling des edel reifenden Alters

Wert und dem Alter die Jugend, dass beide des ewigen Kreises

Sich erfreuen und so sich Leben im Leben vollende!" (9, V. 46-54)

Tod und Leben stehen im ersten Segment in chiastischer Beziehung und auch im zweiten Segment korrespondiert die Formel „Tod im Tod“ mit der Wendung „Leben im Leben“, dazwischen bilden „Jüngling“, „Alters“, „Alter“ und „Jugend“ wiederum einen Chiasmus. Die Überführung der Zeiten in ein ewiges Zeitganzes, in dem alle Zeitunterschiede aufgehoben sind, wird an dieser Stelle nicht nur als immanente Erfüllung des Lebens gefordert, ${ }^{241}$ sondern auch gleich als rhetorische Figur vorgeführt. In dieser Verdichtung von Dargestelltem und Darstellung werden gleichsam die Bewegung der Zeit und die Sukzessivität der Sprache im Sinne der Prägnanz außer Kraft gesetzt. ${ }^{242}$ Ungeachtet des Nacheinanders in der Sprache wird hier eine sinnliche Gleichzeitigkeit bzw. eine horizontale, räumliche Ordnung vorgestellt, ${ }^{243}$ die die Erkenntnis der Gegenstände durch Anschauung ermöglicht. Der eindringlichen Emphase langer, zyklischer Zeitabläufe ist insofern auch ein spezifisch ästhetisches Erkenntnismodell eingeschrieben, in dem sinnlicher Ausdruck und visuelle Anschaulichkeit vor dem inneren Auge die ausschlaggebenden Prinzipien der Wissensgenerierung und -organisation sind. Darin erlangen die methodischen Zugriffe der Exploration, die Goethe in der Morphologie entwirft, herausragende Bedeutung: Wiederholung, Rekurrenz, genaue Beobachtung, Nachvollzug und geduldiges Vergleichen erscheinen hier als potente alternative Strategien zu theoriegeleiteter, rationaler Reflexion. So entsteht ein literarisch

241 Vgl. ebd. 74.

242 Vgl. Schneider: Die Laokoon-Debatte: Kunstreflexion und Medienkonkurrenz im 18. Jahrhundert. S. 68-85.

243 Vgl. Graham: Goethe: Portrait of the Artist. S. 299 und Lypp: Ästhetische Reflexion und ihre Gestaltung in Goethes Hermann und Dorothea. S. 83 . 
generierter, mentaler Eindruck von Ganzheit und gleichzeitig wird dieser als Teil einer prozessualen Gestaltwerdung einsehbar, der nur situativ entsteht und sich wieder auflöst, wenn der prägnante Moment vorbeigeht. Auch dies ist wieder der gleiche Gedanke, wie ihn die Bewegungsmetaphern des Wellengangs und der Metamorphose formulierten - das große Ganze, das in der oben zitierten Stelle sinnfällig als das große Ganze des Lebens erscheint, kann immer wieder erfasst werden, d.h. für einen Moment in einer Form fixiert, letztlich aber nicht aus seiner ständigen Verwandlung gelöst werden. Nicht zuletzt wird damit auch eine Aussage über den vorliegenden Text und insofern das Epische überhaupt gemacht: Es kann weder auf der Ebene der Darstellung noch des Dargestellten eine eigentliche Totalität erreicht werden. Das Fragmentarische ist dem Epischen also schon immer eingeschrieben, das macht es einerseits prekär, gereicht ihm aber gemäß der Morphologie gerade auch zu Lebendigkeit.

\subsubsection{Dynamisierung des Zeitengefüges}

In Hermann und Dorothea bleibt es nicht bei der von der Idylle angeregten Zeit-gestaltung und -reflexion im Zeichen harmonischer Kontinuität. Wohl erscheint die Lebenswelt der Bürger zu Beginn als wohlwollend-nährende, in sich ruhende Idylle. Im „fruchtbaren Tal“ freut man sich besonders guter landwirtschaftlicher Bedingungen:

Solch ein Wetter ist selten zu solcher Ernte gekommen,

Und wir bringen die Frucht herein, wie das Heu schon herein ist,

Trocken; der Himmel ist hell, es ist kein Wölkchen zu sehen,

Und von Morgen wehet der Wind mit lieblicher Kühlung.

Das ist beständiges Wetter! und überreif ist das Korn schon;

Morgen fangen wir an zu schneiden die reichliche Ernte. (1, V. 45-50)

Im vierten Gesang kündigt sich aber bereits leise das Ende des Sommers an, wenn sich Hermanns Mutter auf das kommende Erntedankfest freut (4, V. 34-38) und im Verlauf der Handlung wird die Natur zunehmend unberechenbar und furchterregend. Am Beginn des achten Gesangs gehen Hermann und Dorothea einer sinkenden Sonne entgegen, die „in Wolken tief, gewitterdrohend, verhüllt" eine „ahnungsvolle Beleuchtung“ (8, V. 1-4) erzeugt. Anstatt als zuverlässiger Lebensspender zeigt sich die Natur spätestens jetzt von ihrer bedrohlichen Kehrseite und droht die „schöne Ernte“ mit Hagel und Regen zu zerstören. Die Gefahrenmomente der einbrechenden Nacht, des heraufziehenden Gewitters, das sich bereits zum Sturm wandelt (8, V. 11) und bald den "lieblichen Vollmond“ (8, V. 77 f.) zu verschlingen droht sowie der hereinbrechende Krieg werden weder aufgelöst noch marginalisiert, sondern 
erhalten im Gegenteil immer mehr Gewicht. Die Idylle erscheint damit ganz grundsätzlich gefährdet ${ }^{244}$ und das nicht nur durch äußere Aggressoren, sondern dezidiert auch durch Spannungen und Destabilisierungen der inneren Ordnung. ${ }^{245}$ Im neunten Gesang wird diese umfassende Drohkulisse weiter zugespitzt, einmal, wenn gleich zu Beginn sämtliche Katastrophenzeichen noch einmal gebündelt zitiert werden - die heraufziehenden Wolken, das schnelle Verdunkeln des Mondes und der „Nächte Gefahren“ (9, V. 5-10) und dann erneut in Dorotheas Liebesgeständnis:

Nicht die Nacht, die breit sich bedeckt mit sinkenden Wolken, Nicht der rollende Donner (ich hör ihn) soll mich verhindern, Nicht des Regens Guss, der draußen gewaltsam herabschlägt, Noch der sausende Sturm. (9, V. 174-177)

Nicht nur wird hier der idyllischen Semantisierung der Natur mit dem Gegenbild einer zerstörerisch-chaotischen Natur widersprochen, sondern es wird auch explizit eine Eskalationsgeschichte erzählt, die sich sowohl im Verlauf der Welt- als auch der Privatgeschichte wiederfinden lässt. Wird das Revolutionsgeschehen zwar auf Abstand gehalten und spürt das Städtchen nur den fernen Wellenschlag der Zeit, ${ }^{246}$ nehmen Krieg und Unruhe im Bewusstsein der Figuren doch eine große Rolle ein. Das gilt im besonderen Maß für die von der Geschichte nun angespülten Fremden, den Richter und Dorothea, aber auch den Bürgern drängt sich das Weltereignis immer mehr auf. Gelingt dem Wirt anfänglich noch eine distanziert-optimistische Zukunftsperspektive - „alles deutet auf Frieden“ (1, V. 198) - verdüstert sich diese im Verlauf des Gedichts zusehends. „Aber, ach! wie nah ist der Feind!", warnt Hermann schon im vierten Gesang, „Die Fluten des Rheines / Schützen uns zwar; doch ach! was sind nun Fluten und Berge / Jenem schrecklichen Volke, das wie ein Gewitter daherzieht!“ (4, V. 81-83). In diesem direkten Vergleich wird die Revolution ausdrücklich als unkontrollierbares, naturhaft-archaisches Katastrophenereignis gedeutet und zwar nicht als fruchtbares Zerstörungsmoment zyklischer Erneuerung, sondern als ein apokalyptischer, „alles bedrohende[r] Unfall“ (4, V. 88), der die Deutschen endgültig in „Elend und Knechtschaft“ (4, V. 94) führen wird. Wenn Hermann am Ende zu den Waffen ruft, scheint die von ihm

\footnotetext{
244 Zur prekären Idylle vgl. den Sammelband Schneider; Drath (Hrsg.): Prekäre Idyllen in der Erzählliteratur des deutschsprachigen Realismus.

245 Vgl. Schneider, Sabine: Einleitung. „Himmelfahrten des gedrückten Lebens“. Prekäre Idyllen im bürgerlichen Zeitalter. In: Ebd. S. 1-12.

246 Vgl. Martens: Halten und Dauern? Gedanken zu Goethes Hermann und Dorothea. S. 79-98, hier S. 89 .
} 
antizipierte gewalttätige Auseinandersetzung unmittelbar und ausweichlich bevorzustehen.

In ähnlicher Weise spitzt sich auch der Generationenkonflikt zwischen Vater und Sohn zu, der sich im zweiten Gesang zunächst an der Frage nach der richtigen Braut entzündet und insofern eine Referenz auf die Ilias und den Streit zwischen Achilles und Agamemnon darstellt,, ${ }^{247}$ aber immer mehr die eklatanten Diskrepanzen in Mentalität und Denkweise offenbart. Äußert sich der Wirt zu Beginn noch positiv über Hermann und dessen Fähigkeit, die Kutschpferde zu bändigen (1, V. 16) und folglich Geschwindigkeitskontrolle auszuüben, so kritisierte er bereits am Ende des ersten Gesangs die bedächtige Wesensart des Sohnes. Dessen Schüchternheit und Langsamkeit (1, V. 207), vor allem gegenüber den heiratsfähigen Nachbarsmädchen, drohen die ehrgeizigen Aufstiegspläne des Vaters zu vereiteln. ${ }^{248}$ Auch gilt ihm die eigene Heirat nicht wie Hermanns Mutter als zu wiederholendes Muster, sondern als familiäre Entwicklungsstufe, die es zu überwinden gilt, denn „besser ist besser. Nicht einen jeden betrifft es, / Anzufangen von vorn sein ganzes Leben und Wesen" (2, V. 161 f.). Wünscht sich der Vater die Nachbarin als Schwiegertochter, geht es ihm dabei nicht um die Erhaltung von Tradition oder gleicher Herkunft, vielmehr steht ihm der Sinn nach wirtschaftlichem Vorwärtskommen: „ein begütertes Mädchen“ „mit schöner Mitgift“ soll Hermann heimführen, denn „es behaget so wohl, wenn mit dem gewünschten Weibchen / Auch in Körben und Kasten die nützliche Gabe hereinkommt" (2, V. 170-173). Hermanns Verdruss über die zwar vermögenden, aber eitlen und lieblosen Nachbarstöchter (2, V. 236) erscheint dem Vater deshalb als Trotz gegen die patriarchale Autorität sowie als Ausdruck eines mangelnden gesellschaftlichen Ehrgeizes: „das kommt daher, wenn Ehrgefühl nicht im Busen / Eines Jünglings lebt und wenn er nicht höher hinauf will“ (2, V. 254 f.). Über den Zorn des Vaters verlässt der Sohn die Stube schweigend, „langsam und ohne Geräusch“ (2, V. 259-273), wie es seiner Wesensart entspricht. Allerdings bezieht Hermann seinerseits nun immer stärker Stellung gegen die väterlichen Überzeugungen und deutet die endgültige Ablösung vom Vater bzw. die Überwindung des ökonomischen Denkens durch das individuelle Gefühl, die in der Verlobung mit Dorothea zum Abschluss kommt, bereits vielfach voraus.

Naturgeschehen, Welt- und Privatgeschichte werden durch diese korrespondierenden Entwicklungen wohl in ein sich gegenseitig erhellendes Vergleichsverhältnis gesetzt. Auf dem Hintergrund der Naturereignisse

247 Vgl. FA I, 8. S. 1158.

248 Oschmann: Das Epos in Zeiten des Romans. Goethes Hermann und Dorothea. S. 167-189, hier S. 178 . 
werden die politischen und familiären Vorgänge nämlich als unkontrollierbare Radikalisierungsprozesse einsehbar; Hermanns Adoleszenzprozess beleuchtet die Revolution wiederum als Befreiung von alten, starren Mustern. Die Verlobung von Hermann und Dorothea führt dann schließlich die Möglichkeit einer friedlichen Integration des Fremden in das Bekannte vor. Damit eröffnet die glücklich verlaufende Privatgeschichte nicht zuletzt auch eine hoffnungsvolle Perspektive auf die politischen Veränderungen: Könnten die Ideale und Werte der französischen Revolution friedlich fruchtbar gemacht werden für die deutsche Nation?

Das bedeutet aber weder die von Elsaghe vorgeworfene Hypostasierung der historischen Krise zu einer unabänderlichen, schicksalhaften Naturgewalt, noch dass Hermanns Entwicklung als idealer bürgerlicher Bildungsprozess stilisiert würde. ${ }^{249}$ Die Vorgänge laufen nämlich nicht einfach nebeneinander her, um potenziert die gleiche Aussage zu machen, sondern durchdringen einander vielmehr auf widersprüchliche Weise. So deutet zum Beispiel der Brand der Stadt zwar die Familien- und Geschichtskrise voraus, er dient aber nicht dazu, diese als Naturnotwendigkeiten zu begründen. Denn weder gibt es zwischen Revolution und Brand einen unmittelbaren Zusammenhang - das sind Ereignisse unterschiedlicher Zeitstufen und Größenordnungen - noch repräsentiert das Feuer die Natur als Ganzes, vielmehr tritt es als plötzliche, katastrophale Ausnahme auf. Die Revolution ist in Hermann und Dorothea nicht der naturhafte Ausbruch ${ }^{250}$ bzw. werden Natur und Geschichte nicht zu einem harmonischen großen Ganzen gefügt, sondern treten immer wieder als zwei eigenständige Ordnungen auseinander. Prägnant führt das auch die widersprüchliche Symbolik der Sonne vor, die zunächst als Sinnbild für die ewige Naturordnung des Städtchens steht, dann aber auch der Revolution zugeordnet wird und diese als strahlenden Neubeginn vorstellt. ${ }^{251}$ Zwischen Naturund Geschichtsgeschehen bestehen demnach keine eindeutigen, stabilen Beziehungsstrukturen, es werden jedoch in beiden Bereichen Erscheinungen sichtbar, die einander ähnlich sind. So treten die Entwicklungsbewegungen der verschiedenen Handlungsebenen im Sinne einer ambivalenten Gleichzeitigkeit des Ungleichzeitigen ergänzend nebeneinander. Damit werden

249 Vgl. Elsaghe: Untersuchungen zu Hermann und Dorothea. S. 138 f. In der Rede des Richters würde die Revolution bzw. die Zeitgeschichte durch Naturgleichnisse zu etwas Naturgesetzlichem stilisiert und sogar darüber hinaus zu etwas Übernatürlichem (losgebunden erscheint alles Böse).

250 Vgl. Lypp: Ästhetische Reflexion und ihre Gestaltung in Goethes Hermann und Dorothea. S. 77 .

251 Vgl. Kaiser: Wandrer und Idylle: Goethe und die Phänomenologie der Natur in der deutschen Dichtung von Gessner bis Gottfried Keller. S. 48. 
nun auch die Zeitstufen und ihr Verhältnis zueinander entschieden anders beleuchtet als im idyllischen Zyklizitätsmodell. Hier wird nämlich die ganz eigene Signatur der jeweiligen Zeit hervorgehoben und diese kehrt in ihrer spezifischen Ausprägung nicht wieder: Tatsächlich stellt die Französische Revolution keineswegs eine Wiederholung des biblischen Exodus dar, genauso wenig entspricht der Bund zwischen Hermann und Dorothea völlig dem der Eltern und auch der Brand der Stadt kann nicht mit dem erntebedrohenden Gewitter gleichgesetzt werden.

Die Vergangenheit wird hier nicht zum Exemplum, sie wird im Gegenteil diesmal ganz in Übereinstimmung mit den wirkungsmächtigen, geschichtsphilosophischen und anthropologischen Fortschrittsmodellen als hinter sich gelassene Entwicklungsstufe gedeutet: „Der Jüngling reifet zum Manne. Ein Tag ist nicht dem anderen gleich" (4, V. 126), das weiß auch der unbewegliche Hermann. Damit wird die Emphase allgemeingültiger, überzeitlicher Erscheinungen mit der Frage nach der Möglichkeit und Fassbarkeit einmaliger Erscheinungen unterlaufen. Der Repräsentationscharakter zyklischer Geschichte wird mit der relativen Einmaligkeit historischer Ereignisse und Persönlichkeiten komplementiert.

Der Text beschränkt sich demnach nicht darauf, zeitliches Fortschreiten als lebensbedrohliche Überstürzung abzuhandeln oder den Blick von den damit zusammenhängenden Problemen ganz abzuwenden, sondern er eröffnet sogar gezielt einen positiven Blick darauf. ${ }^{252}$ Die lineare Eigendynamik der Zeit wird in Hermann und Dorothea also auch als produktive, treibende Kraft des Lebendigen und der Freiheit betrachtet. Das Gedicht übernimmt von diesem Standpunkt aus die eigentlich dem Roman zugewiesene kommunikative Funktion, die Vervielfältigung, Vereinzelung und Verzeitlichung der realen Lebenswelt als Erneuerung im Sinne genuiner Innovation zu begrüßen. Die angebrochene Moderne erscheint hier im positiven Licht eines Neubeginns, als Ursprung einer neuen, unvorbelasteten Epoche freier Entfaltungsmöglichkeiten. Dazu gehört auch das dominante, spezifisch zeitlich bestimmte Glücksversprechen, das den Fortschritt als Möglichkeit vorstellt, sich von den Zwangsläufigkeiten der zyklisch-organischen Entwicklung zu befreien und das Alte zu überwinden. Bereits früh im Text klingt diese Idee an, wenn ausgerechnet der Pfarrer die kritisierten Laster des Leichtsinns und der Neugier verteidigt:

252 Vgl. Seidlin: Über Hermann und Dorothea. Ein Vortrag. S. 20-37, hier S. 30. 
Lockte die Neugier nicht den Menschen mit heftigen Reizen,

Sagt! erführ' er wohl nicht je, wie schön sich die weltlichen Dinge

Gegeneinander verhalten? Denn erst verlangt er das Neue,

Suchet das Nützliche dann mit unermüdetem Fleisse;

Endlich erhebt er das Gute, das ihn erhebet und wert macht.

In der Jugend ist ihm ein froher Gefährte der Leichtsinn,

Der die Gefahr ihm verbirgt und heilsam geschwinde die Spuren

Tilget des schmerzlichen Übels, sobald es nur irgend vorbeizog. (1, V. 88-95)

Ganz im Sinne des werkbestimmenden Hin-und-her-Schwankens verwirklicht sich das Prinzip der Bewegung im Zeichen der Freiheit dann allerdings nicht am französischen Revolutionär, sondern tatsächlich an Hermann. Der allgemeinen Überstürzung hält dieser zwar Dauern und Halten entgegen, löst sich aber gerade mit der deutlichen Aussprache für das Konservieren aus der einst starren und stummen Position und beginnt sich damit selbst zu bewegen. Hermanns allmähliche Selbstbewusstwerdung stellt ein anderes, maßvolles Entwicklungs- und Lebenstempo vor und zeigt sich besonders prominent als Finden einer eigenen Stimme. Allein durch die dominante Form der direkten Rede wird bereits ein besonderer Fokus auf die medialen und perspektivischen Implikationen der wörtlichen, mündlichen Sprache gelegt. An Hermann wird darüber hinaus aber dezidiert zur Anschauung gebracht, inwiefern sich das Erlangen eines freien, autonomen Bewusstseins und die Fähigkeit zur Artikulation im Kern aus dem Prinzip der Bewegung speisen: „Ja, ich schwör es, das erstemal ist's, dass frei mir ein solches / Wort die Zunge verlässt, die nicht zu schwatzen gewohnt ist", reflektiert Hermann die eigene Entwicklung, „Aber du lockst mir hervor aus der Brust ein jedes Vertrauen“ (8, V. 30 f.).

Nach der ersten Begegnung mit Dorothea, die ihrerseits das Phänomen der Bewegung nochmals auf eine ganz andere Weise verkörpert - als Flüchtende steht sie exemplarisch für die negativen Konnotationen der Bewegung, wie Entwurzelung, Ausgeliefertsein und Unsicherheit - beginnt Hermann also, in sich hineinzuhorchen und sich immer deutlicher frei auszusprechen. Dass in Hermann etwas in Bewegung geraten ist, wird vom Pfarrer sogleich wahrgenommen: „Kommt Ihr doch als ein veränderter Mensch!“ begrüßt er den Wirtesohn im zweiten Gesang, der fröhlich und heiter von einem Botengang in die Runde der Bürger zurückkehrt und der auf einmal so munter und lebhaft scheint wie nie zuvor (2, V. 6-8). Kurz darauf äußert sich Hermanns Wandlung erstmals konkret, wenn er dem Apotheker und dessen eigennütziger Lebensphilosophie als Einziger widerspricht, und zwar mit Nachdruck: „Keineswegs denk ich wie Ihr und tadle die Rede“ (2, V. 98 f.). Im Gespräch zwischen Mutter und Sohn unter dem Birnbaum wird dann weiter deutlich, wie Hermanns 
erwachendes Bewusstsein ein eindeutig politisches ist und mit wachsendem rhetorischem Geschick einhergeht. Im „innersten Busen“ regt sich nun „Mut und Begier, dem Vaterlande zu leben / Und zu sterben und andern ein würdiges Beispiel zu geben" (4, V. 95-97). Damit entkräftet er den väterlichen Vorwurf der Ehrgeizlosigkeit und begegnet ihm mit Ambitionen, die nicht nur auf sich selbst und ein wirtschaftliches Wohlergehen, sondern weit darüber hinaus auf die Allgemeinheit gerichtet sind: „Sage der Vater alsdann, ob nicht der Ehre Gefühl mir / Auch den Busen belebt und ob ich nicht höher hinauf will!“ (4, V. 109 f.). „Hörte jetzt ein Dritter dich reden“, stellt die Mutter darauf irritiert fest, „er würde fürwahr dich / Höchlich loben und deinen Entschluss als den edelsten preisen, / Durch dein Wort verführt und deine bedeutenden Reden“ (4, V. 113-119).

Wie die Menschen in der Begeisterung für die politische Revolution und ihre neuen Werte eine neue Sprache finden (6, V. 19), findet auch Hermann mit der Zeit eine eigene Stimme, um seine eigenen Gedanken und Überzeugungen auszudrücken: „so still ich auch bin und war, so hat in der Brust mir / Doch sich gebildet ein Herz, das Unrecht hasset und Unbill, / Und ich verstehe recht gut die weltlichen Dinge zu sondern" (4, V. 130-132). Damit macht der Text zunächst auf die grundsätzliche Identifikations- und Organisationskraft von Sprache aufmerksam, darüber hinaus aber gerade auch auf die Notwendigkeit von neuen Zeichen für neue Inhalte, neue Formen für neues Wissen und nimmt insofern Bezug auf die eigene modifizierte Sprachform. Dass mit einem erneuerten Sprechen auch Schwierigkeiten einhergehen, führen die Verständigungsprobleme zwischen Vater und Sohn, aber auch zwischen Hermann und Dorothea vor Augen. Hermann gelingt es zunächst kaum, seine eigenen Erfahrungen, Überzeugungen und Wünsche auch adäquat zu vermitteln. Und im entscheidenden Moment - „die Stunde [war] [g] ünstig“ - versagt ihm gar die Sprache: „er wagte kein weiteres Wort“ (8, V. 63 f.), „[a]lso sassen sie still und schweigend nebeneinander" $(8, \mathrm{~V} .66)$. Das verpasste Liebesgeständnis führt dann zum grundsätzlichen Missverständnis zwischen den Liebenden, das fast bis zum Ende die Verlobung zu verhindern droht. Erst mit den letzten Schlussworten bringt Hermann sein sowohl politisches als auch privates Selbstbewusstsein klar und deutlich zum Ausdruck und damit auch den Selbstbildungsprozess zu einem Abschluss. Damit beharrt die Dichtung darauf, dass die erwünschten Neuerungsprozesse selbst prozesshaft und als solche auf lange Zeitspannen angewiesen sind, um verlässliche neue Ordnungen hervorzubringen. Im Gegensatz zur übereilenden, revolutionären Bewegung hat in Hermann nämlich eine bedächtige eingesetzt, die über den ganzen Text hinweg als vorsichtige Entwicklung nachvollzogen werden kann 
und trotz Innovation Beständigkeit verspricht. ${ }^{253}$ Obwohl sich Hermann vom Vater und dessen Konventionen distanziert und an seinem neugefundenen Selbstbewusstsein festhält, führt die Emanzipation des Sohnes nämlich nicht zum totalen Eklat. Mit der letztlichen Versöhnung von Vater und Sohn wird vielmehr an der Möglichkeit festgehalten, den entstandenen Bruch zwischen Altem und Neuem durch wechselseitige Vermittlung zu überwinden.

\subsection{5 „halten und dauern“: Entschleunigtes Erzählen}

Inwiefern das Gedicht dem Fortschreiten der Geschichte nicht nur literarisch und gattungspoetologisch Rechnung trägt, sondern sogar gezielt auf seine Potenziale hinweist, lässt sich auch bis in die Form der Sprache nachvollziehen. Das nur wenige Stunden umfassende Geschehen wird nämlich Augenblick für Augenblick erfasst, ohne Raffung, Rückwendung oder Vorgriff. ${ }^{254}$ Die komplex ineinander geschlungenen Korrespondenzen der Handlung macht der Text auf der Darstellungsebene durch ein konsequentes nacheinander Erzählen tatsächlich als linear gegliederte Sequenzialität erfahrbar. Die erzählte Zeit wird an keiner Stelle gekürzt, sie wird im Gegenteil durch zahlreiche retardierende Motive gedehnt, sodass die doch relativ überschaubare Handlung verhältnismäßig viel Raum oder eben Erzählzeit einnimmt: So wird die Suche der Bürger nach Dorothea, die an sich bereits eine Handlungsverzögerung darstellt, durch die Begegnung mit dem Richter noch weiter ausgedehnt, und Hermanns Entdeckung des Rings an Dorotheas Finger führt im neunten Gesang zu einem erheblichen Missverständnis, bevor die Liebenden dann doch noch verlobt werden. Der kurze achte Gesang, der den Heimweg von Hermann und Dorothea schildert, kann insgesamt als retardierender Einschub betrachtet werden: Hier werden noch einmal alle Zeichen der Gefährdung zitiert, die schließlich in Dorotheas Fehltritt kumulieren. In den letzten Versen rät Dorothea sogar explizit zum Verharren: „Lass uns ein wenig verweilen, damit dich die Eltern nicht tadeln / Wegen der hinkenden Magd, und ein schlechter Wirt du erscheinest" (8, V. 103 f.). Insofern entfernt das Erzählen tatsächlich, wie es der gattungstheoretischen Vorgabe der Retardation entspricht, die Handlung ganz von ihrem Endpunkt.

Anders als in der Idylle, besonders Voß' Luise, wird der Handlungsverlauf jedoch nicht durch ausschweifende Beschreibungen fast zum Stillstand gebracht, sondern Hermann und Dorothea zeigt ebenso wie der Roman

253 Vgl. Kaiser: Wandrer und Idylle: Goethe und die Phänomenologie der Natur in der deutschen Dichtung von Gessner bis Gottfried Keller. S. 49.

254 Vgl. Lypp: Ästhetische Reflexion und ihre Gestaltung in Goethes Hermann und Dorothea. S. 68. 
sehr wohl eine Bewegung in der Zeit. ${ }^{255}$ Goethe geht es nicht darum, die Dynamisierung der Lebenswelt in der Dichtung stillzulegen, Entwicklung und Reform sind ihm durchaus willkommen. Allerdings nimmt er gezielt die Geschwindigkeit, den Takt dieser Bewegung in den Blick und spricht sich für eine zeitliche Organisation im Zeichen der Entschleunigung aus - seine Erzählung bewegt sich im Gegensatz zum Roman durchaus langsam und stetig vorwärts. Wenn der Apotheker im letzten Gesang den ungeduldigen Eltern erklärt, weshalb er warten könne „wie keiner der Weisen“ (9, V. 19), werden Geduld und Ungeduld nicht nur erneut zum Thema, sondern führt der Text das Zeitmaß der Langsamkeit auch gleich dramaturgisch vor. ${ }^{256}$ Erzählzeit und erzählte Zeit verstreichen in der direkten Rede simultan, das heißt Handlungsund Wortfolge laufen hier parallel, die dargestellte Haltung des Verweilens wird in der Bewegung der Darstellung wiedergegeben - wie die Eltern wird auch der Leser zur Geduld gezwungen. Zeichenökonomisch bedeutet das gleichwohl eine Emphase des Prozesscharakters des Epischen, wie auch eine entscheidende Verlangsamung der Formengeschwindigkeit.

Von der epischen Lizenz, sich frei zwischen den Zeiten zu bewegen, beliebig vor und zurückzugehen in der erzählten Zeit, ${ }^{257}$ macht der Text allerdings keinen Gebrauch. Auf der Ebene der primären Handlung gibt es weder echte Pro- noch Analepsen im Sinne Genettes, ${ }^{258}$ die eine Vor- oder Nachgeschichte erkennbar machen würden und auch keine epische Vorausdeutung. Anstatt in einzelne Zeitphasen aufgespalten zu sein, wie es mehreren Handlungssträngen zuträglich wäre, wird die Begebenheit in einer beschränkten Zeiteinheit geschildert. Bemerkenswerterweise stellen fast alle Figuren in ihren Reden erinnernde Bezüge zur Vergangenheit her oder ahnungsvolle Deutungsversuche über die Zukunft. Die Erzählung wird durch diese impliziten Vergegenwärtigungen anderer Zeiten zwar komplex verdichtet, ${ }^{259}$ aber eine retrogradierende Bewegung, wie sie im Gattungsgespräch als alleinstellendes Merkmal des Epischen beschrieben wird, kommt dadurch nicht zustande. In Hermann und Dorothea verläuft die Handlung konsequent einsinnig nach

255 Vgl. Oschmann: Das Epos in Zeiten des Romans. Goethes Hermann und Dorothea. S. 167189, hier S. 189 .

256 Vgl. Elsaghe: Untersuchungen zu Hermann und Dorothea. S. 133.

257 Vgl. S. $148 \mathrm{ff}$. in diesem Buch.

258 Genette, Gérard: Die Erzählung, aus dem Franz. v. Andreas Knop. München: Fink 1994. Zur Beschreibung spezifisch anachronischer Ordnungsmuster des Erzählens vgl. insb. S. 57 ff. Genette nennt eine narrative Rückwendung in der chronologischen Ordnung der Ereignisfolge Analepse und eine Vorausdeutung entsprechend Prolepse.

259 Vgl. Schneider, Sabine: „Allgemeines Fest beginnt“. Morphologie der Kultur. In: Dies.; Vogel, Juliane (Hrsg.): Epiphanie der Form. Goethes Pandora im Licht seiner Form- und Kulturkonzepte (= Ästhetik um 180o, Bd. 10). Göttingen: Wallstein 2018. S. 119-131. 
vorne, besonders begünstigt wird diese genaue zeitliche Sukzession durch die überwiegende Form der direkten, wörtlichen Rede. Goethe bedient dieses bereits für das antike Epos charakteristische Stilmittel deutlich radikaler als die homerische Vorlage. So stellen die direkte Rede an Gesangsgrenzen besonders exponiert am Anfang des ersten Gesangs und insofern als deutliche Ausrichtung des Gesamttextes zu verstehen - und die reduzierten Zitationsformeln entscheidende Abweichungen von bzw. Erneuerungen der tradierten Form dar. Über weite Strecken nähert sich die Erzählung deshalb einer fast szenischen Darstellung an, die ganz entgegen der gattungstheoretischen Zuschreibung der epischen Vergangenheit Gegenwart erzeugt. ${ }^{260} \mathrm{Im}$ Zusammenwirken der zeitgenössischen Handlung, der beschränkten Zeitspanne und der sprachlichen Form der direkten Rede wird Gegenwart überhaupt zum beherrschenden Darstellungsaspekt.

Das scheint vordergründig alles im Dienste von Unmittelbarkeit und Realitätsbezug zu stehen und insofern einer klaren Modernisierungsabsicht zu folgen. Neben die Vergegenwärtigungsstrategien treten nun allerdings jeweils die sprachlichen Stilmittel des antiken Epos und erzeugen eine bewusste Diskrepanz. Theoretisch soll das Epos eine Darstellung des vollkommen Vergangenen sein, die gleichwohl vergegenwärtigt wird. Konkret verfährt Goethe dann aber anders oder vielmehr sogar entgegengesetzt, stellt er doch eine Gegenwart dar, die durch die antikisierende Sprache in die Vergangenheit entrückt scheint. Durch die Hybridisierung von antiken Stilelementen und vergegenwärtigendem Erzählen erscheint das epische Erzählen selbst prekär, das macht der Text als ambivalentes Schwanken zwischenzeitlich unterschiedlich verfassten Formen sichtbar: ${ }^{261}$ Das Heranholen der antiken Dichtungsform an die Moderne durch einen aktuellen Gegenstand wird durch die beibehaltene antike Stilistik relativiert und der antike Sprachgebrauch wird wiederum durch ein lineares Erzählverfahren ausgeglichen. Auf der Ebene der Darstellung findet also gar kein Retrogradieren im eigentlichen Sinne statt, vielmehr erhält der Text in der konsequent fortlaufenden Aneinanderreihung einzelner Sequenzen eine deutlich lineare Ausrichtung.

August Wilhelm Schlegel erklärt diese gewissermaßen unepische Darstellung zum notwendigen Kunstgriff, denn nur die allseitige Bekanntheit der Helden und ihrer Schicksale erlaube dem Epiker, die Erzählung an jedem beliebigen Punkt ein- oder abzusetzen. Da es sich bei Hermann und Dorothea jedoch um einen gänzlich neuen, unbekannten Stoff handle und nicht um

26o Vgl. Lypp: Ästhetische Reflexion und ihre Gestaltung in Goethes Hermann und Dorothea. S. 68.

261 Vgl. ebd. S. 69. 
eine bereits allgemein bekannte Saga, sei darin deshalb alles richtigerweise „einfach, und gleitet ohne Sprung in einer unveränderten Richtung fort, deren Ziel man bald vorhersieht. ${ }^{262}$ Ein Vergleich mit Goethes anderen epischen Dichtungen legt allerdings nahe, dass es sich bei dieser linear organisierten Erzählweise vielmehr um eine feinsinnige Zeitreflexion und damit eben auch um eine gewollte Heranführung des Epischen an die Moderne handelt. Denn sowohl das Achilleis-Fragment als auch Reineke Fuchs weisen sich ebenfalls durch eine eindeutig fortschreitend bestimmte, gebundene Erzählweise aus, obschon beide äußerst bekannte, in der Tradition verwurzelte Stoffe sind.

In diese Richtung können nun auch Goethes Selbstaussagen interpretiert werden. Im April 1797 findet er seinen Hermann noch retrogradierend, alles scheine ausgemacht und fertig darin und durch die "retrograde Bewegung" fange "gleichsam wieder ein neues Gedicht" an. ${ }^{263}$ Die Frage nach der Retrogration, ob und wie sie Goethes Gedicht bestimmt, wird von der Forschung allerdings bis heute nicht eindeutig beantwortet. Fängt mit dem eigenartig weit hinten stehenden Musenanruf ein neues Gedicht an bzw. wird damit im letzten Gesang ein neuer Lesezyklus initiiert?264 Wird im sechsten Gesang mit der erneuten Begegnung von Hermann und Dorothea eine retrogradierende Bewegung eingeleitet?265 Oder zielt Goethes Bemerkung vielleicht darauf, dass das Gedicht nicht mit der antizipierten Verlobungsszene endet, sondern darüber hinaus geht und an die Liebesgeschichte eine politische anschließt? Im späteren Begleitbrief zum gemeinsamen Aufsatz über das Epische findet sich ein Hinweis darauf, dass Goethe die eigene Gattungsvorgabe vielmehr bewusst hintertreibt, ja hintertreiben muss. Darin schreibt er nämlich, dass sich in Hermann und Dorothea gar „kein ausschließlich episches Motiv, d.h. kein retrogradierendes ${ }^{\text {“ } 266}$ befinden würde, und zwar weil „sich [in der Gegenwart gar] nichts retrogradierendes mehr findet, sondern alles unaufhaltsam vorwärts schreitet“. ${ }^{267}$ Die Gestaltung einer nachvollziehbaren zeitlichen Sukzession sowie das Erzeugen von Gegenwart sind also nicht in erster Linie dem Umstand geschuldet, dass hier zum ersten Mal eine noch unbekannte Geschichte erzählt wird, sondern vielmehr Goethes Bewusstsein für die

\footnotetext{
262 Schlegel: Goethes Hermann und Dorothea. S. 183-221, hier S. 190.

263 Goethe an Schiller, 22.4.1797, BW. S. 378.

264 Vgl. Elsaghe: Untersuchungen zu Hermann und Dorothea. S. 26.

265 Vgl. Geulen: Goethes Hermann und Dorothea. Zur Problematik und inneren Genese des epischen Gedichts. S. 14 .

266 Goethe an Schiller, 23.12.1797, BW. S. 536.

267 Ebd. S. 537 .
} 
tiefschürfende Umwälzung im Zuge der Revolution ${ }^{268}$ und seiner klaren Absicht, die Geschichte zeitgemäß zu erzählen. Zumindest teilweise passt er das Epische damit auch formästhetisch und epistemologisch an den modernen Geschmack und vor allem die neue, dominante Zeitkonzeption der linearen Beschleunigung an.

Auf der Anschauungsebene bleibt die Bezugnahme auf die moderne Fortschrittslogik allerdings stets prekär und beschränkt sich bei weitem nicht auf eine politisch-ideologische Ablehnung der Französischen Revolution, wie es unter anderem die Forschungsarbeiten von Krauss, Elsaghe und Seidlin nahelegen. ${ }^{269}$ Freilich akzentuiert sich die Beschleunigungskritik jeweils besonders deutlich im revolutionären Themenbereich. So wird Dorotheas erstem Verlobten „die Liebe der Freiheit“ zum Verhängnis, die ihn „trieb nach Paris zu gehen“, nur um dort den Tod zu finden. Das Glücksversprechen radikaler Neuerung, sich „über den Trümmern der Welt“ als „erneute Geschöpfe, umgebildet und frei und unabhängig vom Schicksal" wieder zu begegnen, erfüllt sich nicht (9, V. 259-276). Und auch die „schönste Hoffnung“ (6, V. 5) der Menschen, dass die Auflösung der alten Herrschaftsstrukturen zur Etablierung neuer Werte wie Menschenrechte, „begeisternde[r] Freiheit“ und „löbliche Gleichheit" führt (6, V. 10), zerschlägt sich. Am Ende bleibt nur die dringliche Warnung vor den verheerenden Konsequenzen absoluter Freiheit: „Sprech” er doch nie von Freiheit, als könn' er sich selber regieren! / Losgebunden erscheint, sobald die Schranken hinweg sind, / Alles Böse, das tief das Gesetz in die Winkel zurücktrieb“ (6, V. 78-8o). Diese Stellen eröffnen aber nicht nur den Durchblick auf die Kehrseite des politischen Umsturzes, sondern immer auch auf die tieferliegende, allgemeine Problematik der Dynamisierung:

[...] [A]lles bewegt sich

Jetzt auf Erden einmal, es scheint sich alles zu trennen.

Grundgesetze lösen sich auf der festesten Staaten,

Und es löst der Besitz sich los vom alten Besitzer,

Freund sich los von Freund: so löst sich Liebe von Liebe.

$[\ldots]$

Alles regt sich, als wollte die Welt, die gestaltete, rückwärts

Lösen in Chaos und Nacht sich auf und neu sich gestalten. (9, V. 262-266, V. 273 f.)

Die bedingungslose, treibende Vorwärtsbewegung ist ein Phänomen, dessen Freiheitserringung stets mit Destabilisierung verbunden ist und schließlich zu Auflösung und Diskontinuität führt: „[G]elöst sind die Bande der Welt; wer

268 Vgl. Oschmann: Das Epos in Zeiten des Romans. Goethes Hermann und Dorothea. S. 167189, hier S. 189 .

269 Vgl. S. 184 in diesem Buch. 
knüpfet sie wieder / Als allein nur die Not, die höchste, die uns bevorsteht!“ ( 7 , V. 89 f.). Auch dass die moderne Fortschrittseuphorie im Gedicht von der abtretenden Generation verkörpert und so als bereits veraltete, niedergehende Denkweise vorgestellt wird, legt nahe, dass die damit zum Ausdruck gebrachte Kritik auch wesentlich auf das darin eingeschriebene Zeitkonzept abzielt. ${ }^{270}$ Für die fortschrittsgläubige, bürgerliche Steigerungsmentalität steht der Löwenwirt besonders deutlich ein, der Sohn soll dem Vater „nicht gleich [sein], sondern ein Bessrer“ (3, V. 5), denn „zu erhalten und zu erneuen / Und zu verbessern auch“ sei die Lehre der Zeit (3, V. 7 f.). „Wer nicht vorwärts geht, der kommt zurück“ (3, V. 66), ist er deshalb überzeugt. Diese Geisteshaltung einer radikalen, einseitigen Ausrichtung auf die Zukunft bedeutet automatisch die Abwertung, wenn nicht sogar die Abschaffung der Vergangenheit als wissensrelevante Größe und steht in krassem Widerspruch mit dem Traditionsdenken und der Erinnerungskultur von Hermanns Mutter. Bezeichnenderweise findet die jüngere Generation ihre Selbstbestimmung dann aber gerade nicht in der bourgeoisen Aufsteigersehnsucht, sondern im Halten und Dauern ${ }^{271}$ - die Rückbesinnung auf das Gewesene wird damit einerseits von einem starren Konservativismus abgegrenzt und andererseits als die tatsächlich progressive Geisteshaltung ausgewiesen.

Im Beharren geht es gar nicht darum, den diagnostizierten Bruch rückgängig zu machen oder sogar hinter ihn zurückzugehen, sondern darum, die Zerrissenheit überhaupt erst auszuhalten. Ordnung und Chaos bzw. neue und alte Ordnung können hier miteinander in Beziehung gesetzt werden. "Gold und Silber schmilzt aus den alten heiligen Formen; / Alles regt sich, als wollte die Welt, die gestaltete, rückwärts / Lösen in Chaos und Nacht sich auf und neu sich gestalten.“ (9, V. 272-274). Aus dem Verlust der „alten Formen“ können hier nun aber gerade neue gewonnen werden. Das Edelmetall der Vergangenheit, das "geschmolzen im Schutt nun überblieben zerstreut liegt“ (6, V. 91 f.) ist nicht verloren, sondern kann neugestaltet werden, „[w]enig ist es fürwahr, doch auch das wenige köstlich; / Und der Verarmte gräbet ihm nach und freut sich des Fundes" (6, V. 93 f.). In diesem Bild werden Altes und Neues, Dauer und Wechsel zu einer zeitsymbolischen Einheit gefügt, ${ }^{272}$ in der der Anbruch der Moderne nicht Auflösung bedeuten muss, sondern lebendige Verwandlung verheißen kann. Das ist die Verdichtungsleistung der Prägnanz,

270 Vgl. Kaiser: Wandrer und Idylle: Goethe und die Phänomenologie der Natur in der deutschen Dichtung von Gessner bis Gottfried Keller. S. 5 1.

271 Vgl. Martens: Halten und Dauern? Gedanken zu Goethes Hermann und Dorothea. S. 79-98, hier S. 84.

272 Vgl. Lypp: Ästhetische Reflexion und ihre Gestaltung in Goethes Hermann und Dorothea. S. 79 . 
wie sie Sabine Schneider beschreibt: Durch das Erfahrbarmachen eines zeitlichen Kontinuums wird die Gegenwart mit den Zeithorizonten der Vergangenheit und der Zukunft erfüllt. ${ }^{273}$ Dass die kulturelle Herkunft allerdings zum blinden Fleck wird, wenn sich der Blick einsinnig nach vorne richtet und in der modernen Vorstellung unendlicher Progression keine verlässliche Ordnung $\mathrm{zu}$ finden ist, führt der Text immer wieder vor Augen. Diskontinuität stellt sich nicht zuletzt auch auf der Sinnebene ein, folgen die Korrespondenzen zwischen den einzelnen Ereignissen und ihren Zeitphasen doch keiner zuverlässigen, eindeutigen Struktur, sondern werden die hergestellten Zusammenhänge jeweils gerade wieder unterlaufen.

\subsubsection{Der epische Augenblick}

In der Parallelstellung der gegenteiligen Zeitkonzeptionen, den ihnen eigeschriebenen Wissensordnungen sowie dem Nichtauflösen der Spannungen dazwischen wird die Aufmerksamkeit wirklich auf einen Punkt in der Mitte gelenkt, wo all diese Zeitlinien und -bewegungen zusammenlaufen und das Problem von Dauer und Diskontinuität, Gründung und Erneuerung schlechthin zur Darstellung kommt. ${ }^{274}$

Dieses gemeinsame Zentrum ist die Gegenwart, ein einzelner „Tag“ (5, V. 46), eine bestimmte „Stunde“ ( 5, V. 50), ein „Augenblick“ (5, V. 57), der sich aus dem komplexen Zeitgefüge absondert. Dem Eintreten eines einmaligen Augenblicks kommt über den ganzen Text hinweg insofern immense Bedeutung zu, als die Begegnung der Liebenden, die Werbung um Dorothea und schließlich die Verlobung grundsätzlich daran gebunden sind. Im fünften Gesang wird das in der Rede der Mutter besonders deutlich: „wie oft gedachten wir [...] des fröhlichen Tags, der kommen würde, wenn künftig / Hermann, seine Braut sich erwählend, uns endlich erfreute! [...] Nun ist er kommen der Tag; [...] Nun ist die Stunde gekommen!" (5, V. 41-50). Für Hermann kommt aber mit der Entfachung der Leidenschaft nicht nur der Moment der Selbstbewusstwerdung und -behauptung gegenüber dem Vater, sondern darüber hinaus ist auch eine bestimmte, entscheidende Stunde der Stadt- und Weltgeschichte angebrochen. Die Konzentration von allgemeiner und Privatgeschichte zu einem prägnanten Zeitpunkt stellt den Versuch Goethes dar, der Gegenwart als flüchtiger aber auch distinkt neuer Jetzt-Zeit gerade durch die Fixierung $\mathrm{zu}$ einem stillstehenden Moment gerecht zu werden. Das entspricht Schillers

273 Vgl. Schneider: „ein strenger Umriß“ - Prägnanz als Leitidee von Goethes Formdenken im Kontext der Weimarer Kunsttheorie. S. 100.

274 Vgl. Lypp: Ästhetische Reflexion und ihre Gestaltung in Goethes Hermann und Dorothea. S. 77 . 
Beschreibung der idyllischen Zeitorganisation, die „eine Ruhe der Vollendung“ vorstelle, die allerdings nicht aus dem „Stillstand, sondern aus dem Gleichgewicht der Kräfte“ komme, „nicht aus der Leere, sondern aus der Fülle“275 fließe.

In der idyllischen Tradition zielt der fixierte Augenblick auf das Erleben von Ewigkeit und einen zeitlosen Glückszustand ab. ${ }^{276}$ In Goethes Idylle Alexis und Dora baut die ganze narrative Struktur auf einen einzigen Augenblick auf:277 Im Moment der Abfahrt Alexis' verdichten sich gleichwohl der Moment der Begegnung und des Abschieds, derVerlobungundVorbedingung der Untreue. ${ }^{278}$ Die übrige Zeit erscheint leer und bedeutungslos gegenüber diesem absoluten Augenblick, bzw. bleibt unklar, ob er bereits stattgefunden hat oder für die Zukunft ersehnt wird. ${ }^{279}$ Die Erzählung schwebt als ein einzelner, zur Ewigkeit gedehnter Moment frei zwischen Vergangenheit und Zukunft. Das Credo der idyllischen Beschränkung zeigt sich hier, wie auch in der Luise, als radikale Entwicklungslosigkeit und setzt die Figuren in ein naives, unreflektiertes Verhältnis zur Zeit. ${ }^{280}$ Wie Hagel ausführt, haben Idyllenhelden typischerweise keinen Zeitsinn, sie machen keine Erfahrung von Zeitlichkeit und erleben deshalb auch keine Veränderung oder Reflexion - sie entbehren daher jeglicher aktiven Einbildungskraft, auch wenn dann besonders die modernen Idyllenwelten beileibe keine zeitlosen Utopien sind. ${ }^{281}$ Entwicklungs- und Zeitlosigkeit war aber nicht zuletzt auch kennzeichnend für die Charaktere des antiken Epos, deren Epizität und mythologische Bedeutsamkeit unter anderem darin bestand, dass sie immer gleich blieben. ${ }^{282}$

In Hermann und Dorothea sind die Figuren dann aber nicht zeitlos, sondern verfügen auf geradezu signifikante Weise über ein Bewusstsein für die Zeit sowie ihre Dynamik und bringen das auch zum Ausdruck. An Hermann wird nicht nur eine Charakterentwicklung sichtbar gemacht, sondern darüber hinaus auch, wie er dieser gewahr wird. Hermann erinnert sich nämlich daran,

275 Schiller: Über naive und sentimentalische Dichtung. S. 751.

276 Vgl. Tanzer: Fortuna, Idylle, Augenblick. Aspekte des Glücks in der Literatur. S. 176.

277 Vgl. Wellbery: Die Grenzen des Idyllischen bei Goethe. S. 221-240, hier 232.

278 Vgl. Lypp: Ästhetische Reflexion und ihre Gestaltung in Goethes Hermann und Dorothea. S. 72.

279 Vgl. Wellbery: Die Grenzen des Idyllischen bei Goethe. S. 221-240, hier S. 226.

28o Vgl. Hagel: Elliptische Zeiträume des Erzählens. Jean Paul und die Aporien der Idylle. S. 10.

281 Vgl. ebd. S. 19.

282 Vgl. Hamburger, Käte: Beobachtungen über den urepischen Stil. In: Trivium 6.2 (1948). S. 89-122, hier S. 103; Stresau, Hermann: Raum und Zeit in der Epik. In: Die neue Rundschau (1935). S. 551-559, hier S. 553 und Lukács: Die Theorie des Romans (1920). S. 124. 
wie er einst war; er weiß, dass er nun ein Veränderter ist und vermag auch vorauszuschauen:

[...] Und drohen diesmal die Feinde

Oder künftig, so rüste mich selbst und reiche die Waffen.

Weiß ich durch dich nur versorgt das Haus und die liebenden Eltern, Oh, so stellt sich die Brust dem Feinde sicher entgegen.

Und gedächte jeder wie ich, so stünde die Macht auf

Gegen die Macht, und wir erfreuten uns alle des Friedens. (9, V. 313-318)

Das ist eine Zukunftsvorstellung, die in ihrem Kern auf das Erfassen des Hier und Jetzt zurückführt. Damit wird die alle Folgezeit bestimmende Kraft des Augenblicks zu Bewusstsein gebracht und die Gegenwart als labiler Entscheidungsmoment ausgewiesen:

Der Augenblick nur entscheidet

Über das Leben des Menschen und über sein ganzes Geschicke;

Denn nach langer Beratung ist doch ein jeder Entschluss nur

Werk des Moments, es ergreift doch nur der Verständ'ge das Rechte.

Immer gefährlicher ists, beim Wählen dieses und jenes

Nebenher zu bedenken und so das Gefühl zu verwirren. (5, V. 57-62)

An Hermann erscheint das Bewusstsein für die Zeit und ihre Flüchtigkeit insofern als Voraussetzung für die freie Selbstbestimmung des Subjekts. Einerseits rückt der Text dadurch das jeweils Eigene und Individuelle des Einzelnen in den Mittelpunkt des Interesses: Das Ich wird zum Träger der Erkenntnis und seine Selbstbestimmung zum höchsten sittlichen Wert. Hermann schaut im Gegensatz zu seinen Mitbürgern in sich selbst hinein und bildet sich gerade durch die Selbstreflexion zum modernen Individuum. Er bestimmt sein eigenes Schicksal, indem er für sich selbst entscheidet: „Selber geh ich und will mein Schicksal selber erfahren“, dazu hat er sich „im stillen entschlossen“ (6, V. 275 f.).

Gleichzeitig wird die Erfahrung einer neuen, modernen Zeitlichkeit als ein weiteres Phänomen erkennbar, welches sich neben der Erklärung der Menschenrechte, dem Staat als Sozialvertrag und der Aufklärung des Menschen durch Vernunft aus der Entdeckung des Individuums ableiten lässt. Die kritische und reflektierende Bezugnahme auf das veränderte Zeitgefüge erweist sich hier als Keimzelle eines um 1800 noch sehr jungen, zukunftsweisenden bürgerlichen Denkens. Das epische Gedicht führt die Gegenwart als Moment der Wahlfreiheit vor, in dem der Einzelne als souveränes, autonomes Ich agiert; dieses wird durch die Forderung, sich auf eine bestimmte Weise zur Gegenwart zu verhalten, aber auch in die Verantwortung 
genommen. An diesem Punkt wird klar, dass Hermann nicht nur eine alternative, progressive Bürgertumsidee vertritt, ${ }^{283}$ sondern dass durch ihn auch ein moderner ästhetischer Erfahrungsmodus der Subjektivität vermittelt wird. Sein Bericht über die Begegnung mit den Flüchtenden ist, ganz anders als der des Apothekers, auf das Besondere gerichtet, das sich seinem subjektiven Blick offenbart: „[Es] [f]iel mir ein Wagen ins Auge, [...] Nebenher aber ging mit starken Schritten ein Mädchen“ (2, V. 22 f.). Hermann erfährt die Welt eben als ein Subjekt, noch dazu als ein sinnlich-fühlendes. Darüber, wie sich ihm die Gegenwart präsentiert und er sich als Subjekt zu ihr verhält, stellt Hermann keine vernunftgeleiteten Überlegungen an, vielmehr gelangt er durchweg über sein Gefühl zu einer eigenständigen Positionierung. Bereits mit seinen ersten Worten - „Ob ich löblich gehandelt? ich weiß es nicht" - konstatiert er, dass er sich die Welt nicht rational-reflektierend erschließt, „aber mein Herz hat / Mich geheissen zu tun, so wie ich genau nun erzähle“ (2, V. 11 f.). $\mathrm{Ob}$ er die gesammelten Spenden unter den Flüchtenden verteilen oder „sogleich hier / Alles dem Mädchen gäbe“ entscheidet er "gleich in [seinem] Herzen“ (2, V. 63-65). Und auch Hermanns Mutter erkennt: „Ja, er hat gefühlt und gewählt und sich männlich entschieden“ (5, V. 51). Sehen und Fühlen werden in Hermann und Dorothea als die erkenntnisfördernden Prinzipien einer sinnlich-intuitiven Entscheidungsfindung in Szene gesetzt: „dein treues Auge, dein treues Herz hat richtig gewählt!“ (6, $228 \mathrm{f}$ ), bestätigt der Pfarrer Hermanns Wahl. In der Aneignung des Idyllischen - subjektive Empfindung und sinnliche Leidenschaft stellen gemäß Buschmeier die Darstellungsmittel der Idylle ${ }^{284}$ dar - wird das Epische also auch zu einem Erfahrungsraum, der frei ist von rational-kognitiven Verbindlichkeiten und wo sich Subjektivität als autonome und sinnliche Produktivkraft konstituiert. ${ }^{285}$ Der betonte Aspekt einer gefühlsgeleiteten, sinnlichen Selbst- und Welterschließung entspricht dem neuen romantischen Denken, welches das individuelle Gefühl gegenüber gesellschaftlicher Konventionalität bevorzugt. Damit richtet sich Goethe auch hier gegen die zeitgenössische Rationalisierung der Welt, den empirischtheoretischen Zugängen zu ihr und überhaupt gegen die Vernunft als neues dominantes Organisationsprinzip. Ein solcher Akt der Selbstkonstitution im Hinblick auf eine Idee der sinnlich geleiteten Reflexion wird in der berühmten Brunnenszene vorgeführt:

283 Vgl. Kost: Die Fortschrittlichkeit des scheinbar Konventionellen. Das Motiv der Liebesheirat in Goethes Hermann und Dorothea. S. 283.

284 Vgl. Buschmeier: Die Idylle bei Salomon Gessner, Friedrich (Maler) Müller und Johann Heinrich Voß. Kritik und Transformation einer Gattung. S. 220-237, hier S. 226.

285 Vgl. Wellbery: Die Grenzen des Idyllischen bei Goethe. S. 221-240, hier S. 229. 
[...] und auf das Mäuerchen setzten

Beide sich nieder des Quells. Sie beugte sich über, zu schöpfen;

Und er fasste den anderen Krug und beugte sich über.

Und sie sahen gespiegelt ihr Bild in der Bläue des Himmels

Schwanken und nickten sich $\mathrm{zu}$ und grüßten sich freundlich im Spiegel. $(7$, V. $38-42)$

Hier wird die Handlung für einmal tatsächlich stillgelegt, die Erfahrung des gedehnten Augenblicks wird erzählt und erhält dadurch eine besondere Funktion für den gesamten narrativen Zusammenhang des Textes. Im Spiegel erkennen Hermann und Dorothea nicht nur sich selbst, sondern werden sich im Bild ihrer Verbindung auch ihrer Liebe zueinander unmittelbar bewusst und entscheiden sich intuitiv füreinander im Gruß. Nicht eine vernünftigreflektierende Tätigkeit führt hier wie bei Schiller zur höchsten Freiheit und Erkenntnis, sondern eine sinnlich-affektive. Der idyllische Augenblick des sich inne Werdens wird hier darüber hinaus zum Moment einer doppelten Selbsterkenntnis, wobei der aus der Reflexion gewonnene Selbstbezug prekär bleibt - das Bild schwankt nämlich. Das ästhetisch erfahrende Subjekt erfährt sich hier nicht nur selbst, vielmehr bleibt die Selbsterkenntnis deutlich auf ein Gesellschaftsbild bezogen: Schließlich stellen die Geschlechterbeziehungen eine grundsätzliche Operation der Gesellschaftsbildung dar ${ }^{286}$ und im Gegensatz zur Luise entspricht die Brautwerbung in Hermann und Dorothea zum einen nicht der Tradition und zum anderen wird diese Abweichung auch stark thematisiert. Der gesellschaftliche Kontext wird in Goethes Dichtung weder ausgeblendet noch abgelöst, sondern bleibt als Erfahrungsfläche immer noch erhalten. Allerdings geschieht das nicht im Sinne einer ideologischen Restitution gesellschaftlicher Normativität, sondern indem die subjektive Erfahrung auf ein bestimmtes Menschenbild und eine bestimmte Vorstellung von Gesellschaft verweist. In der Begegnung zwischen Hermann und Dorothea wird das Bild einer Gemeinschaft entworfen, die unter Freien und Gleichen nur entsteht, wenn sie sich auch als solche begegnen, sich vertrauen und sich willentlich zum Zusammenschluss entscheiden. Der Einzelne erscheint als Grundpfeiler des Gemeinwesens: Von seiner Fähigkeit, die Ideale und Werte von Freiheit, Gleichheit und Wahrheit zu verinnerlichen, hängt ab, ob sich diese Werte auf das gesamte Sozialwesen übertragen. Die Etablierung von Solidarität und Gemeinsinn als verbindlicher Konsens ist auf die jeweilig subjektive Menschlichkeit des Individuums angewiesen. Das ist nicht die Vorstellung einer bereits humanistisch geformten und abgeschlossenen Idealwelt, sondern die Forderung nach einer Sozialordnung, die den Einzelnen

286 Vgl. ebd. S. 23 . 
gegenüber der Gesellschaft zwar als vorrangig ansieht und dennoch feste, gesellschaftlich verbindliche Strukturen und Werte vermittelt. ${ }^{287}$

Bei Goethes epischem Augenblick handelt es sich deshalb gleichzeitig um einen Moment individueller Selbsterkenntnis wie auch der Gesellschaftsgründung im Zeichen des modernen Nationalstaates, der nicht mehr aus unterworfenen Subjekten, sondern aus politisch partizipierenden Staatsbürgern besteht. Diese Vorstellung von Nation unterscheidet sich deutlich von der Besetzung des Nationalen der Idylle im Allgemeinen und besonders der Luise-Idyllen. Anstatt den Rückzug ins Private proklamiert Goethe nämlich die Politisierung des Einzelnen und den freiwilligen Zusammenschluss zu einer Nation durch gemeinsame Werte und eine gemeinsame Kultur. In Hermanns Reden, sowohl unter dem Birnbaum als auch am Ende, geht es nicht nur um einen martialischen Verteidigungsgestus gegen Frankreich, sondern vielmehr um das Heraustreten der Deutschen aus einer passiven Unmündigkeit. Die neue politische Institution Nationalstaat fordert nämlich jeden dazu auf, sich selbst als mündigen Bürger zu erkennen, sich zu organisieren und am politischen Geschehen teilzunehmen - das sind die Lehren, die Goethe aus seiner Italienreise gezogen und in seinem Kulturbegriff produktiv gemacht hat. ${ }^{288}$ Bei Goethe verpflichtet die Befreiung aus den rigiden Machtverhältnissen der Feudalgesellschaft zur aktiven Mitbestimmung der neuen Ordnung - und ja, wenn nötig auch zu deren Verteidigung. Das moderne Subjekt ist nicht mehr selbstverständlich in einen größeren Zusammenhang eingebunden, es muss diesen Zusammenhang immer wieder selbst herstellen und sich dazu positionieren. Tatsächlich hat Deutschland der politischen Selbstermächtigung Frankreichs nichts entgegenzustellen und genau in diese historische Leerstelle schreibt Goethe seinen Text hinein. Damit unternimmt er den ambitionierten Versuch, ein aufgeklärtes politisches Bewusstsein und eine entsprechende Vorstellung von moderner Staatsbürgerlichkeit ästhetisch zu begründen. Den Beginn einer neuen Epoche und das Finden einer neuen Gesellschaftsform erfasst er dabei sensibel als fragilen Gründungsmoment. In Hermann und Dorothea bleiben nämlich sowohl der Selbstbezug als auch die darin vorgestellte Idee von Vergesellschaftung stets prekär bzw. nur temporär. ${ }^{289}$ Darauf verweisen der schwankende Charakter des Spiegelbildes sowie der auf die Brunnenszene folgende Fehltritt Dorotheas, der knackende Fuss und ihr drohender Fall (8,

287 Vgl. Kost: Die Fortschrittlichkeit des scheinbar Konventionellen. Das Motiv der Liebesheirat in Goethes Hermann und Dorothea. S. 285.

288 Vgl. S. 81 ff. in diesem Buch.

289 Vgl. Schneider: Ordnung der Kunst und Ordnung der Häuslichkeit. Arkadischer Topik, Idylle und das deutsche bürgerliche Epos des 19. Jahrhunderts. S. 13-33, hier S. 21. 
V. 90). In Goethes Gedicht geht es gerade nicht um selbstzufriedene Selbstbespiegelung und die unkritische Verklärung einer bürgerlichen Existenz in dem von der Antike geborgten Licht epischer Übergröße. Stattdessen wird in der hybriden Form des Epischen vielmehr eine herausfordernde, messende Selbstbegegnung angeboten, eine strenge Konfrontation des Menschen mit sich selbst und schließlich die Möglichkeit zur Selbsterkenntnis. ${ }^{290}$

Die gegenwärtige Stunde wird hier deshalb nicht als zeitlose Ewigkeit inszeniert, sondern als zwar entscheidender, aber auch flüchtiger Augenblick im Laufe der Zeit gezeigt. In Hermann und Dorothea wird Zeit als formende Kraft erlebt und eine moderne - sprich relative -Gegenwartserfahrung gemacht. Was diese Gegenwart ist, was sie bedeutet, muss in der geistigen Auseinandersetzung mit Vergangenheit und Zukunft immer wieder aufs Neue entwickelt werden. Besonders eindringlich wird das Verhandeln des neuen Zeitbegriffs einer dynamischen Gegenwart im neunten Gesang vor Augen geführt. Dieser erfährt durch den Untertitel „Aussicht“ einerseits eine grundsätzliche Ausrichtung auf die Zukunft, im Moment der ebenfalls zukunftsgerichteten Verlobung erinnert sich Dorothea dann gleichwohl an ihren ersten Verlobten und dessen fatalistische Brandrede. Damit wird an einer neuralgischen Textstelle retardierendes Zeitverhalten vorgeführt und zwar sowohl als Darstellungsmittel als auch auf der Handlungsebene. Das flüchtige Jetzt wird durch das Herüberziehen der Vergangenheit zum einen und das Heranholen der Zukunft zum anderen ausgedehnt und gleichzeitig angefüllt: Für einen fixierten Moment treten die Zeitstufen auf der Darstellungsebene gleichzeitig in Erscheinung und verdichten sich zu einer prägnanten Gegenwart. ${ }^{291}$ Diese findet in den beiden Verlobungsringen Dorotheas ein eindringliches Symbol, während der eine in der Gegenwart eine Zukunftsaussicht eröffnet, vergegenwärtigt der andere als Andenken das Gewesene. ${ }^{292}$ Dabei ersetzt der eine nicht den anderen, sondern beide zusammen werden an Dorotheas Finger zum Zeichen der Einheit, des neuen-alten Bundes. In diesem Augenblick scheinen die Spannungen zwischen den Gegensätzen für einmal harmonisch gelöst.

Der prägnante Moment ist aber nicht ein idyllisch erfüllter Glücksmoment, durch das Erinnern an die aufrüttelnde, weltpolitische Rede wird das Versprechen von Glück und Erfüllung in Zukunft auf der Handlungseben grundsätzlich relativiert. ${ }^{293}$ Das sich gegenwärtig einstellende Glück wird sogleich

290 Vgl. Seidlin: Über Hermann und Dorothea. Ein Vortrag. S. 20-37, hier S. 27.

291 Vgl. Schneider: „ein strenger Umriß“ - Prägnanz als Leitidee von Goethes Formdenken im Kontext der Weimarer Kunsttheorie. S. 100 f.

292 Vgl. Elsaghe: Untersuchungen zu Hermann und Dorothea. S. 53.

293 Vgl. ebd. S. 95. 
wieder gestört und damit die Strategie der Idylle gerade umgekehrt. Anstatt im Zeichen der Ewigkeit wird der gegenwärtige Augenblick in Hermann und Dorothea als flüchtiger, transitorischer konzipiert, für den die Vorstellung von Ewigkeit nunmehr zur Folie geworden ist. ${ }^{294}$ Die temporale Opposition von Kontinuität und Diskontinuität wird dadurch in ein dialektisches Verhältnis überführt, in dem Bruch und Anschluss, Krise und Überwindung als dynamisch ineinandergreifende Phänomene beleuchtet werden. An zwei Organisatoren der Räumlichkeit wird das besonders augenfällig: Zum einen reicht das Tor des Wirtshauses als einziges Element in die Zeit vor dem Brand zurück (2, V. 143 f.), ihm ist also ein hohes Alter zu eigen und es verbürget durch sein Fortbestehen eine zeitliche Kontinuität bis in die Gegenwart. Zum anderen ist das „Pförtchen“ bemerkenswert, das „der Ahnherr einst“ „[a] us besonderer Gunst, durch die Mauer des Städtchens gebrochen“ hatte und das nun, „nur angelehnt“, den Raum gleichwohl teilt und transitorisch macht (4, V. 19-21). Die räumliche Durchlässigkeit - „die Türen, die untre sowie die obre, des Weinbergs / Standen gleichfalls offen" (4, V. 46 f.) - ermöglicht explizit auch eine Begegnung der Zeiten. Hier bestehen die alten Grundlagen noch und können an die Gegenwart angeknüpft werden, gesichert ist dieser Anschluss allerdings nicht. Denn die Gegenwart bleibt in Hermann und Dorothea, selbst wenn sie zu einem prägnanten Augenblick verdichtet wird, stets krisenhaft bzw. trägt gleichzeitig das Potenzial zur kontinuierlichen Erneuerung und die Katastrophe in sich: „das Ja mich / Glücklich macht auf ewig, das Nein mich auf ewig zerstöret“ (6, V. 285 f.) - mit diesen Worten antizipiert Hermann eine zutiefst unsichere Zukunft, die die Vorstellung einer verbürgten, totalen Zeitlichkeit grundsätzlich unterläuft.

In der folgenden Konstruktion scheint die glückliche Wunschvorstellung zunächst gesichert: „Oh, dass ich die Traute / Freudig und schnell heimführte! Vielleicht auch schleich ich alleine / Jene Pfade nach Haus und betrete froh sie nicht wieder." (6, V. 292-294). Mit dem wie ein Scharnier in der Mitte stehenden Relativitätsmarker ,vielleicht" kippt der bisherige Ausruf dann aber in ein dystopisches Unglücksbild. Die Gegenwart wird im epischen Augenblick also als grundsätzlich offen gezeigt, als unterschiedlich interpretier- und nutzbar. Ähnlich wie die Revolution und die Verlobung wird sie damit als schwankende Latenzzeit erfasst, in der sowohl ein gefestigter Zustand, eine Ehe oder ein Nationalstaat, als auch die Auflösung in Chaos enthalten sind. Mit Hermann und Dorothea stellt Goethe immer wieder die Frage nach dem „wie weiter?“, dem Verhältnis von Freiheit und Regelkonformität, Selbst- und

294 Vgl. Lypp: Ästhetische Reflexion und ihre Gestaltung in Goethes Hermann und Dorothea. S. 72. 
Fremdbestimmung, Individuum und Gesellschaft - dabei geht es nicht darum, eine Antwort zu finden, sondern gerade um das Ausstellen der Krise. Der Text stellt weder eine Anleitung zum bürgerlichen Leben, noch eine ewige Ordnung oder ein zeitlos gültiges Menschenbild dar, vielmehr zeigt er all das als überholt auf. 